
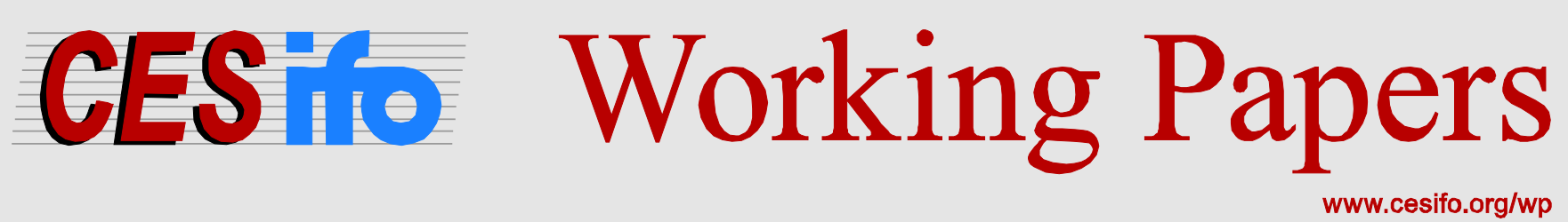

\title{
Uncertainty-driven Business Cycles: Assessing the Markup Channel
}

\author{
Benjamin Born \\ Johannes Pfeifer
}

\author{
CESIFO WORKING PAPER NO. 6303 \\ CATEgory 7: Monetary POLICY AND InTERnational FinANCE \\ JANUARY 2017
}

An electronic version of the paper may be downloaded

- from the SSRN website:

- from the RePEc website:

- from the CESifo website:

WWW.SSRN.com

Www.RePEc.org

www.CESifo-group.org/wp 


\title{
Uncertainty-driven Business Cycles: Assessing the Markup Channel
}

\begin{abstract}
A growing recent literature relies on a precautionary pricing motive embedded in representative agent DSGE models with sticky prices and wages to generate negative output effects of uncertainty shocks. We assess whether this theoretical model channel is consistent with the data. Building a New Keynesian model, we show that indeed with sufficient nominal rigidities markups increase and output falls after uncertainty shocks. The model is also used as a business cycle accounting device to construct aggregate markups from the data. Time-series techniques are employed to study the conditional comovement between markups and output in the data. Consistent with the model's precautionary wage setting, we find that wage markups increase after uncertainty shocks. Price markups in contrast fall. This finding - inconsistent with the model - is corroborated by industry-level data. Overall, these results point to a prominent role for sticky wages in the transmission of uncertainty shocks.
\end{abstract}

JEL-Codes: E320, E010, E240.

Keywords: uncertainty shocks, price markup, wage markup.

\author{
Benjamin Born \\ University of Bonn \\ Bonn / Germany \\ born@uni-bonn.de
}

\author{
Johannes Pfeifer \\ University of Mannheim \\ Mannheim / Germany \\ pfeifer@uni-mannheim.de
}

\section{January 2017}

We would like to thank Angela Abbate, Klaus Adam, Matthias Hartmann, Keith Kuester, Ariel Mecikovsky, Gernot Müller, Morten Ravn, Mirko Wiederholt, and various seminar audiences for helpful comments and suggestions. Special thanks go to Randy A. Becker and Wayne Gray for important clarifications regarding the NBER-CES Manufacturing Industry Database. 


\section{Introduction}

Since the seminal paper by Bloom (2009), many studies have focused on the effects of uncertainty shocks on economic fluctuations (see Bloom 2014, for a survey). While time-series approaches regularly find negative effects of uncertainty shocks on output (Bachmann et al. 2013; Baker et al. 2016; Jurado et al. 2015, and numerous others), it has proven surprisingly difficult to generate negative output effects after uncertainty shocks in representative agent models as uncertainty shocks are expansionary in the standard RBC model. As shown by Basu and Bundick (forthcoming), countercyclical markups of the form present in standard New Keynesian models are key to match the empirical evidence. Many recent DSGE studies rely on this countercyclical movement of price and/or wage markups conditional on uncertainty shocks. ${ }^{1}$ However, direct empirical evidence on the presence of this transmission channel is limited. ${ }^{2}$

We therefore assess whether this so-called "markup channel" is consistent with the data. To this end, we build a New Keynesian DSGE model with time-varying price and wage markups that serves two purposes. First, the dynamic dimension of the model is used to generate predictions on the effects of uncertainty shocks on price and wage markups that can be empirically tested. In the model, an increase in uncertainty leads to an increase in both price and wage markups and a decline in output, whereas without nominal rigidities the precautionary labor supply motive dominates and output increases. Second, the intratemporal first-order conditions can be used as a Chari et al. (2007)-type business cycle accounting framework to construct aggregate price and wage markups from the data.

Time-series techniques are then used to identify uncertainty shocks in the data and to study whether the conditional comovement between markups and output is consistent with the one implied by the model. Overall, we find that in the data, contrary to the model's

\footnotetext{
${ }^{1}$ E.g. Fernández-Villaverde et al. (2015), Born and Pfeifer (2014), Basu and Bundick (forthcoming), Başkaya et al. (2013), Mumtaz and Zanetti (2013), Plante and Traum (2012), Cesa-Bianchi and FernandezCorugedo (2014), Johannsen (2014), and Leduc and Liu (2016). The latter two rely on the existence of the ZLB and a frictional labor market, respectively, to amplify the effects of aggregate uncertainty. Notable exceptions that do not rely on countercyclical markups are Christiano, Motto, et al. (2014) and Chugh (2016), who embed uncertainty in a financial accelerator mechanism.

${ }^{2}$ Fernández-Villaverde et al. (2015) provide some tentative evidence.
} 
prediction, price markups tend to fall after uncertainty shocks. However, wage markups increase as the model predicts. These findings are robust to different identification schemes as well as uncertainty and markup measures.

We then turn to disaggregated industry-level evidence and investigate whether the model-predicted price markup response may simply be hidden by heterogeneity in price stickiness at the industry level. Qualitatively, the industry-level results look very similar to the aggregate evidence. The price markup does not increase significantly and even drops in the long run. We therefore do not find evidence for the price markup channel in disaggregated industry-level data either.

Our investigation of the price and wage markups is related to Nekarda and Ramey (2013) and Karabarbounis (2014), respectively. ${ }^{3}$ Nekarda and Ramey (2013) argue that aggregate price markups are pro- to acyclical unconditionally and also regularly do not show the conditional movement after shocks predicted by standard New Keynesian models. However, they do not consider uncertainty shocks and only focus on the price markup, while the main effect might work through wage markups. This is important as e.g. Karabarbounis (2014) argues that about $90 \%$ of the cyclical movement in the labor wedge derives from movements in the household component of this wedge, i.e. the gap between the marginal rate of substitution and the real wage. ${ }^{4}$

To measure aggregate uncertainty, we use a variety of measures and approaches. The first uncertainty proxy is a model-consistent measure derived from the particle smoother used to parameterize the model. We also employ the general macroeconomic uncertainty measure of Jurado et al. (2015) (JLN) and identify exogenous shocks via a recursive ordering. ${ }^{5}$ Given that many uncertainty measures are available at monthly frequency while we only have quarterly markup data, we will employ two different approaches to deal with this mixed-frequency problem: a two-step frequentist procedure following Kilian

\footnotetext{
${ }^{3}$ See also Shimer (2010). Our paper is also related to earlier papers studying the (unconditional) cyclical movement of (price) markups (e.g. Bils 1987; Rotemberg and Woodford 1991), surveyed in Rotemberg and Woodford (1999), as well as "business cycle accounting" studies like Chari et al. (2007), Hall (1997), and Parkin (1988). Galí et al. (2007) is an influential study that decomposes the labor wedge into a firm and a household component to study the welfare implications.

${ }^{4}$ See Basu and House (2016) and Bils et al. (2016) for an opposing viewpoint.

${ }^{5}$ Our results are robust to using different uncertainty proxies such as the Baker et al. (2016)-economic policy uncertainty proxy or the VIX and different identification schemes.
} 
(2009) and Born, Breuer, et al. (2014), which relies on local projections (Jordá 2005), and a Bayesian mixed-frequency VAR following Eraker et al. (2015).

Section 2 provides a detailed exposition on the mechanism embedded in New Keynesian models that gives rise to contractionary uncertainty effects. Section 3 presents a baseline New Keynesian DSGE with time-varying wage and price markups and documents the predicted conditional comovement of output and markups following demand and supply uncertainty shocks. The intratemporal first-order conditions of the model also provide an accounting framework, which is used to construct price and wage markups from the data. Section 4 then identifies uncertainty shocks from the data, studies whether the conditional comovement between markups and output is consistent with the one implied by the model, and provides robustness checks. Section 5 investigates the price markup response at the industry level. Section 6 concludes.

\section{Precautionary pricing: a stylized model}

As shown by Basu and Bundick (forthcoming), the reason that uncertainty is expansionary in the standard RBC model is the presence of a "precautionary labor supply" motive. When faced by higher uncertainty, the household does not only self-insure by consuming less and investing more, but also by working more. From the neoclassical production function, where TFP is unaffected by uncertainty and capital is predetermined, follows that this increase in labor results in an output expansion that fuels higher savings. The solution to generate contractionary effects of uncertainty is to break this tight link between labor supply and production. This can be achieved by introducing monopolistic competition in labor and goods markets, which gives rise to time-varying markups. In the presence of sticky prices and wages, firms and households in their price- and wage-setting decisions face a convex marginal revenue product. This gives rise to inverse Oi (1961)-Hartman (1972)-Abel (1983)-effects and precautionary pricing when faced with uncertainty about future economic variables. Price-setters face the following choice: If prices are set too low, more units need to be sold at too low a price, which is bad for the firm. In contrast, if 


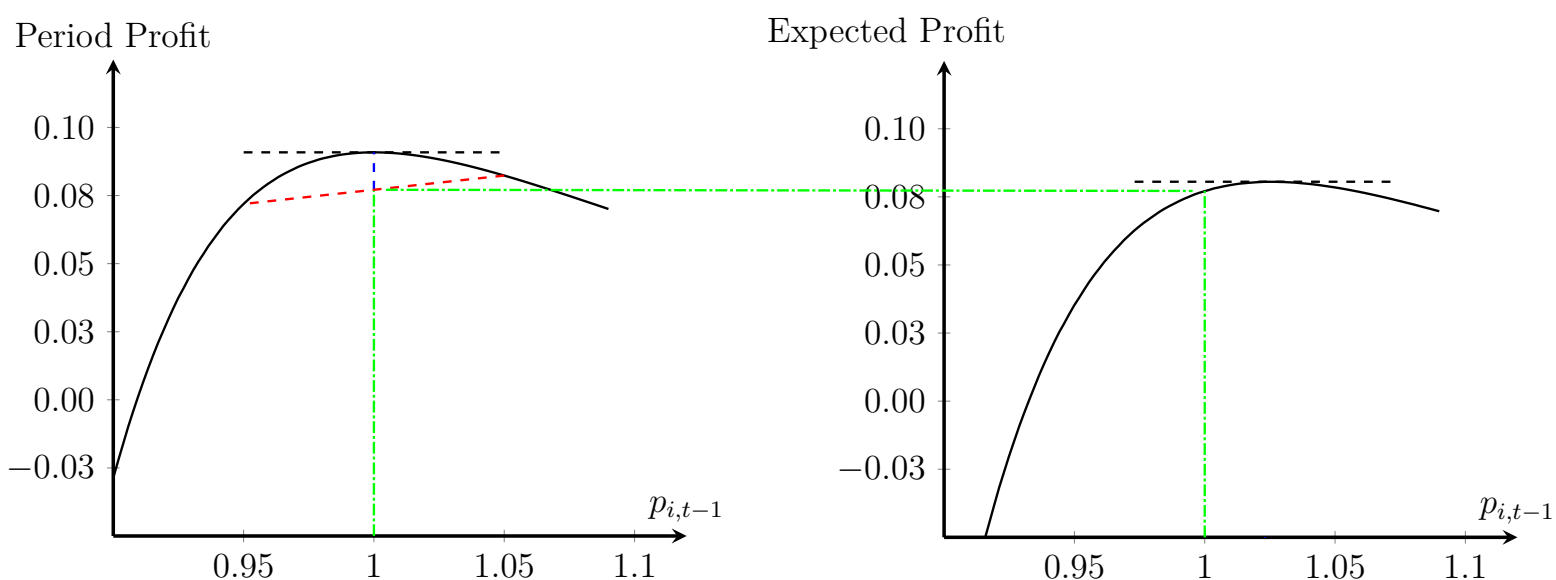

Figure 1: Stylized pricing example. Notes: period profit (left panel) and expected profit of the firm (right panel) as a function of the price $p_{i, t-1}$. The black dashed line indicates the maximum of the respective function. The red dashed line displays the mean preserving spread to the optimal price that the firm faces. The green dashed dotted line indicates the profits when choosing the mean optimal price of 1 .

prices are set too high, the higher price compensates for being able to sell fewer units. Due to this asymmetric, nonlinear effect, price setters prefer to err on the side of too high prices and increase their markups. If this increase in markups after uncertainty shocks is strong enough, it dampens demand and decreases output.

To see this more clearly, consider the following stylized partial equilibrium example. A firm $i$ of a continuum of identical, monopolistically competitive firms chooses its optimal price $p_{i, t-1}$ subject to a Dixit-Stiglitz-type demand function $y_{i, t}=\left(\frac{p_{i, t-1}}{p_{t}}\right)^{-\theta_{p}} y_{t}$, where $y_{t}$ is aggregate demand, $\theta_{p}$ is the demand elasticity, and $p_{t}$ the aggregate price level. For the mechanism to be as transparent as possible, we assume the firm is subject to a Taylor (1980)-type pricing friction in that it has to set its price one period in advance. ${ }^{6}$ Its output is produced using a constant returns to scale production function that is linear in labor: $y_{i, t}=l_{i, t}$. The labor market is assumed to be competitive, with the economy-wide wage being denoted by $w_{t}$. Real firm profits are then given by

$$
\pi=\left[\frac{p_{i, t-1}}{p_{t}}-\frac{w_{t}}{p_{t}}\right]\left(\frac{p_{i, t-1}}{p_{t}}\right)^{-\theta_{p}} y_{t} .
$$

Assuming, without loss of generality, that $y_{t}=1$ and $w_{t}=\left(\theta_{p}-1\right) / \theta_{p}$, this simplifies

\footnotetext{
${ }^{6}$ This same general mechanism is also present in the Rotemberg price adjustment cost framework used in the medium-scale New Keynesian model below as well as in Calvo- and Menu Cost-models. In all of these settings, marginal profits are convex in the price (see, e.g., Balleer et al. 2016; Fernández-Villaverde et al. 2015).
} 
to

$$
\pi=\left[\frac{p_{i, t-1}}{p_{t}}-\frac{\theta_{p}-1}{\theta_{p}} \frac{1}{p_{t}}\right]\left(\frac{p_{i, t-1}}{p_{t}}\right)^{-\theta_{p}}
$$

Expression (2.2) shows that there are two different channels through which prices affect profits. First, a higher price $p_{i, t-1}$ has an immediate price impact on the revenue, while leaving the marginal costs unaffected. But second, there is an additional impact on the quantity sold. The left panel of Figure 1 shows the profit function for $\theta_{p}=11$. As is well-known, in the absence of uncertainty the firm will optimally charge a gross markup $\frac{\theta_{p}}{\theta_{p}-1}$ over marginal costs, resulting in a profit-maximizing price of $p_{i, t-1}=1$.

Assume now that the firm faces uncertainty about the optimal price, because the aggregate price level is with probability $1 / 2$ either $p_{t}=1 / 1.05$ or $p_{t}=1 / 0.95$, so that in the absence of pricing frictions, either $p_{i, t}=0.95$ or $p_{i, t}=1.05$ is optimal. Thus, compared to the previous situation, the optimal price is subject to a mean-preserving spread. ${ }^{7}$ Setting the price at the expected optimal $p_{i, t-1}=1$ is suboptimal, because it would lead to lower expected profits due to the marginal profit being convex in the price. Rather, the optimal price in this case is slightly higher at $p_{i, t-1}=1.02$. This can be seen in the expected profit schedule as a function of $p_{i, t-1}$ shown in the right panel of Figure 1.

The same mechanism is at work in the household sector where the households have to maximize utility by setting a nominal wage subject to an equivalent demand function for their labor services.

\section{Model}

In this section we construct a prototypical New Keynesian DSGE model that embeds the previously outlined mechanism on the firm and household side. The model serves two purposes. First, the dynamic dimension of model can be used to generate predictions on the effects of uncertainty shocks on price and wage markups. Second, the intratemporal first-order conditions can be used as a Chari et al. (2007)-type business cycle accounting

\footnotetext{
${ }^{7}$ For ease of exposition we consider a mean-preserving spread to the endogenous variable. The same effect would arise following a mean-preserving spread to aggregate price $p_{t}$, but in this case an additional Jensen's Inequality effect would complicate matters due to the price level entering in the denominator.
} 
framework to construct aggregate price and wage markups from the data.

The model economy is populated by a continuum of intermediate good firms producing differentiated intermediate goods using bundled labor services and capital, and a final good firm bundling intermediate goods to a final good. A continuum of households $j \in[0,1]$ sells differentiated labor services to a labor bundler. In addition, the model features a government sector that finances government spending with distortionary taxation and transfers, and a monetary authority, which sets the nominal interest rate according to an interest rate rule. The full set of model equations is relegated to Appendix A.1.

\subsection{Firms}

The final good $Y_{t}$ is assembled from a continuum of differentiated intermediate inputs $Y_{t}(i), i \in[0,1]$, using the constant returns to scale Dixit-Stiglitz-technology

$$
Y_{t}=\left[\int_{0}^{1} Y_{t}(i)^{\frac{\theta_{p}-1}{\theta_{p}}} d i\right]^{\frac{\theta_{p}}{\theta_{p}-1}}
$$

where $\theta_{p}>0$ is the elasticity of substitution between intermediate goods. Standard cost minimization yields the demand for good $i$ :

$$
Y_{t}(i)=\left[\frac{P_{t}(i)}{P_{t}}\right]^{-\theta_{p}} Y_{t}
$$

where $P_{t}$ is the aggregate price level.

The monopolistically competitive intermediate good firms produce $Y_{t}(i)$ using capital $K_{t}(i)$ and a hired composite labor bundle $N_{t}(i)$ according to a CES production function

$$
Y_{t}(i)=Y^{\text {norm }}\left\{\alpha\left[K_{t}(i)\right]^{\frac{\psi-1}{\psi}}+(1-\alpha)\left[Z_{t}\left(N_{t}(i)-N^{o}\right)\right]^{\frac{\psi-1}{\psi}}\right\}^{\frac{\psi}{\psi-1}}-\Phi
$$

Here, $0 \leq \alpha \leq 1$ parameterizes the labor share and $Y^{\text {norm }}$ is a normalization factor that makes output equal to one in steady state. ${ }^{8} \psi$ is the elasticity of substitution between capital and labor, with $\psi=1$ being the Cobb-Douglas case. The fixed cost of production $\Phi$ reduces economic profits to zero in steady state, thereby ruling out entry or exit (see,

\footnotetext{
${ }^{8}$ Note that both parameters are not structural parameters as they depend on the units of measurement of the input factors. For more details on how to deal with such dimensional constants, see Cantore and Levine (2012).
} 
e.g., Christiano, Eichenbaum, et al. 2005). $N^{o}=\phi_{o} N$, where $N$ denotes steady-state labor, is overhead labor used in the production of goods. ${ }^{9} Z_{t}$ denotes a stationary, laboraugmenting technology process specified below. Each intermediate good firm owns its own capital stock, whose law of motion is given by

$$
K_{t+1}(i)=\left(1-\delta-\frac{\phi_{K}}{2}\left(\frac{I_{t}(i)}{K_{t}(i)}-\delta\right)^{2}\right) K_{t}(i)+I_{t}(i), \phi_{K} \geq 0,
$$

where $\delta$ denotes the quarterly depreciation rate of the capital stock. Equation (3.3) includes capital adjustment costs at the firm level of the form introduced by Hayashi (1982).

Intermediate good producers are owned by households and therefore use the households' stochastic discount factor for discounting. They maximize the present discounted value of per period profits subject to the law of motion for capital and the demand from the final good producer:

$$
\left[\frac{P_{t}(i)}{P_{t}}\right]^{1-\theta_{p}} Y_{t}-\frac{W_{t}}{P_{t}} N_{t}(i)-I_{t}(i)-\frac{\phi_{p}}{2}\left(\frac{P_{t}(i)}{P_{t-1}(i)}-\Pi\right)^{2} Y_{t},
$$

where $N_{t}(i)$ is hired in a competitive rental market at given wage rate $W_{t}$. The last term denotes price adjustment costs as in Rotemberg (1982), where $\Pi$ is steady-state inflation. From the firms' cost minimization problem follows the first-order condition for labor inputs as

$$
\Xi_{p, t} \frac{W_{t}}{P_{t}}=M P L_{t}
$$

where $\Xi_{p, t}$ is the gross price markup over marginal costs. Due to monopolistic competition, $\Xi_{p, t}$ will generally not be equal to 1 as firms set a markup over marginal costs. Timevariation in this markup is a central element of shock transmission in the New Keynesian model.

\subsection{Households}

Following Erceg et al. (2000), we assume that the economy is populated by a continuum of monopolistically competitive households, supplying differentiated labor $N_{t}(j)$ at wage

\footnotetext{
${ }^{9}$ See Ratto et al. (2009) for one of the earliest DSGE models with overhead labor.
} 
$W_{t}(j)$ to a labor bundler who then supplies the composite labor input to the intermediate good producers. Formally, the aggregation technology follows a Dixit-Stiglitz form

$$
N_{t}=\left[\int_{0}^{1} N_{t}(j)^{\frac{\theta_{w}-1}{\theta_{w}}} d j\right]^{\frac{\theta_{w}}{\theta_{w}-1}}, \theta_{w}>0 .
$$

Expenditure minimization yields the optimal demand for household $j$ 's labor as

$$
N_{t}(j)=\left[\frac{W_{t}(j)}{W_{t}}\right]^{-\theta_{w}} N_{t} \quad \forall j .
$$

Household $j$ has preferences

$$
V_{t}=\sum_{h=0}^{\infty} \beta^{h} \frac{\left[\left(C_{t+h}(j)\right)^{\eta}\left(1-N_{t+h}(j)\right)^{1-\eta}\right]^{1-\sigma}}{1-\sigma},
$$

where the parameter $\sigma \geq 0$ measures the risk aversion, $0<\beta<1$ is the discount rate, and $0<\eta<1$ denotes the share of the consumption good in the consumption-leisure Cobb-Douglas bundle.

The household faces the budget constraint

$$
\begin{aligned}
\left(1+\tau_{t}^{c}\right) C_{t}(j)+\frac{B_{t}(j)}{P_{t}} \leq & \left(1-\tau_{t}^{n}\right) \frac{W_{t}(j)}{P_{t}} N_{t}(j)+R_{t-1} \frac{B_{t-1}(j)}{P_{t}}+D_{t}(j) \\
& -\frac{\phi_{w}}{2}\left(\Pi^{-1} \frac{W_{t}(j)}{W_{t-1}(j)}-1\right)^{2} Y_{t}+T_{t}
\end{aligned}
$$

where the household earns income from supplying differentiated labor, which is taxed at rate $\tau_{t}^{n}$. In addition, it receives real dividends $D_{t}(j)$ from owning a share of the firms in the economy and a real gross return $R_{t-1}\left(B_{t-1}(j) / P_{t}\right)$ from investing in a zero net supply riskless nominal bond. The household spends its income on consumption $C_{t}(j)$, taxed at rate $\tau_{t}^{c}$, real savings in the private bond $B_{t}(j) / P_{t}$, and to cover the costs of adjusting its wage (the second to last term on the right hand side). Finally, $T_{t}$ denotes transfers/lump-sum taxes.

The optimization problem of the household involves maximizing (3.8) subject to the budget constraint (3.9) and the demand for the household's differentiated labor input (3.7). The first-order condition for labor supply implies that a gross markup over the 
after-tax marginal rate of substitution $\Xi_{w, t}$ is chosen such that

$$
\frac{W_{t}}{P_{t}}=\Xi_{w, t} \frac{1+\tau_{t}^{c}}{1-\tau_{t}^{n}} \frac{V_{N, t}}{V_{C, t}}
$$

where $V_{N}$ and $V_{C}$ are the partial derivatives of the utility function with respect to labor and consumption, respectively.

\subsection{Government Sector}

The government's budget constraint is given by

$$
\tau_{t}^{c} C_{t}+\tau_{t}^{n} \frac{W_{t}}{P_{t}} N_{t}=G_{t}+T_{t}
$$

where $G_{t}$ is exogenous government consumption and where we have suppressed aggregation over households $j$ for notational convenience.

The model is closed by assuming that the central bank follows a Taylor rule that reacts to inflation and output:

$$
\frac{R_{t}}{R}=\left(\frac{R_{t-1}}{R}\right)^{\rho_{R}}\left(\left(\frac{\Pi_{t}}{\Pi}\right)^{\phi_{R \pi}}\left(\frac{Y_{t}}{Y_{t}^{H P}}\right)^{\phi_{R y}}\right)^{1-\rho_{R}} .
$$

Here, $0 \leq \rho_{R} \leq 1$ is a smoothing parameter introduced to capture the empirical evidence of gradual movements in interest rates, $\Pi$ is the target inflation rate set by the central bank, and the parameters $\phi_{R \pi}$ and $\phi_{R y}$ capture the responsiveness of the nominal interest rate to deviations of inflation from its steady-state value and output from its model-consistent Hodrick and Prescott (HP) filter trend $Y_{t}^{H P}$, respectively (this specification follows Born and Pfeifer 2014). ${ }^{10}$

\footnotetext{
${ }^{10}$ The HP filtered output gap is embedded into the dynamic rational expectations model following the approach of Cúrdia et al. (2015)
} 


\subsection{Exogenous shock processes}

The two exogenous processes for government spending and TFP follow AR(1)-processes with stochastic volatility:

$$
\begin{aligned}
& \hat{Z}_{t}=\rho_{z} \hat{Z}_{t-1}+\sigma_{t}^{z} \varepsilon_{t}^{z} \\
& \hat{G}_{t}=\rho_{g} \hat{G}_{t-1}+\phi_{g y} \hat{Y}_{t-1}+\sigma_{t}^{g} \varepsilon_{t}^{g} \\
& \sigma_{t}^{z}=\left(1-\rho_{\sigma^{z}}\right) \bar{\sigma}^{z}+\rho_{\sigma^{z}} \sigma_{t-1}^{z}+\eta_{\sigma^{z}} \varepsilon_{t}^{\sigma^{z}} \\
& \sigma_{t}^{g}=\left(1-\rho_{\sigma^{g}}\right) \bar{\sigma}^{g}+\rho_{\sigma^{g}} \sigma_{t-1}^{g}+\eta_{\sigma^{g}} \varepsilon_{t}^{\sigma^{g}},
\end{aligned}
$$

where the $\varepsilon_{t}^{i}, i \in\left\{z, g, \sigma^{z}, \sigma^{g}\right\}$ are standard normally distributed i.i.d. shock processes, hats denote percentage deviations from trend, and $\phi_{g y}$ governs the output feedback to government spending. $\sigma_{t}^{z}$ and $\sigma_{t}^{g}$ are our proxies for supply and demand uncertainty, respectively, with $\varepsilon_{t}^{\sigma^{z}}$ and $\varepsilon_{t}^{\sigma^{z}}$ being the corresponding uncertainty shocks.

\subsection{Equilibrium}

The use of Rotemberg price and wage adjustment costs implies the existence of a representative firm and a representative household. We consider a symmetric equilibrium in which all intermediate good firms charge the same price and choose the same labor input and capital stock. Similarly, all households set the same wage, supply the same amount of labor, and will choose the same consumption and savings.

The resource constraint then implies that output is used for consumption, investment, government spending, and to pay for price and wage adjustment costs:

$$
Y_{t}=C_{t}+I_{t}+G_{t}+\frac{\phi_{w}}{2}\left(\Pi^{-1} \frac{W_{t}}{W_{t-1}}-1\right)^{2} Y_{t}+\frac{\phi_{p}}{2}\left(\Pi^{-1} \frac{P_{t}}{P_{t-1}}-1\right)^{2} Y_{t}
$$

\subsection{Parametrization}

Table 1 displays the parametrization of our model. The capital share $\alpha$ is set to one third and the depreciation rate $\delta$ to imply an annual depreciation rate of 10 percent. The discount factor $\beta=0.99$ implies an annualized interest rate of $4 \%$ in steady state. The capital adjustment cost parameter $\phi_{k}$ is set to 2.09, the value estimated in Basu and 
Table 1: Model Parametrization

\begin{tabular}{llcl}
\hline Parameter & Description & Value & Target \\
\hline$\alpha$ & Capital share & 0.078 & Capital share of 1/3 \\
$\beta$ & Discount factor & 0.99 & $4 \%$ annualized interest rate \\
$\delta$ & Depreciation rate & 0.025 & $10 \%$ per year \\
$\sigma$ & Risk aversion & 2 & standard value \\
$\phi_{k}$ & Cap. adj. costs & 2.09 & Basu and Bundick (forthcoming) \\
$\phi_{p}$ & Price adj. costs & 105 & Implied average duration of 1 year \\
$\phi_{w}$ & Wage adj. costs & 798 & Implied average duration of 1 year \\
$\theta_{w}$ & Labor subst. ela. & 10 & $11 \%$ steady-state markup \\
$\theta_{p}$ & Goods subst. ela. & 10 & $11 \%$ steady-state markup \\
$\eta$ & Leisure share & 0.462 & Frisch elasticity of 1 \\
$\phi^{o}$ & Overh. lab. share & 0.11 & Nekarda and Ramey (2013) \\
$\psi$ & Subst. ela. CES & 0.5 & Chirinko (2008) \\
$\Phi$ & Fixed costs & 0.03 & 0 Steady-state profits \\
$\Pi$ & Ss gross inflation & 1 & Zero inflation \\
$\rho_{r}$ & Interest smoothing & 0.836 & Born and Pfeifer (2014) \\
$\phi_{R \pi}$ & Inflation feedback & 1.78 & Born and Pfeifer (2014) \\
$\phi_{R y}$ & Output feedback & 0.32 & Born and Pfeifer (2014) \\
$\tau^{c}$ & Cons. tax rate & 0.094 & Sample mean \\
$\tau^{n}$ & Labor tax rate & 0.220 & Sample mean \\
$G / Y$ & G/Y share & 0.206 & Sample mean \\
$Y^{n o r m}$ & Output normalization & 1.373 & Output of 1 \\
\hline
\end{tabular}

Bundick (forthcoming), which implies an elasticity of the investment to capital ratio with respect to Tobin's marginal $q$ of $1.9 .^{11}$

The price adjustment cost parameter $\phi_{p}$ is chosen to imply the same slope of the linear New Keynesian Phillips Curve as a Calvo model with an average price duration of 1 year (see e.g. Keen and Wang 2007). Similarly, the wage adjustment cost parameter is chosen to imply an average wage contract duration of 1 year (see Born and Pfeifer 2016). The two substitution elasticity parameters $\theta_{p}$ and $\theta_{w}$ are set to 10 , which implies a steady-state markup of $11 \%$ and is an intermediate value between the 5 percent markup estimated in Altig et al. (2011) and the 20 percent found in Justiniano et al. (2013). ${ }^{12}$

We consider a zero inflation steady state, i.e. $\Pi=1$. The Taylor rule parameters are taken from Born and Pfeifer (2014). The risk aversion parameter is set to $\sigma=2$. The

\footnotetext{
${ }^{11}$ See Appendix A.2.2.

${ }^{12}$ See Born and Pfeifer (2014) for a discussion of the importance of this parameter for the size of uncertainty effects.
} 
leisure share in the Cobb-Douglas utility bundle $\eta$ is set to imply a Frisch elasticity of $1 .^{13}$ We set the share of overhead labor to 11\%, following the evidence of Levitt et al. (2013) that adding a second shift in car manufacturing plants increases labor by $80 \%$. Given that automobile plants run two shifts most of the time, this means overhead labor accounts for $20 / 180=0.11$ (see Nekarda and Ramey 2013). The fixed costs $\Phi$ are set to imply 0 profits in steady state, thereby ruling out entry and exit. ${ }^{14}$ The substitution elasticity between capital and labor is set to $\psi=0.5$, the midpoint of the estimates surveyed in Chirinko (2008). The fiscal parameters are set to their sample mean over 1964Q1 to 2015Q4. The tax rates are computed as average effective tax rates following Jones (2002). ${ }^{15}$

Table 2: Prior and Posterior Distributions of the Shock Processes

\begin{tabular}{|c|c|c|c|c|c|c|}
\hline \multirow[t]{2}{*}{ Parameter } & \multicolumn{3}{|c|}{ Prior distribution } & \multicolumn{3}{|c|}{ Posterior distribution } \\
\hline & Distribution & Mean & Std. Dev. & Mean & $5 \%$ & $95 \%$ \\
\hline \multicolumn{7}{|c|}{ G process } \\
\hline$\rho_{\sigma^{z}}$ & Beta* $^{*}$ & 0.90 & 0.100 & 0.513 & 0.313 & 0.708 \\
\hline$\rho_{z}$ & Beta* $^{*}$ & 0.90 & 0.100 & 0.945 & 0.883 & 0.999 \\
\hline$\eta_{\sigma^{z}}$ & Gamma & 0.50 & 0.100 & 0.003 & 0.002 & 0.004 \\
\hline $\bar{\sigma}^{z}$ & Uniform & 0.05 & 0.014 & 0.008 & 0.007 & 0.009 \\
\hline$\phi_{g y}$ & Normal & 0.00 & 1.000 & 0.028 & -0.026 & 0.083 \\
\hline \multicolumn{7}{|c|}{ TFP process } \\
\hline$\rho_{\sigma^{g}}$ & Beta* & 0.90 & 0.100 & 0.517 & 0.312 & 0.722 \\
\hline$\rho_{g}$ & Beta* $^{*}$ & 0.90 & 0.100 & 0.773 & 0.692 & 0.855 \\
\hline$\eta_{\sigma^{g}}$ & Gamma & 0.50 & 0.100 & 0.002 & 0.002 & 0.003 \\
\hline $\bar{\sigma}^{g}$ & Uniform & 0.05 & 0.014 & 0.007 & 0.006 & 0.008 \\
\hline
\end{tabular}

Note: Beta* indicates that the parameter divided by 0.999 follows a beta distribution.

Finally, the exogenous processes are estimated via Bayesian techniques using sequential Monte Carlo Methods. ${ }^{16}$ We employ a Sequential Importance Resampling (SIR) filter (Gordon et al. 1993) with 20,000 particles to construct the likelihood of the stochastic volatility processes. Draws from the posterior are generated using the Metropolis-Hastings

\footnotetext{
${ }^{13}$ See Appendix A.2.1.

${ }^{14}$ Note that in contrast to e.g. Smets and Wouters (2007), these fixed costs are non-labor related fixed costs as the latter are captured in the overhead labor share.

${ }^{15}$ While we allow tax rates to vary in the empirical analysis, we keep them fixed at their steady-state value for the model analysis. See Appendix $\mathrm{C}$ for details on the construction of tax rates.

${ }^{16}$ Our approach is described in more detail in Appendix B of Born and Pfeifer (2014).
} 
algorithm. We generate a Monte Carlo Markov Chain with 205,000 draws of which 5000 are used as a burn-in. ${ }^{17}$ As the proposal density, we use a multivariate normal distribution with the identity matrix as the covariance matrix, scaled to achieve an acceptance rate of about 25 percent. Smoothed objects are constructed using the backward-smoothing routine of Godsill et al. (2004) with 20,000 particles for the smoother. To construct output, government spending, and TFP deviations from trend, a one-sided HP-filter $(\lambda=1600)$ is used. For TFP, we cumulate the utilization-adjusted TFP series constructed by Fernald (2012). Table 2 displays the prior and posterior distributions, while Figure A.1 shows the smoothed volatilities.

\subsection{Model Impulse Responses}

As outlined in Section 2, precautionary price and wage setting in response to an increase in uncertainty lead to an increase in both price and wage markups. Thinking about a stylized labor market as depicted in the schematic diagram shown in Figure 2, this should cause both the labor demand and supply curves to shift to the left, resulting in an overall decrease in hours worked and a reduction in aggregate output $Y_{t}$.

We can now feed an uncertainty shock into our general-equilibrium model to study the effects on markups and real activity in a richer model environment. Figure 3 displays the impulse responses to a four-standard deviation government spending (i.e. demand) uncertainty shock $\varepsilon_{t}^{\sigma^{g}}$ (top panel) and to a four-standard deviation technology (i.e. supply) uncertainty shock $\varepsilon_{t}^{\sigma^{z}}$ (bottom panel). ${ }^{18}$ We denote the log wage markup with $\xi_{t}^{w} \equiv$ $\log \left(\Xi_{w, t}\right)$ and the $\log$ price markup with $\xi_{t}^{p} \equiv \log \left(\Xi_{p, t}\right)$. We see that, indeed, an increase in uncertainty leads to an increase in both price and wage markups and a decline in output. When the shock dies out, the markups converge back to their pre-shock values as does output. We do not show here the response of the real wage, which increases. As the labor market diagram in Figure 2 makes clear, its theoretical response is ambiguous, depending

\footnotetext{
${ }^{17}$ The Raftery and Lewis (1992) convergence diagnostics with quantile $q=0.025$, precision $r=0.01$, and probability of attaining this precision $s=0.95$ suggests that this is sufficient for convergence.

${ }^{18} \mathrm{IRFs}$ are generalized impulse response functions, shown as percentage deviations from the stochastic steady state, computed using third-order perturbation techniques with the pruning algorithm of Andreasen et al. (2013). We use four-standard deviation shocks as this is the typical shock size used in the empirical literature, because it is about the increase in uncertainty proxies during the Great Recession.
} 


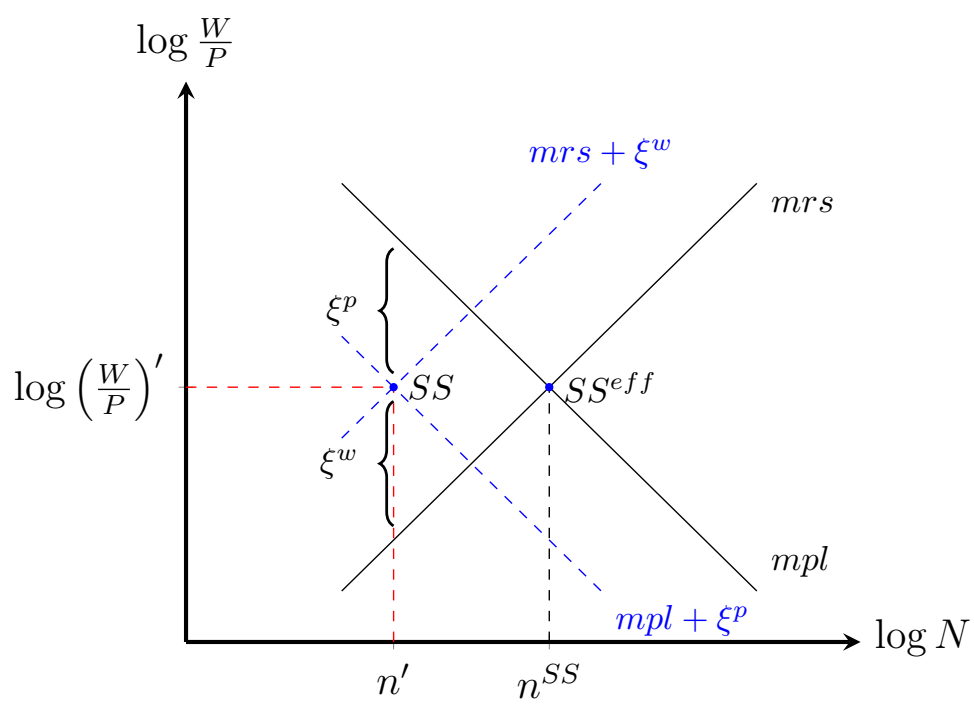

Figure 2: Stylized labor market. Notes: Labor supply is characterized by the condition that the log marginal rate of substitution ( $\mathrm{mrs}$ ) is equal to the log real wage, while the labor supply curve is characterized by the log marginal product of labor $(\mathrm{mpl})$ being equal to the log real wage. The point $S S^{e f f}$ denotes the efficient steady state where $m r s$ and $m p l$ are equal. The presence of a wage and price markup $\left(\xi^{w}\right.$ and $\left.\xi^{p}\right)$ drives a wedge between the two curves and the real wage.

on whether the wage or price markup response is stronger, increasing for the former and falling for the latter.

A necessary ingredient for the negative response of output to an uncertainty shock is the presence of at least one type of nominal rigidity. Figures A.2 and A.3 in the appendix show the IRFs with only price and wage rigidity, respectively. In both cases, there is a drop in output, which is less pronounced than in the baseline case with both types of stickiness. Finally, A.4 shows the IRFs in the model without nominal rigidities. In this case the precautionary labor supply motive dominates and output increases.

\subsection{Constructing aggregate markups}

Our ultimate goal is to compare the theoretical model IRFs with their empirical counterparts. To this end, we need to construct aggregate markups from the data.

Using the intratemporal first-order conditions of the model, empirical measures of both price and wage markups can be constructed in a business cycle accounting-style exercise. Using the Cobb-Douglas felicity function from Section 3, the wage markup over 

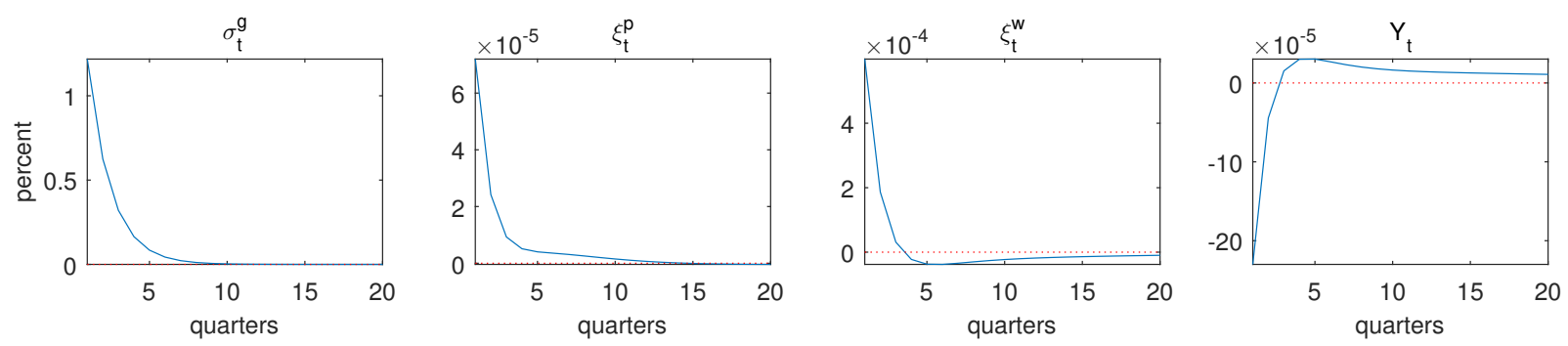

(a) Government Spending Volatility
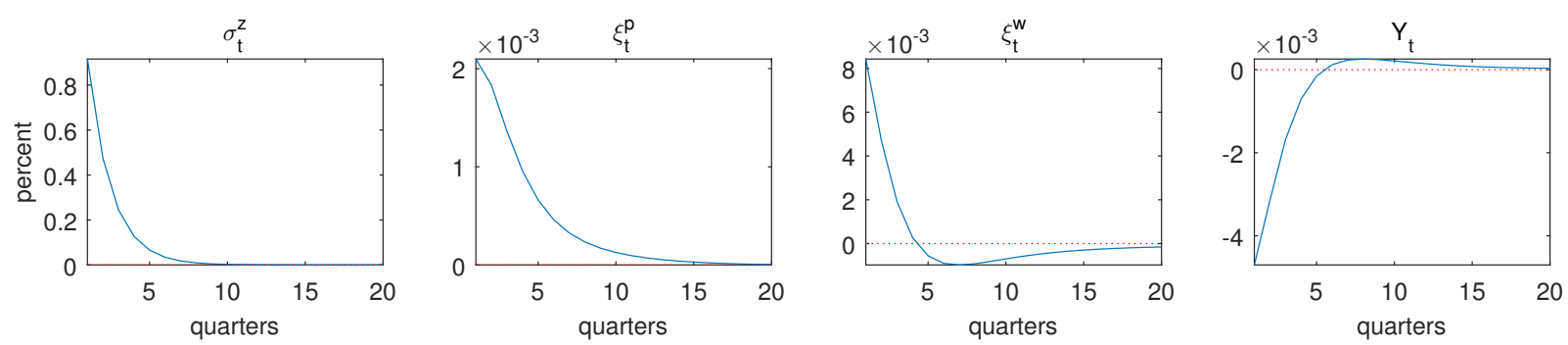

(b) Technology Volatility

Figure 3: Model IRFs to a four-standard deviation government spending volatility shock (Panel a) and to a technology volatility shock of the same size (Panel b). Notes: Theoretical responses measured in percentage deviations from the stochastic steady state.

the marginal rate of substitution satisfies

$$
\Xi_{w, t} \frac{1-\eta}{\eta} \frac{C_{t}}{1-N_{t}}=\frac{1-\tau_{t}^{n}}{1+\tau_{t}^{c}} \frac{W_{t}}{P_{t}}
$$

Expanding this fraction and taking $\operatorname{logs}, \xi_{t}^{w} \equiv \log \left(\Xi_{w, t}\right)$ can be computed from

$$
\xi_{t}^{w}=\log \left(\frac{1-\tau_{t}^{n}}{1+\tau_{t}^{c}}\right)+\log \left(\frac{W_{t} N_{t}}{P_{t} Y_{t}}\right)+\log \left(\frac{Y_{t}}{C_{t}}\right)-\log \left(\frac{1-\eta}{\eta}\right)+\log \left(\frac{1-N_{t}}{N_{t}}\right)
$$

where the second term on the right is the labor share.

The firm-side price markup $\xi_{t}^{p} \equiv \log \left(\Xi_{p, t}\right)$ can be constructed using the CES-production function (3.1) as (see Appendix B for details)

$$
\xi_{t}^{p}=\log \left((1-\alpha)\left(Y^{n o r m}\right)^{\frac{\psi-1}{\psi}}\right)+\frac{\psi-1}{\psi} Z_{t}+\frac{1}{\psi} \log \left(\frac{Y_{t}+\Phi}{N_{t}-N^{o}}\right)-\log \left(\frac{W_{t}}{P_{t}}\right) .
$$

To compute both price and wage markups, all that is needed are aggregate time series on output, consumption, taxes, labor-augmenting technology, and various labor market variables like hours worked and wages. On the household side we follow Karabarbounis (2014) and rely on broad, encompassing measure of hours, employment, and population that takes the substantial U.S. military employment into account (see Cociuba et al. 


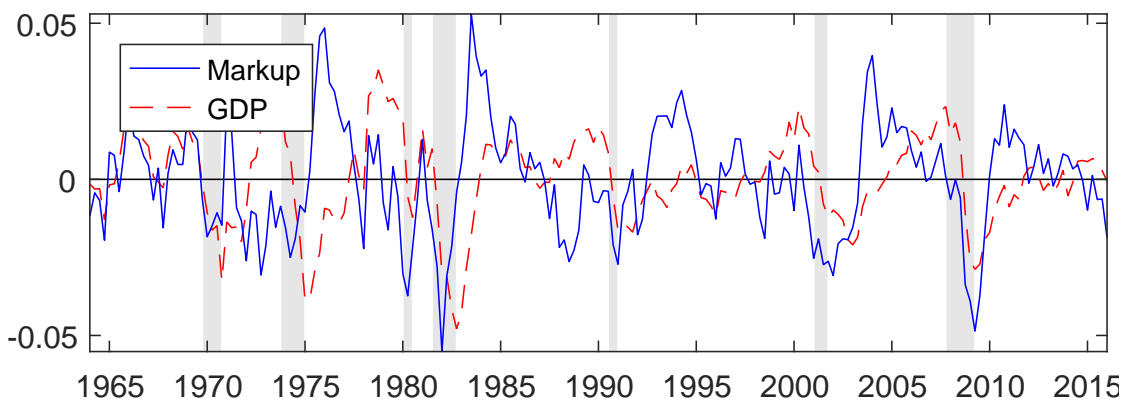

(a) Price Markup

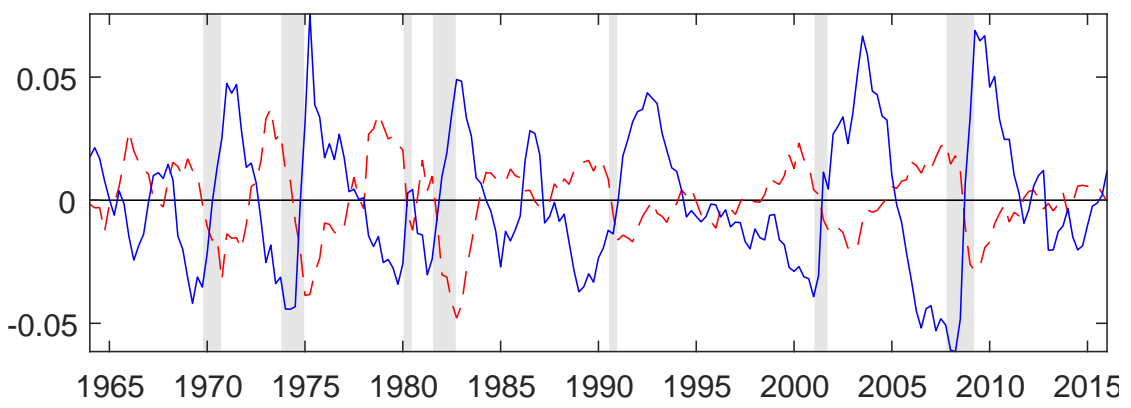

(b) Wage Markup

Figure 4: Cyclical component of the price markup $\xi_{t}^{p}$ (top panel) and of the wage markup $\xi_{t}^{w}$ (bottom panel) over time. Blue solid lines: respective markup; red dashed line: GDP. Grey shaded areas denote NBER recessions.

2012) when measuring the marginal rate of substitution. On the firm side, it is crucial to correctly measure the marginal product of labor. For this purpose, we follow Nekarda and Ramey (2013) and rely on data from the private business sector, which distinguishes production from overhead workers. We use Fernald (2012)'s utilization-adjusted TFP measure to back out labor-augmenting technology. ${ }^{19}$

Figure 4 shows the HP-filtered $(\lambda=1600)$ markups over time. As already documented in Nekarda and Ramey (2013), the price markup tends to have its trough during or shortly after recessions, while its peak happens in the middle of expansions. In contrast, the wage markup tends to peak during recessions. This finding is consistent with evidence presented by Karabarbounis (2014), Shimer (2010), and Galí et al. (2007). The cyclical behavior of the markups is confirmed by the cross-correlograms depicted in Figure 5. While the price markup is acyclical, the correlation becomes negative for leads: a drop in GDP today signals an increase in the price markup in the future. In contrast, the wage markup shows a pronounced countercyclicality.

\footnotetext{
${ }^{19}$ Appendix $\mathrm{C}$ describes the respective data sources used in detail.
} 

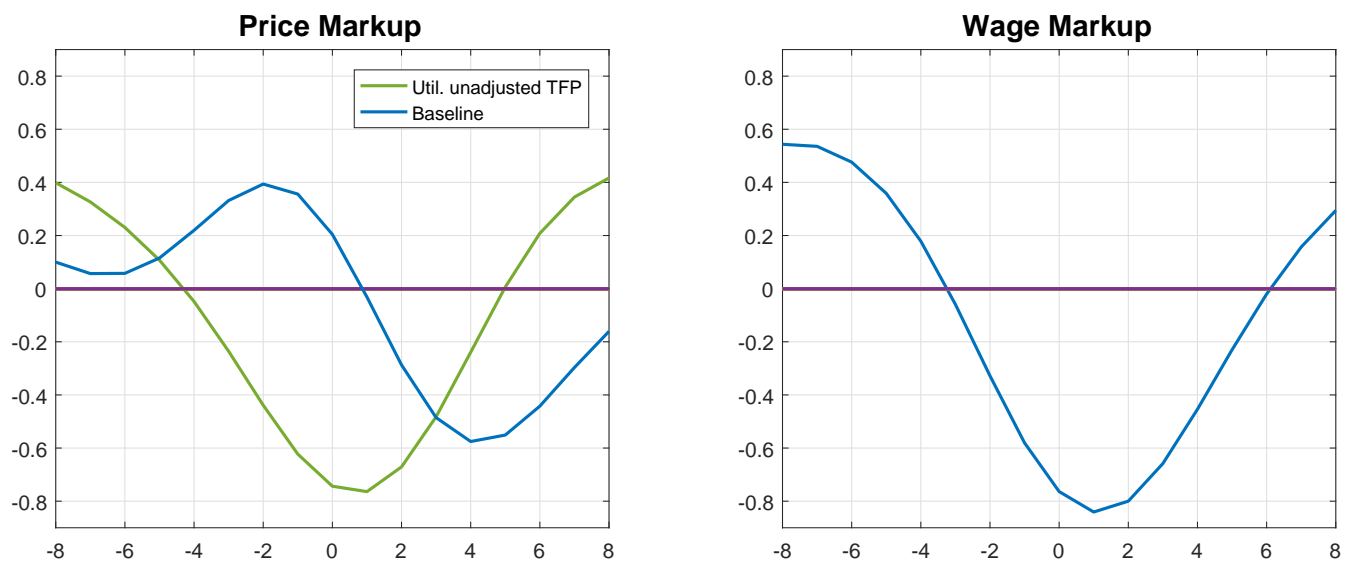

Figure 5: Correlation of the cyclical components of the price markup $\xi_{t+j}^{p}$ and the wage markup $\xi_{t+j}^{w}$ with output $y_{t}$. The price markup is shown for both utilization-adjusted (blue line) and unadjusted (green line) TFP measures.

\section{Aggregate evidence}

In this section, we investigate the responses of aggregate price and wage markups to exogenous uncertainty shocks. We first consider a model-consistent uncertainty measure in the form of smoothed uncertainty shocks from the particle smoother (see Section 3.6), before turning to broader measures of aggregate uncertainty.

\subsection{Model-consistent uncertainty measures}

For our first approach, we use the median quarterly smoothed uncertainty shocks $e_{t} \in$ $\left\{\hat{\varepsilon}_{t}^{\sigma_{g}}, \hat{\varepsilon}_{t}^{\sigma_{z}}\right\}$ (where hats denote estimates from the smoother) from the estimated TFP and government spending processes that drive our DSGE model (see Section 3.4). These shocks are included in a local projection model (Jordá 2005) of the form

$$
x_{t+h}=\alpha_{h}+\beta_{h} t+\gamma_{h} e_{t}+\eta_{t, h} .
$$

Here, $\gamma_{h}$ denotes the response of a particular variable $x_{t+h}$ at horizon $h$ to an exogenous variation in uncertainty at time $t, e_{t}$. In our baseline $x_{t+h}$ stands for either price or wage markup or GDP. $\alpha_{h}$ and $\beta_{h} t$ are a constant and a linear time trend, respectively. The error term $\eta_{t, h}$ is assumed to have a zero mean and strictly positive variance. We estimate model (4.1) using OLS where, in order to improve the efficiency of the estimates, we include the residual of the local projection at $t+h-1$ as an additional regressor in the 

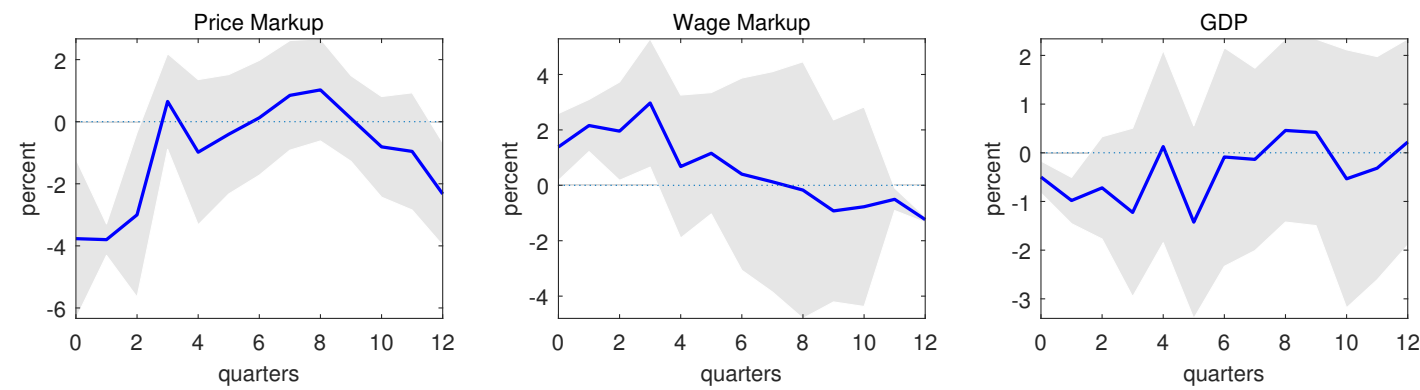

(a) Technology uncertainty.
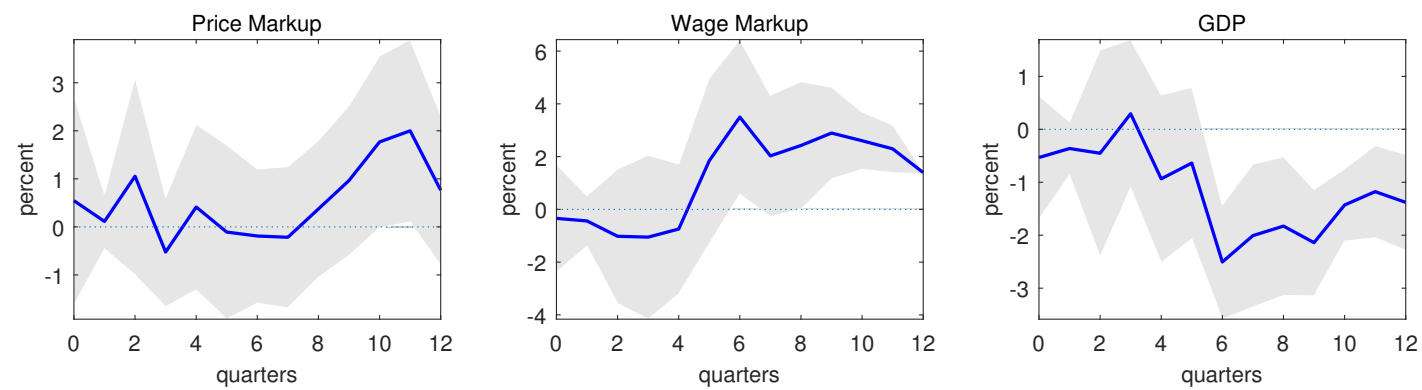

(b) Government spending uncertainty.

Figure 6: Local projection responses to model-consistent uncertainty shocks. Notes: Shaded areas denote $90 \%$ confidence intervals based on Newey-West standard errors.

regression for $t+h$ (see Jordá 2005). ${ }^{20}$

Figure 6 presents the results. As expected, an increase in technological uncertainty is associated with a drop in GDP. However, the conditional markup response in the data partially differs from the one predicted by the model. On impact, the price markup falls. In contrast, the DSGE model implies that the price markup quickly peaks and then declines back to its stochastic steady state as the effect of price stickiness subsides over time. ${ }^{21}$ The movement of the wage markup squares better with the model: it increases after an uncertainty shock and then slowly declines back to steady state.

The evidence after a government spending uncertainty shock is not as conclusive, but also does not lend strong support to the model mechanism.

\subsection{Two-step approach using broad macro uncertainty measure}

The first set of impulse responses from the model-consistent uncertainty measures tentatively suggests that the conditional behavior of the price markup is not consistent with the

\footnotetext{
${ }^{20}$ As shown in Pagan (1984), the standard error estimate on the residual is consistent.

${ }^{21}$ This conditional markup response is consistent with the conditional comovement Nekarda and Ramey (2013) found after other types of shocks, which also contradicted the sticky price model.
} 
model prediction. However, the bands were relatively wide. This is not entirely surprising as TFP measures are notoriously noisy and government spending shocks are hard to identify. Thus, we would like to rely on an uncertainty proxy that is still closely linked to the model concept of uncertainty, but at the same time has a better signal-to-noise ratio. A measure satisfying this criterion has recently been proposed by Jurado et al. (2015). Their measure is closely linked to the concept of forecast error uncertainty employed in business cycle models, but relies on a broad information set to extract the signal. ${ }^{22}$ We think that this is currently the broadest and at the same time cleanest uncertainty measure available. ${ }^{23}$

We are ultimately interested in the dynamic response of markups to innovations, or "shocks", to uncertainty. Given that the JNL uncertainty measure is available at monthly frequency while we only have quarterly markup data, we will employ a two-step procedure following Kilian (2009) and Born, Breuer, et al. (2014). In the first step, to identify structural uncertainty shocks, we follow Bloom (2009) and Jurado et al. (2015) and employ a Cholesky-ordering within a monthly VAR framework. The structural shocks are then aggregated to quarterly frequency by averaging the monthly shocks and, in the second step, fed into a local projection as in (4.1). ${ }^{24}$ We pursue this approach, because the monthly time horizon of the VAR makes the recursive timing assumption underlying the identification scheme more plausible than in a quarterly VAR.

Our sample ranges from 1964M1 to 2015M12. The variable vector $X_{t}$ in our VAR contains 1) real industrial production, 2) total non-farm employment, 3) real personal

\footnotetext{
${ }^{22}$ Jurado et al. (2015) stress that in order to measure uncertainty, it is important to purge the predictable component of volatility. They estimate a factor-based forecasting model on 279 monthly economic and financial time series. Given their estimated factors, they then compute forecast errors for 132 of these variables and subsequently use the forecast errors to construct an uncertainty time series for each variable based on the assumption that these follow a stochastic volatility process. Their macroeconomic uncertainty measure is the common factor of the uncertainty connected to the individual variables. We use their one-period ahead forecast measure (i.e. $h=1$, not to be confused with the forecast horizon in the local projection).

${ }^{23}$ Measures like the economic policy uncertainty index by Baker et al. (2016) have a very narrow focus, while financial market-based measures like the VIX or realized (return) volatility are likely to be contaminated by changes in risk aversion and financial market conditions (see e.g. Bekaert et al. 2013; Caldara et al. 2016; Stock and Watson 2012). We will employ these alternative measures in the robustness section.

${ }^{24}$ Using the average follows Kilian (2009). Readers worried about time aggregation are referred to the mixed-frequency VAR below.
} 
consumption expenditures, 4) the personal consumption expenditure deflator, 5) real new orders, 6) the manufacturing real wage, 7) hours worked in manufacturing, 8) the Wu and Xia (2016) shadow federal funds rate, ${ }^{25}$ 9) the S\&P 500 Index, 10) M2 money growth, and 11) the 1-step ahead JLN uncertainty proxy. ${ }^{26}$ Formally, we estimate the following VAR using OLS

$$
X_{t}=\mu+\alpha t+A(L) X_{t-1}+\nu_{t}
$$

where and $\mu$ and $\alpha$ t are a constant and time trend, respectively, $A(L)$ is a lag polynomial of degree $\mathrm{p}=6$, and $\nu_{t} \stackrel{i i d}{\sim}(0, \Sigma)$. In terms of identification, we assume a lower-triangular matrix $B$, which maps reduced-form innovations $\nu_{t}$ into structural shocks $\varepsilon_{t}=B \nu_{t}$.

After averaging the monthly shocks and feeding them into the local projection model, the resulting IRFs are plotted in Figure 7. They corroborate our previous finding. After an uncertainty shock, the wage markup increases significantly, consistent with a precautionary wage setting motive as in the model. The same does not apply to the price markup, which tends to decline.
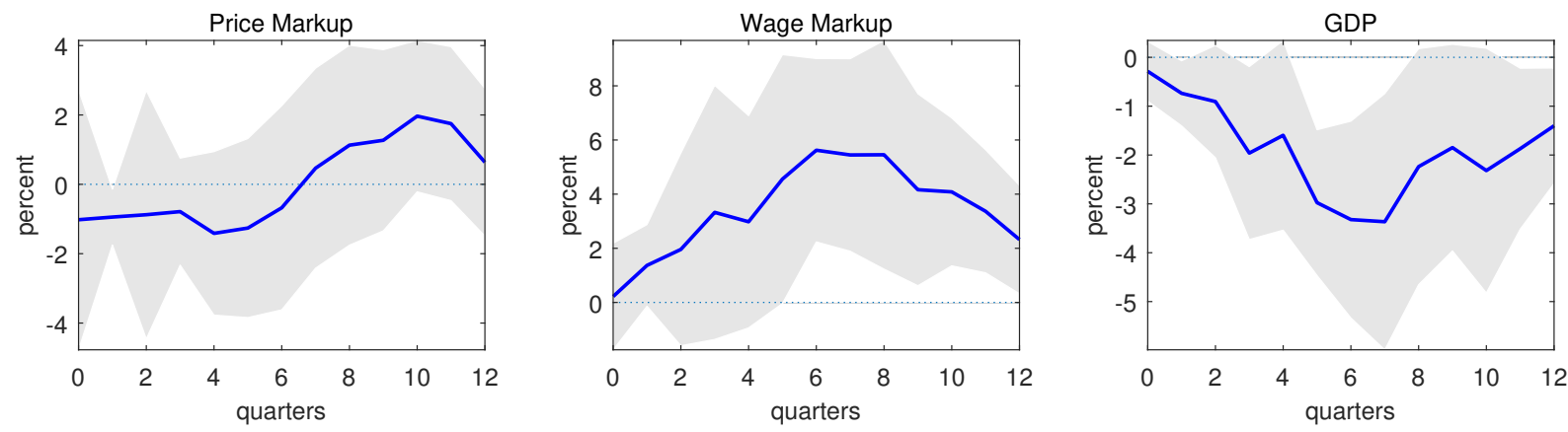

Figure 7: Local projection responses to a JLN-based uncertainty shock in the two-step model. Notes: Shaded areas denote $90 \%$ confidence intervals based on Newey-West standard errors.

\subsection{Mixed-frequency VAR}

While the two-step approach does not impose cross-equation restrictions and is therefore more flexible and robust than a VAR, it comes at the disadvantage of not making full

\footnotetext{
${ }^{25}$ We use this measure to alleviate concerns about the effective zero lower bound introducing a nonlinearity the VAR is not being able to capture. Using the effective federal funds rate instead yields very similar results.

${ }^{26}$ See Appendix D.2 for a detailed description of the macro dataset and the transformations used for the respective variables.
} 
use of high-frequency information. As mentioned before, the constructed markups are only available at quarterly frequency. To use all available monthly information on the other variables, we assume that we cannot observe the monthly realizations of the markup measure and treat these data as missing values. Following the Bayesian VAR framework outlined in Eraker et al. (2015), we can then employ a Gibbs sampler to deal with these missing observations by sampling the missing data from their conditional distribution.

Our sample again ranges from 1964M1 to 2015M12, on which we estimate the 11variable VAR in equation (4.2) with $p=6$, but where we add our quarterly markup measures as an additional twelfth variable observed every third month. Consistent with the model, we order the markups after the respective uncertainty measure so that markups can react on impact. We use a shrinking prior of the Independent Normal-Wishart type (Kadiyala and Karlsson 1997), where the mean and precision are derived from a Minnesota-type prior (Doan et al. 1984; Litterman 1986) ${ }^{27}$ In the Gibbs sampler, we use 25,000 draws, of which we discard the first 5,000 draws as a burn-in. ${ }^{28}$ We use $90 \%$ highest posterior density intervals (HPDIs) based on 1000 random posterior draws after burn-in.

Figure 8 presents the impulse responses of the wage and price markup following an economic uncertainty shock. ${ }^{29}$ As with the model-consistent measure and the two-step approach, wage markups increase after an uncertainty shock but price markups fall.

Figure 9 displays the total markup or "labor wedge", i.e. the sum of the price and wage markup. During the first few months, it is dominated by the price markup response and slightly falls, before it becomes dominated by the wage markup and increases subsequently. As the figure shows, after an uncertainty shock the real wage increases while hours worked fall. This response is perfectly consistent with a situation where the wage markup increases while the price markup stays flat (see the stylized labor market diagram in Figure 2). ${ }^{30}$ While the model does not predict the same hump-shaped movement, it predicts the

\footnotetext{
${ }^{27}$ See Appendix D.1 for details.

${ }^{28}$ The Raftery and Lewis (1992) convergence diagnostics suggests that this is sufficient for convergence.

${ }^{29}$ Figure D.5 presents IRFs of all variables to an uncertainty shock.

${ }^{30}$ The model with only rigid wages also delivers an increases in the real wage and a drop in hours worked.
} 

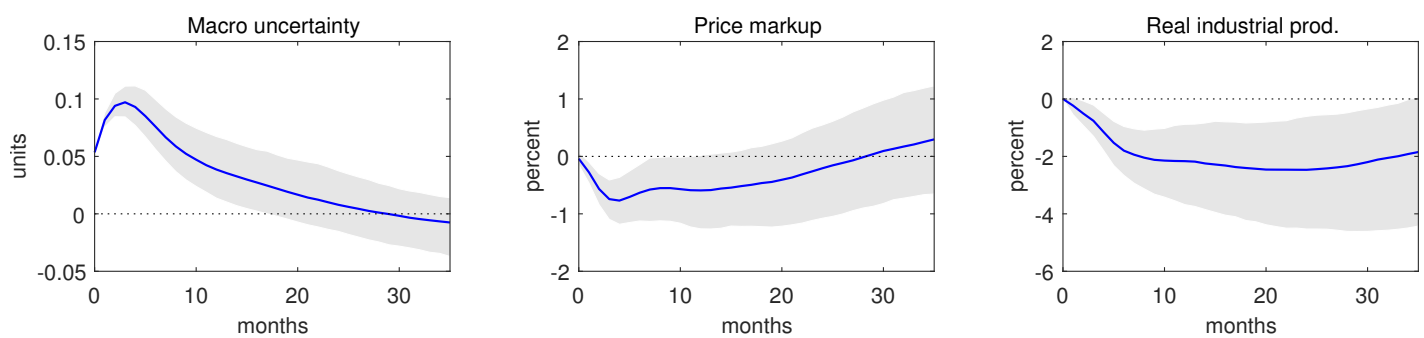

(a) Price Markup.
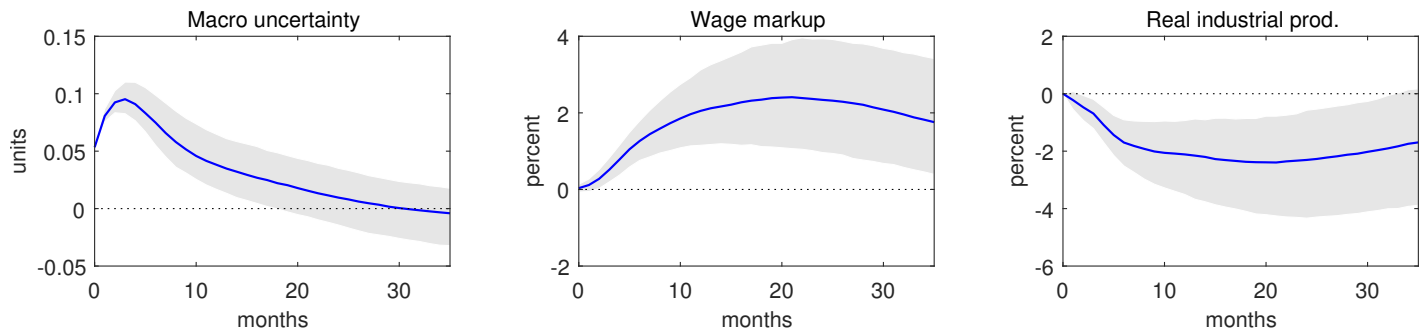

(b) Wage Markup.

Figure 8: IRFs to JLN-based uncertainty shock in the mixed-frequency VAR. Notes: Bands are pointwise $90 \%$ HPDIs. The respective markups are rotated into the VAR as the 12 th variable.
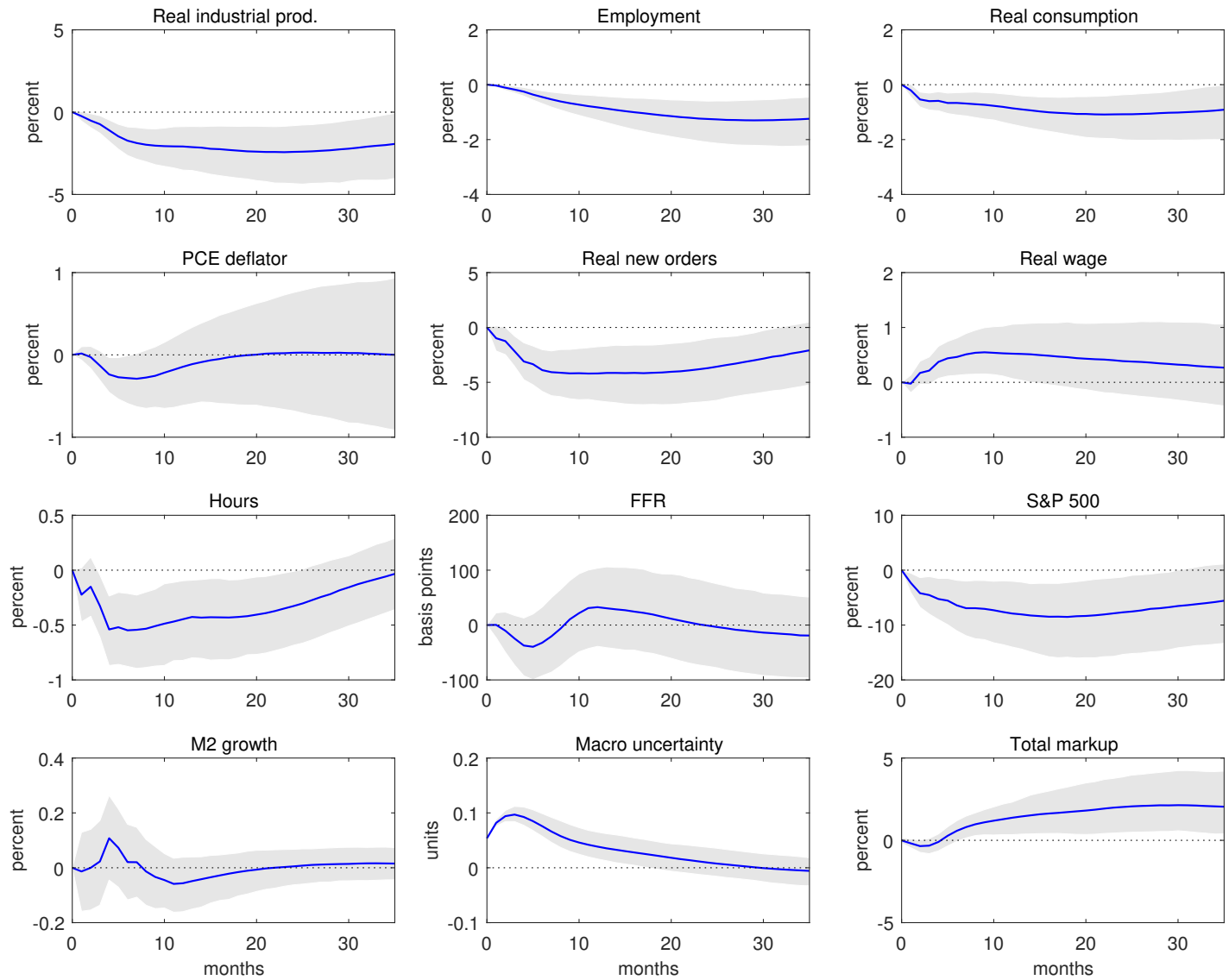

Figure 9: IRFs to JLN-based uncertainty shock in the mixed-frequency VAR including the total markup. Notes: Bands are pointwise $90 \%$ HPDIs. The total markup is computed as the sum of the price and wage markup. 
same countercyclical movement of the wage markup. At least in that regard, the data is consistent with the markup channel in New Keynesian models and the role of uncertainty shocks more generally. Empirically, most of the movement in the labor wedge seems to come from this margin. ${ }^{31}$ However, from the vantage point of the basic New Keynesian model with only sticky prices, the price markup response presents a challenge.

We also compute the posterior unconditional forecast error variance share explained by the identified uncertainty shock. Uncertainty shocks account for about $13 \%$ of output fluctuations, $15 \%$ of the wage markup, but only $8 \%$ of the price markup. Taken together, uncertainty shocks account for $11 \%$ of total labor wedge fluctuations (see Table D.3 in the appendix).

\subsection{Robustness}

While our results seem to be robust across different time-series approaches, one might wonder whether they depend on the ordering of variables in the VAR, the chosen uncertainty proxy, or the assumptions made to construct markups. We will address these concerns in the following.

\section{Bloom (2009) VAR}

Bloom (2009) considers a different, 8-variable VAR where uncertainty is ordered second and measured by stock market volatility. In a first step, we check whether using the VIX instead of the JNL measure makes a difference in our VAR 11+1. Figure 10 confirms that the results are robust to this change.

Next, we investigate the original Bloom 8-variable VAR with uncertainty, measured by the VIX, ordered second. We add our markup measure as the ninth variable. ${ }^{32}$ Results from the mixed-frequency estimation are shown in Figure 11. They are very similar to the baseline results, indicating that the ordering of the uncertainty measure is not crucial for our results. ${ }^{33}$

\footnotetext{
${ }^{31}$ Bils et al. (2016) have recently argued for a more equal split.

${ }^{32}$ See Appendix D.3 for a detailed variable listing and Figure D.6 for a full set of IRFs.

${ }^{33}$ Figure D.7 shows that the IRFs when using the Jurado et al. (2015) measure ordered second in the VAR are similar.
} 

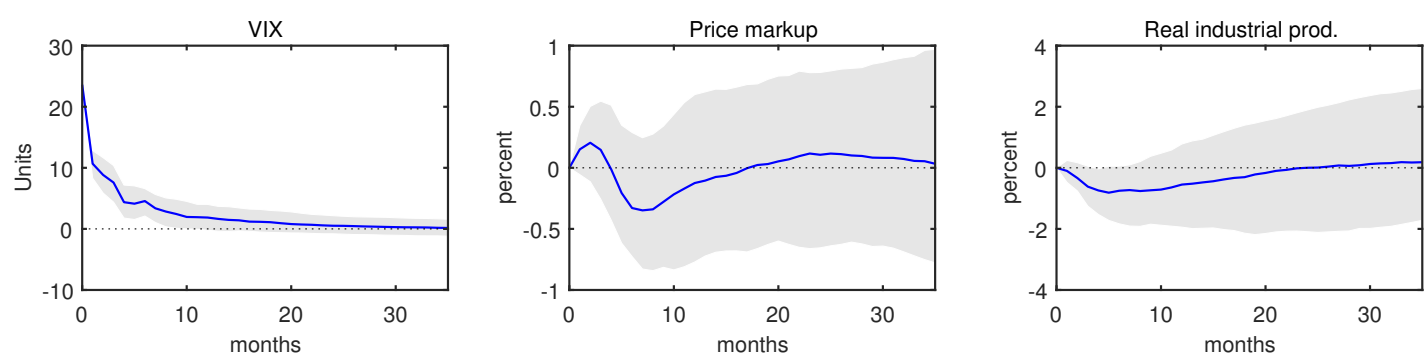

(a) Price Markup
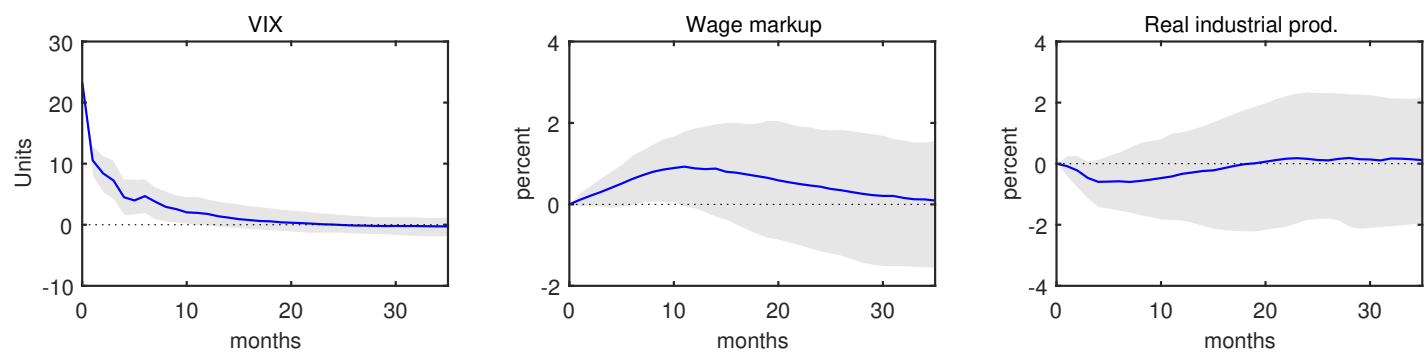

(b) Wage Markup

Figure 10: IRFs to VIX-based uncertainty shocks in the mixed-frequency 11+1-VAR. Notes: Bands are pointwise $90 \%$ HPDIs.
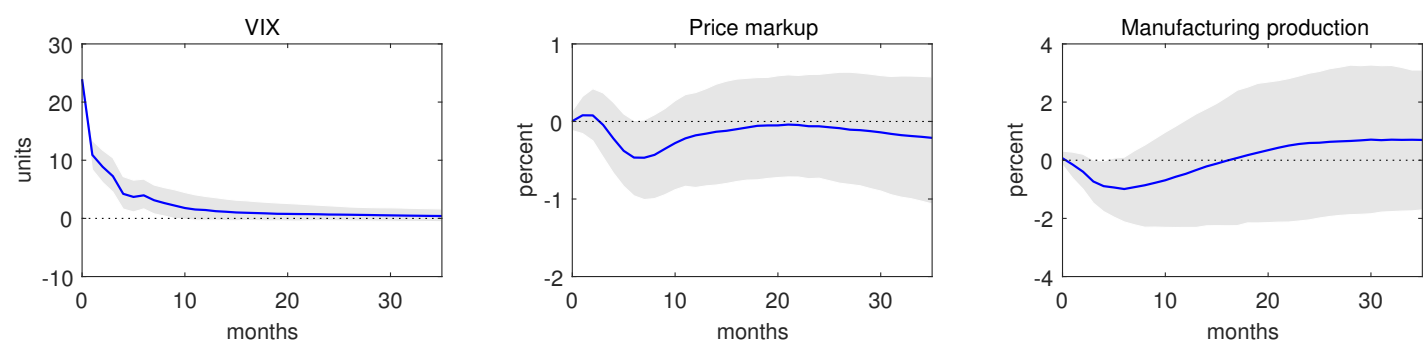

(a) Price Markup
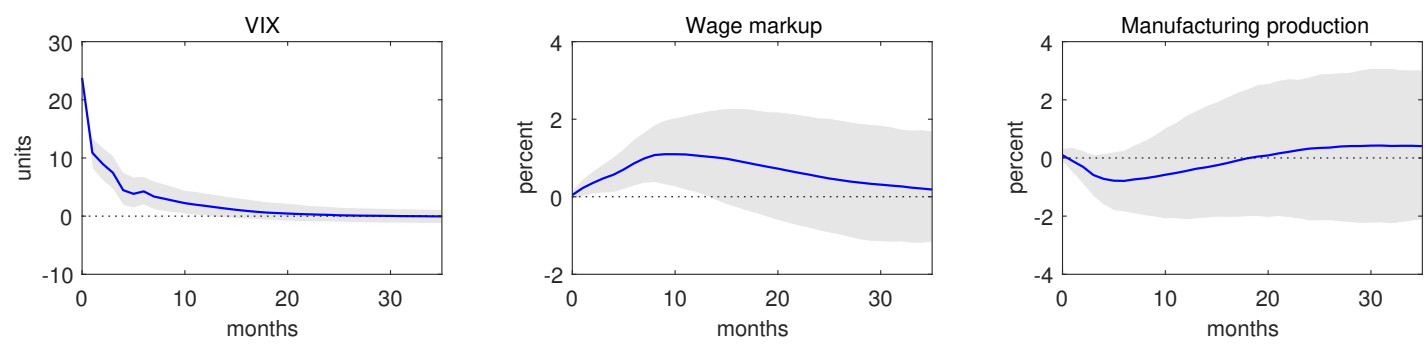

(b) Wage Markup

Figure 11: IRFs to uncertainty shocks measured via the VIX ordered second in the mixed-frequency 8+1-VAR. Notes: Included variables as in Bloom (2009) plus markup measure. Bands are pointwise $90 \%$ HPDIs.

\section{Alternative markup measurements}

In our baseline price markup measure, we employ the utilization-adjusted TFP measure of Fernald (2012), which results in an acyclical price markup. As a robustness check, we also use Fernald's utilization-unadjusted TFP measure. This results in a strongly 
countercyclical price markup (see the green line in the left panel of Figure 5), which, as Nekarda and Ramey (2013) note, is very similar to the countercyclical markup measure constructed in Galí et al. (2007). Estimating our mixed-frequency VAR including this alternative price markup measure yields the IRFs reported in Panel (a) of Figure 12. The drop in the price markup is less pronounced than in the baseline, but there is still no robust evidence for an increase.
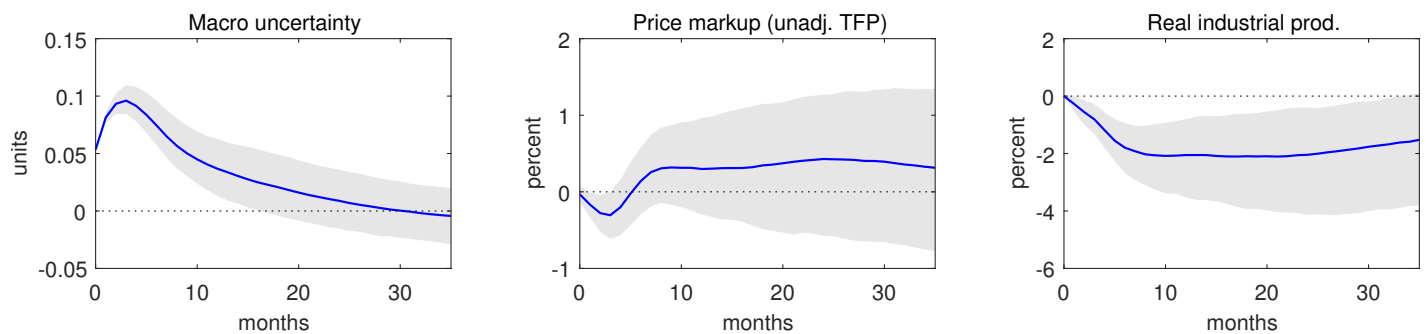

(a) Price markup measured with utilization-unadjusted TFP
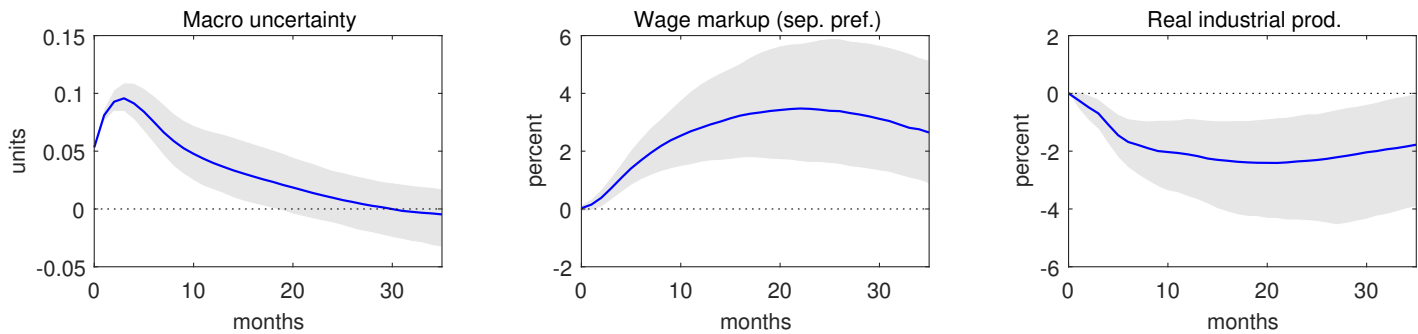

(b) Wage markup measured with separable preferences

Figure 12: IRFs to JLN-based uncertainty shocks in the mixed-frequency 11+1-VAR. Notes: Bands are pointwise 90\% HPDIs.

We also check the robustness of the wage markup response with respect to the preference specification used. Instead of the Cobb-Douglas type felicity function used in the baseline, we construct the wage markup using separable isoelastic preferences of the type $\log \left(C_{t}\right)-\psi N_{t}^{1+1 / \eta}$, where we again set the Frisch elasticity $\eta$ to one. ${ }^{34}$ This results in a wage markup that is more volatile over the business cycle (Karabarbounis 2014). The results in Panel (b) of Figure 12 show a somewhat stronger increase in the wage markup with this measure, but are otherwise similar to the baseline.

With respect to the price markup, one might worry that the correction for overhead labor, fixed costs, and a CES production function might be overdoing things. Figure 13 therefore reports the responses of three "conventional" markup measures based on a setup

\footnotetext{
${ }^{34}$ The labor disutility parameter $\psi$ only affects the constant in our markup measure and therefore can be set to 1 without loss of generality.
} 

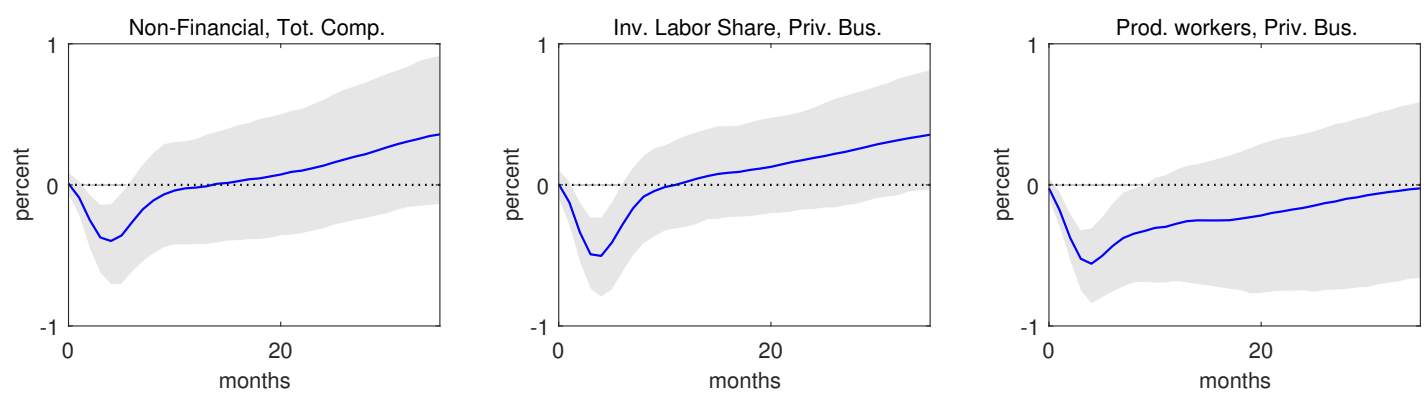

Figure 13: IRFs of Cobb-Douglas production function-based price markups to JNL-based uncertainty shocks in the mixed-frequency 11+1-VAR. Notes: left panel: based on total compensation in non-financial business sector; middle panel: based on labor share of production and supervisory workers in private business sector; right panel: based on labor share production workers only in private business sector. Bands are pointwise $90 \%$ HPDIs.

with no fixed costs and a Cobb-Douglas production function. In this case, the aggregate price markup corresponds to the inverse labor share. The left panel of Figure 13 displays the response of the price markup for the labor share based on total compensation in the non-financial business sector (available from the NIPA tables). The middle panel uses the labor share of production and supervisory workers in the private business sector, while the right panel is based on production workers only in the private business sector, i.e. excludes overhead workers (both available from the BLS). In all three cases, the price markup significantly drops after an uncertainty shock. The first two measures, which are based on all workers, tend to recover somewhat more quickly than the third measure, which excludes overhead labor. But even for the first two measures, we do not find a significant increase of the price markup within the first three years.

\section{Other uncertainty measures}

Recently Caldara et al. (2016) and Ludvigson et al. (2015) have argued that it is important to distinguish between macroeconomic and financial uncertainty, with the latter driving the former. Figure D.8 tests this conjecture within the context of our VAR model by displaying the IRFs in response to the Ludvigson et al. (2015) financial uncertainty measure. The results are similar to the ones of the macro uncertainty measure.

Baker et al. (2016) have constructed an index of economic policy uncertainty. It is more narrow than the Jurado et al. (2015) uncertainty measure in that it only captures 
the political dimension of uncertainty, but is at the same time broader in that it not only captures risk, but also Knightian uncertainty. Despite these differences, the responses of the respective markups, displayed in Figure D.9, show a familiar pattern: the wage markup increases while the price markup falls. ${ }^{35}$

\section{Industry-level evidence}

In the previous section, we have documented that there is scant empirical evidence for price markup increases after uncertainty shocks at the aggregate level. In this section we dig deeper and investigate whether the model-predicted price markup response may simply be hidden by heterogeneity in price stickiness at the industry level.

\subsection{Constructing industry-specific markups}

Based on the NBER CES Manufacturing Industry Database (Bartelsman and Gray 1996; Becker et al. 2016) we construct price markups and output measures at the four digit SIC-industry level (see Appendix C.5 for details). As we have argued before, a robust result of representative agent models with convex adjustment costs is that negative output effects of uncertainty are directly related to nominal stickiness. As a first pass at the data, we therefore estimate the contemporaneous response of real output for each SIC4 industry and plot it against average price durations for these industries. To compute this response, for each industry we regress the log of real output $y_{t}$ on the aggregate uncertainty shock, a constant, and a linear time trend:

$$
\log \left(y_{t}\right)=\alpha_{0}+\alpha_{1} t+\alpha_{2} \bar{e}_{t}+\varepsilon_{t}
$$

The aggregate uncertainty shock $\bar{e}_{t}$ is the annual average of the monthly uncertainty shocks estimated using the VAR (4.2). Implied average price durations are computed for SIC4 industries based on the estimated New Keynesian Phillips Curves in Petrella

\footnotetext{
${ }^{35}$ In this case, due to non-availability of the EPU measure, the sample only starts in 1985, potentially explaining the non-significant drop in industrial production.
} 
and Santoro (2012). ${ }^{36}$ Figure 14 plots the resulting estimates $\hat{\alpha}_{2}$ against average price durations. There does not seem to be a linear relationship between price stickiness and the output effects of uncertainty shocks. The regression line is flat and the slope coefficient is insignificant at the $5 \%$ level.

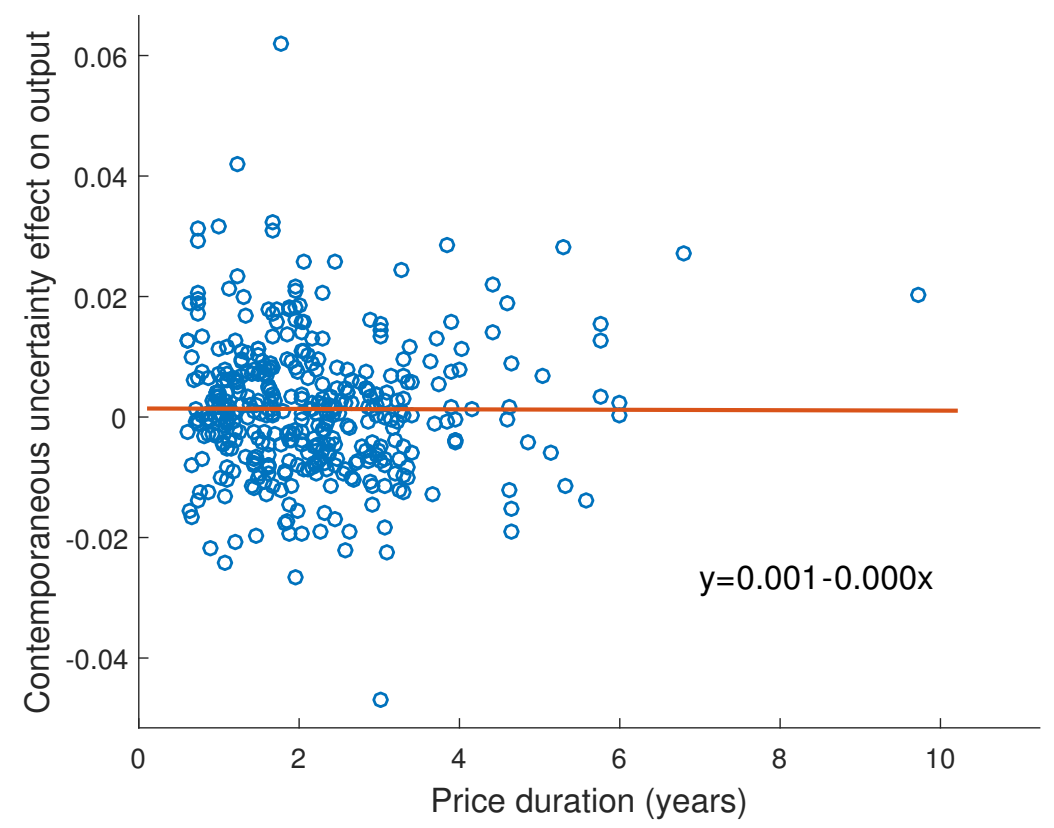

Figure 14: Implied average price duration at the SIC4 industry-level vs. output effects of aggregate uncertainty shock. Notes: Implied average price durations are based on Petrella and Santoro (2012); output effect estimates derived from industry-specific local projection on mean annual JNL shocks from VAR-11.

\subsection{Regression evidence}

As price stickiness per se does not seem seem to be related to the output effects of uncertainty, we now investigate the markup channel itself. Specifically, we run a panel version of the local projection (4.1)

$$
x_{i, t+h}=\alpha_{i, h}+\beta_{i, h} t+\gamma_{h} \bar{e}_{t}+\eta_{i, t+h} .
$$

Again, $\gamma_{h}$ denotes the response of a particular variable $x_{t+h}$ at horizon $h$ to an exogenous variation in uncertainty at time $t, \bar{e}_{t}$, where $x_{t+h}$ is either the industry-specific price markup or industry-specific real output. $\alpha_{i, h}$ and $\beta_{i, h} t$ are industry-specific constant and

\footnotetext{
${ }^{36}$ For that purpose, we translate their estimated slope of the New Keynesian Phillips Curve into a Calvo price duration parameter, using $\beta=0.99$.
} 
time trend, respectively. The results of the pooled OLS regression are shown in Figure 15. Shaded areas denote 90\% confidence intervals based on Driscoll and Kraay (1998) standard errors. Qualitatively, the results look very similar to the aggregate evidence. Industry-level output (left panel) declines after a one-standard deviation uncertainty shock and recovers after about 3 years followed by an overshoot. The price markup based on a CES production function and production-worker compensation does not increase significantly and even drops after 4 years. We therefore also do not find evidence for the price markup channel in disaggregated industry level data.
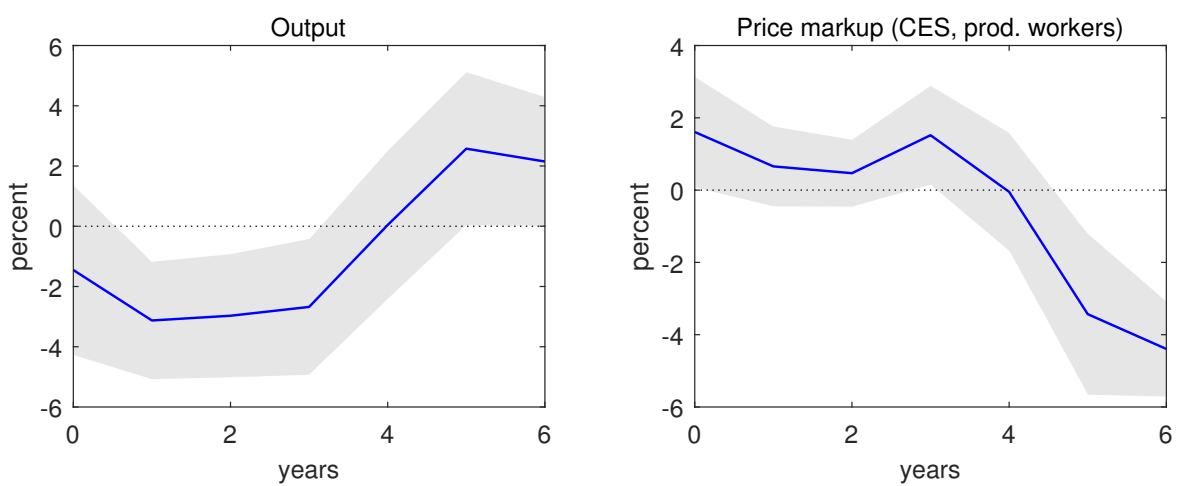

Figure 15: IRFs of industry-level output and price markup to aggregate uncertainty shocks. Notes: Shaded areas denote 90\% confidence intervals based on Driscoll-Kray standard errors.

This result does not depend on the specific choice of CES production function or production-worker compensation. Figure 16 presents evidence for price markups constructed using all workers (left panel) and a Cobb-Douglas production function (middle panel), respectively. Markups fall (insignificantly) on impact and only turn positive after about three years, before falling again.

\section{Conclusion}

The question of the markup channel as an empirically plausible transmission mechanism of uncertainty shocks into the macroeconomy is highly relevant for the policy debate given that the supposedly negative influence of policy uncertainty has become a recurring theme in the political discourse. With much of the model-based evidence featuring this supposed transmission mechanism it is of paramount importance to subject it to a rigorous empirical 

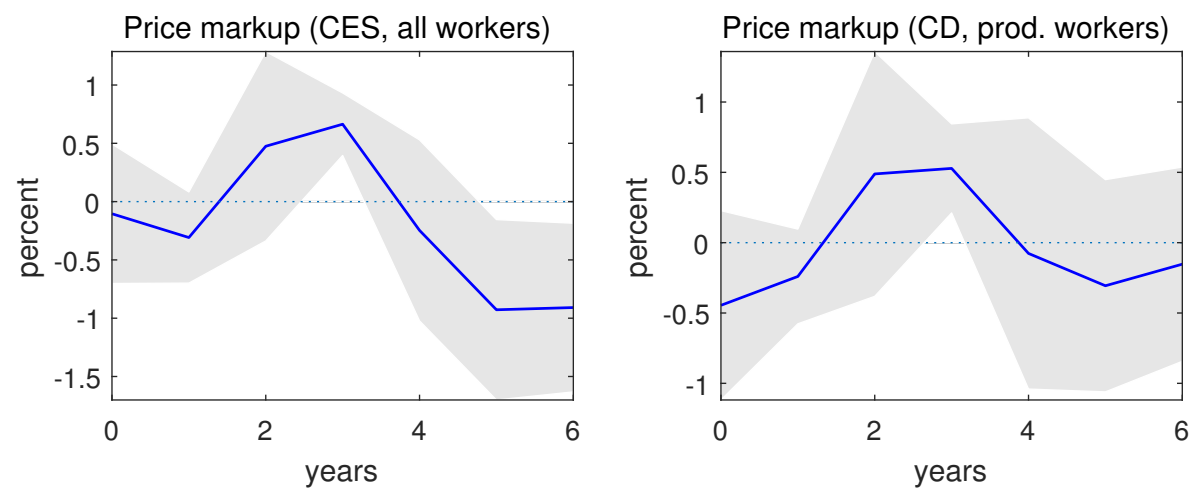

Figure 16: IRFs of industry-level price markups to aggregate uncertainty shocks for alternative markup constructions. Notes: Left panel: markups constructed assuming CES production function and using the compensation of all workers; right panel: Markups constructed assuming Cobb-Douglas (CD) production function and using production worker compensation. Shaded areas denote $90 \%$ confidence intervals based on DriscollKray standard errors.

assessment. We construct a DSGE model to measure markups and generate theoretical markup responses following uncertainty shocks. We then provide empirical evidence on the response of markups to uncertainty shocks. Contrary to the model's prediction, price markups tend to fall. However, wage markups increase after uncertainty shocks. Our results suggest that sticky wages play a more important role in the transmission of aggregate uncertainty shocks to economic variables than sticky prices. ${ }^{37}$

\footnotetext{
${ }^{37}$ See also Barattieri et al. (2014), Daly and Hobijn (2014), and Galí (2011) on the importance of sticky wages.
} 


\section{References}

Abel, Andrew B. (1983). "Optimal investment under uncertainty". American Economic Review 73 (1), 228-33.

Aguiar, Mark, Erik Hurst, and Loukas Karabarbounis (2013). "Time use during the Great Recession". American Economic Review 103 (5).

Altig, David, Lawrence J. Christiano, Martin Eichenbaum, and Jesper Lindé (2011). "Firm-specific capital, nominal rigidities and the business cycle". Review of Economic Dynamics 14 (2), 225-247.

Andreasen, Martin M., Jesús Fernández-Villaverde, and Juan F. Rubio-Ramírez (2013). "The pruned state-space system for non-linear DSGE models: theory and empirical applications". NBER Working Papers 18983.

Bachmann, Rüdiger, Steffen Elstner, and Eric R. Sims (2013). "Uncertainty and economic activity: evidence from business survey data". American Economic Journal: Macroeconomics 5 (2), 217-249.

Baker, Scott R., Nicholas Bloom, and Steven J. Davis (2016). "Measuring economic policy uncertainty". Quarterly Journal of Economics 131 (4), 1593-1636.

Balleer, Almut, Nikolay Hristov, and Dominik Menno (2016). "Financial market imperfections and the pricing decision of firms: theory and evidence". Mimeo.

Barattieri, Alessandro, Susanto Basu, and Peter Gottschalk (2014). "Some evidence on the importance of sticky wages". American Economic Journal: Macroeconomics 6 (1), 70-101.

Bartelsman, Eric J. and Wayne Gray (1996). "The NBER Manufacturing Productivity Database". NBER Technical Working Paper 205.

Başkaya, Yusuf Soner, Timur Hülagü, and Hande Küşük (2013). "Oil price uncertainty in a small open economy". IMF Economic Review 61 (1), 168-198.

Basu, Susanto and Brent Bundick (forthcoming). "Uncertainty shocks in a model of effective demand". Econometrica.

Basu, Susanto and Christopher L. House (2016). "Allocative and remitted wages: new facts and challenges for Keynesian models". NBER Working Paper 22279.

Becker, Randy, Wayne Gray, and Jordan Marvakov (2016). "NBER-CES Manufacturing Industry Database: technical notes". Mimeo.

Bekaert, Geert, Marie Hoerova, and Marco Lo Duca (2013). "Risk, uncertainty and monetary policy". Journal of Monetary Economics 60 (7), 771-788.

Bils, Mark (1987). "The cyclical behavior of marginal cost and price". American Economic Review 77 (5), 838-55.

Bils, Mark, Peter J. Klenow, and Benjamin A. Malin (2016). "Resurrecting the role of the product market wedge in recessions". Mimeo. 
Bloom, Nicholas (2009). "The impact of uncertainty shocks". Econometrica 7 r (3), 623685.

(2014). "Fluctuations in Uncertainty". Journal of Economic Perspectives 28 (2), $153-76$.

Born, Benjamin, Sebastian Breuer, and Steffen Elstner (2014). "Uncertainty and the Great Recession". German Council of Economic Experts Working Papers 04/2014.

Born, Benjamin and Johannes Pfeifer (2014). "Policy risk and the business cycle". Journal of Monetary Economics 68, 68-85.

- (2016). "The New Keynesian Wage Phillips Curve: Calvo vs. Rotemberg". CEPR Working Paper 11568.

Caldara, Dario, Christina Fuentes-Albero, Simon Gilchrist, and Egon Zakrajšek (2016). "The macroeconomic impact of financial and uncertainty shocks". European Economic Review 88, 185-207.

Cantore, Cristiano and Paul Leslie Levine (2012). "Getting normalization right: dealing with 'dimensional constants' in macroeconomics". Journal of Economic Dynamics and Control 36 (12), 1931-1949.

Cesa-Bianchi, Ambrogio and Emilio Fernandez-Corugedo (2014). "Uncertainty in a model with credit frictions". Bank of England Working Paper 496.

Chang, Yongsung and Jay H. Hong (2006). "Do technological improvements in the manufacturing sector raise or lower employment?" American Economic Review 96 (1), $352-368$.

Chari, V. V., Patrick J. Kehoe, and Ellen R. McGrattan (2007). "Business cycle accounting". Econometrica 75 (3), 781-836.

Chirinko, Robert S. (2008). " $\sigma$ : the long and short of it". Journal of Macroeconomics 30 (2), 671-686.

Christiano, Lawrence J., Martin Eichenbaum, and Charles L. Evans (2005). "Nominal rigidities and the dynamic effects of a shock to monetary policy". Journal of Political Economy 113 (1), 1-45.

Christiano, Lawrence J., Roberto Motto, and Massimo Rostagno (2014). "Risk shocks". American Economic Review 104 (1), 37-65.

Chugh, Sanjay K. (2016). "Firm risk and leverage-based business cycles". Review of Economic Dynamics 20, 111-131.

Cociuba, Simona, Edward Prescott, and Alexander Ueberfeldt (2012). "U.S. hours and productivity behavior using CPS hours worked data:1947III-2011IV". Mimeo. Arizona State University.

Cúrdia, Vasco, Andrea Ferrero, Ging Cee Ng, and Andrea Tambalotti (2015). "Has U.S. monetary policy tracked the efficient interest rate?" Journal of Monetary Economics $70,72-83$. 
Daly, Mary C. and Bart Hobijn (2014). "Downward nominal wage rigidities bend the Phillips Curve". Journal of Money, Credit and Banking 46 (S2), 51-93.

Doan, Thomas, Robert Litterman, and Christopher Sims (1984). "Forecasting and conditional projection using realistic prior distributions". Econometric Reviews 3 (1), $1-100$.

Domeij, David and Martin Floden (2006). "The labor-supply elasticity and borrowing constraints: why estimates are biased". Review of Economic Dynamics 9 (2), 242-262.

Driscoll, John C. and Aart C. Kraay (1998). "Consistent Covariance Matrix Estimation With Spatially Dependent Panel Data". The Review of Economics and Statistics 80 (4), 549-560.

Edge, Rochelle M., Refet S. Gürkaynak, and Burçin Kisacikoğlu (2013). "Judging the DSGE model by its forecast". Mimeo.

Eraker, Bjørn, Ching Wai (Jeremy) Chiu, Andrew T. Foerster, Tae Bong Kim, and Hernán D. Seoane (2015). "Bayesian Mixed Frequency VARs". Journal of Financial Econometrics 13 (3), 698-721.

Erceg, Christopher J., Dale W. Henderson, and Andrew T. Levin (2000). "Optimal monetary policy with staggered wage and price contracts". Journal of Monetary Economics 46 (2), 281-313.

Fernald, John (2012). "A quarterly, utilization-adjusted series on total factor productivity". Federal Reserve Bank of San Francisco Working Paper 2012-19.

Fernández-Villaverde, Jesús, Pablo A. Guerrón-Quintana, Keith Kuester, and Juan F. Rubio-Ramírez (2015). "Fiscal volatility shocks and economic activity". Amercian Economic Review 105 (11), 3352-3384.

Galí, Jordi (1999). "Technology, employment, and the business cycle: do technology shocks explain aggregate fluctuations?" American Economic Review 89 (1), 249-271.

- (2011). "The return of the wage Phillips curve". Journal of the European Economic Association 9 (3), 436-461.

Galí, Jordi, Mark Gertler, and J. David López-Salido (2007). "Markups, gaps, and the welfare costs of business fluctuations". Review of Economics and Statistics 89 (1), $44-59$.

Godsill, Simon J., Arnaud Doucet, and Mike West (2004). "Monte Carlo smoothing for nonlinear time series". Journal of the American Statistical Association 99 (465), $156-168$.

Gordon, N. J., D. J. Salmond, and A. F. M. Smith (1993). "Novel approach to nonlinear/nonGaussian Bayesian state estimation". IEE Proceedings F - Radar and Signal Processing $140(2), 107-113$.

Hall, Robert E. (1997). "Macroeconomic fluctuations and the allocation of time". Journal of Labor Economics 15 (1), 223-250. 
Hartman, Richard (1972). "The effects of price and cost uncertainty on investment". Journal of Economic Theory 5 (2), 258-266.

Hayashi, Fumio (1982). "Tobin's marginal q and average q: a neoclassical interpretation". Econometrica 50 (1), 213-24.

Johannsen, Benjamin K. (2014). "When are the effects of fiscal policy uncertainty large?" Finance and Economics Discussion Series 2014-40. Federal Reserve Board.

Jones, John Bailey (2002). "Has fiscal policy helped stabilize the postwar U.S. economy?" Journal of Monetary Economics 49 (4), 709-746.

Jordá, Òscar (2005). "Estimation and inference of impulse responses by local projections". American Economic Review 95 (1), 161-182.

Jurado, Kyle, Sydney C. Ludvigson, and Serena Ng (2015). "Measuring uncertainty". American Economic Review 105 (3), 1177-1216.

Justiniano, Alejandro, Giorgio E. Primiceri, and Andrea Tambalotti (2013). "Is there a trade-off between inflation and output stabilization?" American Economic Journal: Macroeconomics 5 (2), 1-31.

Kadiyala, K. Rao and Sune Karlsson (1997). "Numerical methods for estimation and inference in Bayesian VAR-models". Journal of Applied Econometrics 12 (2), 99-132.

Karabarbounis, Loukas (2014). "The labor wedge: MRS vs. MPN". Review of Economic Dynamics 17 (2), 206-223.

Keen, Benjamin and Yongsheng Wang (2007). "What is a realistic value for price adjustment costs in New Keynesian models?" Applied Economics Letters 14 (11), 789 793.

Kilian, Lutz (2009). "Not all oil price shocks are alike: disentangling demand and supply shocks in the crude oil market". American Economic Review 99 (3), 1053-69.

Koop, Gary and Dimitris Korobilis (2010). "Bayesian Multivariate Time Series Methods for Empirical Macroeconomics". Foundations and Trends in Econometrics 3 (4), 267-358.

Leduc, Sylvain and Zheng Liu (2016). "Uncertainty shocks are aggregate demand shocks". Journal of Monetary Economics 82, 20-35.

Leeper, Eric M., Michael Plante, and Nora Traum (2010). "Dynamics of fiscal financing in the United States". Journal of Econometrics 156 (2), 304-321.

Levitt, Steven D., John List, and Chad Syverson (2013). "Toward an understanding of learning by doing: evidence from an automobile assembly plant". Journal of Political Economy 121 (4), 643-681.

Litterman, Robert B. (1986). "Forecasting with Bayesian vector autoregressions: five years of experience". Journal of Business 86 Economic Statistics 4 (1), 25-38.

Ludvigson, Sydney C., Sai Ma, and Serena Ng (2015). "Uncertainty and business cycles: exogenous impulse or endogenous response?" NBER Working Paper 21803.

McCracken, Michael W. and Serena Ng (2015). "FRED-MD: a monthly database for macroeconomic research". Working Paper 2015-12. Federal Reserve Bank of St. Louis. 
Mendoza, Enrique G., Assaf Razin, and Linda L. Tesar (1994). "Effective tax rates in macroeconomics: cross-country estimates of tax rates on factor incomes and consumption". Journal of Monetary Economics 34 (3), 297-323.

Mumtaz, Haroon and Francesco Zanetti (2013). "The impact of the volatility of monetary policy shocks". Journal of Money, Credit and Banking 45 (4), 535-558.

Nekarda, Christopher J. and Valerie A. Ramey (2011). "Industry evidence on the effects of government spending". American Economic Journal: Macroeconomics 3 (1), 36-59. - (2013). "The cyclical behavior of the price-cost markup". NBER Working Papers 19099.

Oi, Walter Y. (1961). "The desirability of price instability under perfect competition". Econometrica 29 (1), 58-64.

Pagan, Adrian (1984). "Econometric issues in the analysis of regressions with generated regressors". International Economic Review 25 (1), 221.

Parkin, Michael (1988). "A method for determining whether parameters in aggregative models are structural". Carnegie-Rochester Conference Series on Public Policy 29, $215-252$.

Petrella, Ivan and Emiliano Santoro (2012). "Inflation dynamics and real marginal costs: new evidence from u.s. manufacturing industries". Journal of Economic Dynamics and Control 36 (5), 779-794.

Plante, Michael and Nora Traum (2012). "Time-varying oil price volatility and macroeconomic aggregates". Caepr Working Papers 2012-002.

Raftery, Adrien E. and Steven Lewis (1992). "How many iterations in the Gibbs sampler?" Bayesian Statistics. Ed. by José M. Bernardo, James O. Berger, A. Philip Dawid, and Adrian F. M. Smith. Vol. 4. Oxford: Clarendon Press, 763-773.

Ramey, Valerie A. (1991). "Markups and the business cycle: comment". NBER Macroeconomics Annual. Ed. by Olivier Jean Blanchard and Stanley Fischer. Vol. 6. The University of Chicago Press, 134-139. URL: http://www. jstor.org/stable/3585051.

Ratto, Marco, Werner Roeger, and Jan in 't Veld (2009). "QUEST III: an estimated openeconomy DSGE model of the euro area with fiscal and monetary policy". Economic Modelling 26 (1), 222-233.

Rotemberg, Julio J. (1982). "Sticky Prices in the United States". Journal of Political Economy 90 (6), 1187-1211.

Rotemberg, Julio J. and Michael Woodford (1991). "Markups and the business cycle". NBER Macroeconomics Annual. Ed. by Olivier Jean Blanchard and Stanley Fischer. Vol. 6. MIT Press, 63-140.

- (1999). "The cyclical behavior of prices and costs". Handbook of Macroeconomics. Ed. by John B. Taylor and Michael Woodford. Vol. 1B. North-Holland, 1051-1135.

Shimer, Robert (2010). Labor markets and business cycles. Ed. by Hans-Joachim Voth. Princeton University Press. 
Smets, Frank and Rafael Wouters (2007). "Shocks and frictions in US business cycles: a Bayesian DSGE approach". American Economic Review 97 (3), 586-606.

Stock, James H. and Mark W. Watson (2012). "Disentangling the channels of the 2007-09 recession". Brookings Papers on Economic Activity Spring, 81-156.

Taylor, John B (1980). "Aggregate dynamics and staggered contracts". Journal of Political Economy 88 (1), 1-23.

Wu, Jing Cynthia and Fan Dora Xia (2016). "Measuring the macroeconomic impact of monetary policy at the zero lower bound". Journal of Money, Credit and Banking 48 (2-3), 253-291. 


\section{A Theoretical Model}

\section{A.1 Model Equations}

The model equations after imposing a symmetric equilibrium are given by:

1. Production function:

$$
Y_{t}=Y^{n o r m}\left[\alpha K_{t}^{\frac{\psi-1}{\psi}}+(1-\alpha)\left(Z_{t}\left(N_{t}-N^{o}\right)\right)^{\frac{\psi-1}{\psi}}\right]^{\frac{\psi}{\psi-1}}-\Phi
$$

2. Firm FOC for renting $N_{t}$ :

$$
\Xi_{p, t} \frac{W_{t}}{P_{t}}=M P L_{t}
$$

3. Definition marginal product of labor

$$
M P L_{t}=Y^{n o r m}\left[\alpha K_{t}^{\frac{\psi-1}{\psi}}+(1-\alpha)\left(Z_{t}\left(N_{t}-N^{o}\right)\right)^{\frac{\psi-1}{\psi}}\right]^{\frac{\psi}{\psi-1}-1} \frac{(1-\alpha)\left(Z_{t}\left(N_{t}-N^{o}\right)\right)^{\frac{\psi-1}{\psi}}}{N_{t}-N^{o}},
$$

which, in the presence of no overhead labor and fixed costs, simplifies to

$$
M P L_{t}=(1-\alpha)\left(Z_{t}\right)^{\frac{\psi-1}{\psi}}\left(\frac{Y_{t}}{N_{t}}\right)^{\frac{1}{\psi}}
$$

4. Firm profits:

$$
D_{t}=Y_{t}-N_{t} \frac{W_{t}}{P_{t}}-I_{t}-\frac{\phi_{P}}{2}\left(\Pi_{t}-\bar{\Pi}\right)^{2} Y_{t}
$$

5. Firm FOC for renting $K_{t}$ :

$$
\Xi_{p, t} R_{t}^{K}=M P K_{t}
$$

6. Definition marginal product of capital

$$
M P K_{t}=Y^{n o r m}\left[\alpha K_{t}^{\frac{\psi-1}{\psi}}+(1-\alpha)\left(Z_{t}\left(N_{t}-N^{o}\right)\right)^{\frac{\psi-1}{\psi}}\right]^{\frac{\psi}{\psi-1}-1} \frac{\alpha K_{t}^{\frac{\psi-1}{\psi}}}{K_{t}}
$$

which, in the presence of no fixed costs, simplifies to

$$
M P K_{t}=\alpha\left(\frac{Y_{t}}{K_{t}}\right)^{\frac{1}{\psi}}
$$

7. Firm FOC for $P_{t}$ :

$$
\begin{aligned}
\phi_{p}\left[\Pi^{-1} \frac{P_{t}}{P_{t-1}}-1\right] \Pi^{-1} \frac{P_{t}}{P_{t-1}} & =\left(1-\theta_{p}\right)+\theta_{p} \Xi_{p, t}^{-1} \\
& +\phi_{p} \mathbb{E}_{t}\left\{M_{t+1} \frac{Y_{t+1}}{Y_{t}}\left[\Pi^{-1} \frac{P_{t+1}}{P_{t}}-1\right]\left[\Pi^{-1} \frac{P_{t+1}}{P_{t}}\right]\right\},
\end{aligned}
$$


where $M_{t}$ is the stochastic discount factor defined below.

8. Firm FOC for capital:

$$
\begin{aligned}
q_{t} & =\mathbb{E}_{t}\left\{M _ { t + 1 } \left(R_{t+1}^{K}+q_{t+1}\left(1-\delta-\frac{\phi_{K}}{2}\left(\frac{I_{t+1}}{K_{t+1}}-\delta\right)^{2}\right.\right.\right. \\
& \left.\left.\left.+\phi_{K}\left(\frac{I_{t+1}}{K_{t+1}}-\delta\right) \frac{I_{t+1}}{K_{t+1}}\right)\right)\right\}
\end{aligned}
$$

9. Firm FOC for investment:

$$
\frac{1}{q_{t}}=1-\phi_{K}\left(\frac{I_{t}}{K_{t}}-\delta\right)
$$

10. Definition value function:

$$
V_{t}=\frac{\left(C_{t}^{\eta}\left(1-N_{t}\right)^{1-\eta}\right)^{1-\sigma}}{1-\sigma}+\beta \mathbb{E}_{t} V_{t+1}
$$

11. Definition marginal utility of wealth:

$$
\lambda_{t}\left(1+\tau_{t}^{c}\right)=V_{C, t}
$$

12. Partial derivative of lifetime utility with respect to consumption:

$$
V_{C, t}=\eta \frac{1}{C_{t}}\left(C_{t}^{\eta}\left(1-N_{t}\right)^{1-\eta}\right)^{1-\sigma}
$$

13. FOC with respect to $\mathrm{W}$ :

$$
\begin{aligned}
0 & =V_{N_{t}}+\lambda_{t}\left[\left(1-\theta_{w}\right)\left(1-\tau_{t}^{n}\right) N_{t} \frac{W_{t}}{P_{t}}-\phi_{w}\left(\Pi^{-1} \frac{W_{t}}{W_{t-1}}-1\right) \frac{W_{t}}{\Pi W_{t-1}} Y_{t}\right] \\
& +\beta \lambda_{t+1}\left[\phi_{w}\left(\Pi^{-1} \frac{W_{t+1}}{W_{t}}-1\right) \Pi^{-1} \frac{W_{t+1}}{W_{t}} Y_{t+1}\right]
\end{aligned}
$$

14. Partial derivative of lifetime utility with respect to labor:

$$
V_{N, t}=-(1-\eta) \frac{1}{1-N_{t}}\left(C_{t}^{\eta}\left(1-N_{t}\right)^{1-\eta}\right)^{1-\sigma}
$$

15. Definition stochastic discount factor:

$$
M_{t+1} \equiv \frac{\frac{\partial V_{t}}{\partial C_{t+1}}}{\frac{\partial V}{\partial C_{t}}} \frac{1+\tau_{t}^{c}}{1+\tau_{t+1}^{c}}=\beta \frac{1+\tau_{t}^{c}}{1+\tau_{t+1}^{c}}\left(\frac{C_{t+1}^{\eta}\left(1-N_{t+1}\right)^{1-\eta}}{C_{t}^{\eta}\left(1-N_{t}\right)^{1-\eta}}\right)^{1-\sigma}\left(\frac{C_{t}}{C_{t+1}}\right)
$$

16. Euler Equation

$$
1=R_{t} \mathbb{E}_{t}\left\{M_{t+1} \Pi_{t+1}^{-1}\right\}
$$


17. Taylor Rule:

$$
\frac{R_{t}}{R}=\left(\frac{R_{t-1}}{R}\right)^{\rho_{R}}\left(\left(\frac{\Pi_{t}}{\Pi}\right)^{\phi_{R \pi}}\left(\frac{Y_{t}}{Y_{t}^{H P}}\right)^{\phi_{R y}}\right)^{1-\rho_{R}}
$$

18. Law of motion for capital:

$$
K_{t+1}=\left(1-\delta-\frac{\phi_{K}}{2}\left(\frac{I_{t}}{K_{t}}-\delta\right)^{2}\right) K_{t}+I_{t}
$$

19. Definition of model-consistent HP-filter output gap:

$$
\begin{aligned}
& Y_{t}^{H P}(1+6 \times 1600)+Y_{t-1}^{H P}(-4 \times 1600)+E_{t} Y_{t+1}^{H P}(-4 \times 1600)+Y_{t-2}^{H P} \times 1600+E_{t} Y_{t+2}^{H P} 1600 \\
& =Y_{t}(6 \times 1600)+Y_{t-1}(-4 \times 1600)+E_{t} Y_{t+1}(-4 \times 1600)+Y_{t-1} 1600+E_{t} Y_{t+1} 1600
\end{aligned}
$$

20. Budget constraint household after imposing that $B_{t} / P_{t}=0 \forall t$ :

$$
\left(1+\tau_{t}^{c}\right) C_{t}=\left(1-\tau_{t}^{n}\right) \frac{W_{t}}{P_{t}} N_{t}+C_{t}-\frac{\phi_{w}}{2}\left(\Pi^{-1} \frac{W_{t}}{W_{t-1}}-1\right)^{2} Y_{t}+T_{t}+D_{t}
$$

21. Budget constraint government:

$$
\tau_{t}^{c} C_{t}+\tau_{t}^{n} \frac{W_{t}}{P_{t}} N_{t}=G_{t}+T_{t}
$$

These 21 equations define the evolution of the following 21 variables: $C_{t}, I_{t}, K_{t}, D_{t}, \lambda_{t}$, $M_{t}, M P L_{t}, M P K_{t}, N_{t}, \Pi_{t}, q_{t}, R_{t}, R_{t}^{K}, T_{t}, V_{t}, V_{C, t}, V_{N, t}, \frac{W_{t}}{P_{t}}, \Xi_{p, t}, Y_{t}, Y_{t}^{H P}$

Finally, the exogenous processes for $\hat{Z}_{t}, \sigma_{t}^{z}, \hat{G}_{t}$, and $\sigma_{t}^{g}$ are given by

$$
\begin{aligned}
\hat{Z}_{t} & =\rho_{z} \hat{Z}_{t-1}+\sigma_{t}^{z} \varepsilon_{t}^{z} \\
\hat{G}_{t} & =\rho_{g} \hat{G}_{t-1}+\phi_{g y} \hat{Y}_{t-1}+\sigma_{t}^{g} \varepsilon_{t}^{g} \\
\sigma_{t}^{z} & =\left(1-\rho_{\sigma^{z}}\right) \bar{\sigma}^{z}+\rho_{\sigma^{z}} \sigma_{t-1}^{z}+\eta_{\sigma^{z}} \varepsilon_{t}^{\sigma^{z}} \\
\sigma_{t}^{g} & =\left(1-\rho_{\sigma^{g}}\right) \bar{\sigma}^{g}+\rho_{\sigma^{g}} \sigma_{t-1}^{g}+\eta_{\sigma^{g}} \varepsilon_{t}^{\sigma^{g}}
\end{aligned}
$$

Note that for the purpose of model simulations, we set $\tau_{t}^{c}=\tau^{c}$ and $\tau_{t}^{n}=\tau^{n}$.

\section{A.2 Additional Derivations for Model Calibration}

\section{A.2.1 Frisch Elasticity}

This section shows how to compute the Frisch elasticity of labor supply for our model. The resulting expression will be used in steady-state computations to determine the weight of leisure in the Cobb-Douglas felicity function, i.e. when determining $\eta$. As shown in e.g. 
Domeij and Floden (2006), the Frisch elasticity $\eta^{\lambda}$ can be computed from:

$$
\eta^{\lambda}=\frac{U_{N}(C, N)}{\left(U_{N N}(C, N)-\frac{U_{C N}^{2}(C, N)}{U_{C C}}(C, N)\right)} \frac{1}{N}
$$

For the felicity function

$$
U(C, N)=\frac{\left(C^{\eta}(1-N)^{1-\eta}\right)^{1-\sigma}}{1-\sigma}=\frac{C^{\eta(1-\sigma)}(1-N)^{(1-\eta)(1-\sigma)}}{1-\sigma},
$$

we get

$$
\begin{aligned}
U_{N} & =-(1-\eta)\left(C^{\eta}\right)^{1-\sigma}(1-N)^{(1-\eta)(1-\sigma)-1}=-(1-\eta)(1-\sigma) \frac{U(C, N)}{(1-N)} \\
U_{N N} & =(1-\eta)(1-\sigma)((1-\eta)(1-\sigma)-1) \frac{U(C, N)}{(1-N)^{2}} \\
U_{C} & =\eta C^{\eta(1-\sigma)-1}(1-N)^{(1-\eta)(1-\sigma)}=\eta(1-\sigma) \frac{U(C, N)}{C} \\
U_{C C} & =\eta(\eta(1-\sigma)-1)(1-\sigma) \frac{U(C, N)}{C^{2}} \\
U_{C N} & =-\eta(1-\eta)(1-\sigma) C^{\eta(1-\sigma)-1}(1-N)^{(1-\eta)(1-\sigma)-1} \\
& =-\eta(1-\eta)(1-\sigma)(1-\sigma) \frac{U(C, N)}{C(1-N)}
\end{aligned}
$$

After a lot of tedious algebra, we get that

$$
\eta^{\lambda}=\frac{U_{N}(C, N)}{\left(U_{N N}(C, N)-\frac{U_{C N}^{2}(C, N)}{U_{C C}}(C, N)\right)} \frac{1}{N}=\frac{1-\eta(1-\sigma)}{1-(1-\sigma)} \frac{1-N}{N}
$$

\section{A.2.2 Investment Adjustment Costs}

The FOC for investment implies

$$
\frac{1}{q_{t}}=1-\phi_{K}\left(\frac{I_{t}}{K_{t}}-\delta\right)
$$

which can be written as

$$
\log \left(\frac{I_{t}}{K_{t}}\right)=\log \left(\frac{1}{\phi_{K}}-\frac{1}{\phi_{K}} e^{-\log q_{t}}+\delta\right)
$$

The elasticity of the investment to capital-ratio with respect to Tobin's $q$ is then given by

$$
\frac{\partial \log \left(\frac{I_{t}}{K_{t}}\right)}{\partial \log q_{t}}=\frac{1}{\frac{1}{\phi_{K}}-\frac{1}{\phi_{K}} e^{-\log q_{t}}+\delta}\left(-\frac{1}{\phi_{K}} e^{-\log q_{t}}(-1)\right)
$$


In steady state, this evaluates to:

$$
\frac{\partial \log \left(\frac{I}{K}\right)}{\partial \log q}=\frac{1}{\delta} \frac{1}{\phi_{K}} .
$$

\section{A.3 Steady State}

The stochastic discount factor, equation (A.15), in steady state evaluates to

$$
M=\beta,
$$

while the first-order condition for investment, equation (A.9), gives Tobin's marginal $q$ as

$$
q=1
$$

Plugging this into (A.8) yields

$$
R_{K}=\frac{1}{\beta}-(1-\delta)
$$

and the pricing FOC (A.7) in steady state implies that

$$
\Xi_{t, p}=\frac{\theta_{p}}{\theta_{p}-1}
$$

The wage setting FOC (A.13) implies

$$
V_{N}=\frac{V_{C}}{1+\tau^{c}}\left[\left(\theta_{w}-1\right)\left(1-\tau_{t}^{n}\right) \frac{W}{P} N\right] .
$$

Using the definition of marginal utility, (A.12),

$$
V_{C}=\eta \frac{\left(C^{\eta}(1-N)^{1-\eta}\right)^{1-\sigma}}{C}
$$

and the definition of $V_{N},(\mathrm{~A} .14)$,

$$
V_{N}=-(1-\eta) \frac{\left(C^{\eta}(1-N)^{1-\eta}\right)^{1-\sigma}}{1-N}
$$

equation (A.42) reduces to

$$
\frac{1-\eta}{1-N} \theta_{w}=\frac{\eta}{1+\tau^{c}} \frac{1}{C}\left[\left(\theta_{w}-1\right)\left(1-\tau^{n}\right) \frac{W}{P}\right]
$$

With net output normalized to 1 by appropriately setting $Y^{\text {norm }}$, which is determined later, and the labor and capital share given by $\aleph$ and $1-\aleph$, respectively, we have

$$
\aleph=\frac{\frac{W}{P} N}{Y}=\frac{\frac{W}{P} N}{1} \Rightarrow W / P=\frac{\aleph}{N}
$$


and similarly

$$
K=\frac{1-\aleph}{R^{K}} .
$$

Equation (A.47) can be used with (A.40) to directly compute $K$ and via the law of motion for capital, equation (A.18), also investment

$$
I=\delta K
$$

Next, substituting for the real wage in (A.45) from (A.46), one obtains

$$
\frac{1-\eta}{\eta} \frac{C}{1-N}=\frac{\theta_{w}-1}{\theta_{w}} \frac{1-\tau^{n}}{1+\tau^{c}} \frac{\aleph}{N} .
$$

Solving this equation for consumption yields

$$
C=\frac{\theta_{w}-1}{\theta_{w}} \frac{1-\tau^{n}}{1+\tau^{c}} \aleph \frac{1-N}{N} \frac{\eta}{1-\eta} .
$$

Consolidating the household and government budget constraints, equations (A.20) and (A.21), and using equation (A.48) and the definition of firm dividends, equation (A.4), yields:

$$
C+\delta K=Y=1 \text {. }
$$

Plugging in from (A.50) for consumption yields

$$
\frac{\theta_{w}-1}{\theta_{w}} \frac{1-\tau^{n}}{1+\tau^{c}} \aleph \frac{1-N}{N} \frac{1-\eta}{\eta}+\delta K=1,
$$

where $K$ is already known from (A.47).

The Frisch elasticity $\eta^{\lambda}$ is calibrated to 1 . From (A.33) then follows that

$$
\eta=\frac{\theta}{1-\sigma}\left[1-\eta^{\lambda}\left(1-\frac{1-\sigma}{\theta}\right) \frac{N}{1-N}\right]
$$

Plugging (A.53) into (A.52), one obtains a nonlinear equation for $N$ :

$$
0=\frac{\theta_{w}-1}{\theta_{w}} \frac{1-\tau^{n}}{1+\tau^{c}} \aleph \frac{1-N}{N} \frac{1-\frac{1}{1-\sigma}\left(1-(1-1-\sigma) \frac{N}{1-N}\right)}{\frac{1}{1-\sigma}\left(1-(1-1-\sigma) \frac{N}{1-N}\right)}+\delta K-1 .
$$

This equation is solved numerically for hours worked $N$. Consumption immediately follows from (A.50), $\eta$ from (A.53), the real wage from (A.46), and dividends from (A.4).

Up to this point, we have assumed that net output is normalized to 1 . We are now in a position to compute the variables and parameters of the production side of our model, including the normalizing technology factor $Y^{\text {norm }}$ that allowed working with $Y=1$.

Fixed costs $\Phi$ are set equal to steady-state profits, which are the difference between 
output and factor payments:

$$
\Phi=Y^{n o r m}\left(\alpha K^{\frac{\psi-1}{\psi}}+(1-\alpha)\left(N-N^{o}\right)^{\frac{\psi-1}{\psi}}\right)^{\frac{\psi}{\psi-1}}-K R^{K}-W N .
$$

With technology being in steady state, i.e. $Z=1$, the firm FOCs, equations (A.2)-(A.6), imply:

$$
\begin{aligned}
& R^{K}=\Xi Y^{\text {norm }}\left(\alpha K^{\frac{\psi-1}{\psi}}+(1-\alpha)\left(N-N^{o}\right)^{\frac{\psi-1}{\psi}}\right)^{\frac{\psi}{\psi-1}-1} \alpha K^{\frac{\psi-1}{\psi}-1} \\
& \frac{W}{P}=\Xi Y^{\text {norm }}\left(\alpha K^{\frac{\psi-1}{\psi}}+(1-\alpha)\left(N-N^{o}\right)^{\frac{\psi-1}{\psi}}\right)^{\frac{\psi}{\psi-1}-1}(1-\alpha)\left(N-N^{o}\right)^{\frac{\psi-1}{\psi}-1}
\end{aligned}
$$

so that (A.55) with $N^{o}=\phi_{o} N$ becomes

$$
\begin{aligned}
\Phi= & Y^{\text {norm }}\left(\alpha K^{\frac{\psi-1}{\psi}}+(1-\alpha)\left(N-N^{o}\right)^{\frac{\psi-1}{\psi}}\right)^{\frac{\psi}{\psi-1}} \\
& -\Xi Y^{\text {norm }}\left(\alpha K^{\frac{\psi-1}{\psi}}+(1-\alpha)\left(N-N^{o}\right)^{\frac{\psi-1}{\psi}}\right)^{\frac{\psi}{\psi-1}-1} \alpha K^{\frac{\psi-1}{\psi}} \\
& -\Xi Y^{\text {norm }}\left(\alpha K^{\frac{\psi-1}{\psi}}+(1-\alpha)\left(N-N^{o}\right)^{\frac{\psi-1}{\psi}}\right)^{\frac{\psi}{\psi-1}-1}(1-\alpha)\left(N-N^{o}\right)^{\frac{\psi-1}{\psi}} \frac{N}{N-N^{o}} \\
= & Y^{\text {norm }}\left(\alpha K^{\frac{\psi-1}{\psi}}+(1-\alpha)\left(N-N^{o}\right)^{\frac{\psi-1}{\psi}}\right)^{\frac{1}{\psi-1}}\left(1-\Xi \frac{\alpha K_{t}^{\frac{\psi-1}{\psi}}+(1-\alpha)\left(N-N^{o}\right)^{\frac{\psi-1}{\psi}} \frac{1}{\left(1-\phi_{o}\right)}}{\alpha K_{t}^{\frac{\psi-1}{\psi}}+(1-\alpha)\left(N_{t}-N^{o}\right)^{\frac{\psi-1}{\psi}}}\right)
\end{aligned}
$$

In the absence of overhead labor, this reduces to

$$
\Phi=(1-\Xi) Y^{n o r m}\left(\alpha K^{\frac{\psi-1}{\psi}}+(1-\alpha) N^{\frac{\psi-1}{\psi}}\right)^{\frac{1}{\psi-1}} .
$$

Net output $Y$ is given by production minus fixed costs:

$$
\begin{aligned}
& Y=Y^{\text {norm }}\left(\alpha K^{\frac{\psi-1}{\psi}}+(1-\alpha)\left(N-N^{o}\right)^{\frac{\psi-1}{\psi}}\right)^{\frac{\psi}{\psi-1}}-\Phi \\
& \stackrel{(\mathrm{A.58)}}{=} Y^{\text {norm }}\left(\alpha K^{\frac{\psi-1}{\psi}}+(1-\alpha)\left(N-N^{o}\right)^{\frac{\psi-1}{\psi}}\right)^{\frac{\psi}{\psi-1}} \Xi \frac{\alpha K^{\frac{\psi-1}{\psi}}+(1-\alpha)\left(N-N^{o}\right)^{\frac{\psi-1}{\psi}} \frac{1}{\left(1-\phi_{o}\right)}}{\alpha K^{\frac{\psi-1}{\psi}}+(1-\alpha)\left(N-N^{o}\right)^{\frac{\psi-1}{\psi}}},
\end{aligned}
$$

which in the absence of overhead labor reduces to

$$
Y=Y^{n o r m}\left(\alpha K^{\frac{\psi-1}{\psi}}+(1-\alpha)\left(N-N^{o}\right)^{\frac{\psi-1}{\psi}}\right)^{\frac{\psi}{\psi-1}} .
$$

Equation (A.60) implies that the normalizing technology factor $Y^{\text {norm }}$ is given by 
$Y^{n o r m}=\left[\left(\alpha K^{\frac{\psi-1}{\psi}}+(1-\alpha)\left(N-N^{o}\right)^{\frac{\psi-1}{\psi}}\right)^{\frac{\psi}{\psi-1}} \Xi \frac{\left(\alpha K_{t}^{\frac{\psi-1}{\psi}}+(1-\alpha)\left(N-N^{o}\right)^{\frac{\psi-1}{\psi}} \frac{1}{\left(1-\phi_{o}\right)}\right)}{\left(\alpha K^{\frac{\psi-1}{\psi}}+(1-\alpha)\left(N-N^{o}\right)^{\frac{\psi-1}{\psi}}\right)}\right]^{-1}$

All the previous equations require knowledge of the labor share parameter $\alpha$, which is not a true structural parameter in the sense that it depends on the units of the model variables (see Cantore and Levine 2012, for details). It can be computed from the actual labor share $\aleph$ using

$$
\begin{aligned}
1-\aleph= & \frac{K R^{K}}{Y}=\frac{K \Xi Y^{\text {norm }}\left(\alpha K^{\frac{\psi-1}{\psi}}+(1-\alpha)\left(N-N^{o}\right)^{\frac{\psi-1}{\psi}}\right)^{\frac{\psi}{\psi-1}-1} \alpha K^{\frac{\psi-1}{\psi}-1}}{Y^{\text {norm }}\left(\alpha K^{\frac{\psi-1}{\psi}}+(1-\alpha)\left(N-N^{o}\right)^{\frac{\psi-1}{\psi}}\right)^{\frac{\psi}{\psi-1}} \Xi \frac{\alpha K^{\frac{\psi-1}{\psi}}+(1-\alpha)\left(N-N^{o}\right)^{\frac{\psi-1}{\psi}} \frac{1}{1-\phi_{o}}}{\alpha K^{\frac{\psi-1}{\psi}}+(1-\alpha)\left(N-N^{o}\right)^{\frac{\psi-1}{\psi}}}} \\
= & \frac{\alpha K^{\frac{\psi-1}{\psi}}}{\alpha K^{\frac{\psi-1}{\psi}}+(1-\alpha)\left(N-\bar{N}^{o}\right)^{\frac{\psi-1}{\psi}} \frac{1}{1-\phi_{o}}}
\end{aligned}
$$

Solving for $\alpha$ yields

$$
\alpha=\frac{\aleph\left(N-N^{o}\right)^{\frac{\psi-1}{\psi}} \frac{1}{1-\phi_{o}}}{(1-\aleph) K^{\frac{\psi-1}{\psi}}+\aleph\left(N-N^{o}\right)^{\frac{\psi-1}{\psi}} \frac{1}{1-\phi_{o}}},
$$

allowing us to compute the normalizing technology factor $Y^{\text {norm }}$ from (A.61) and the fixed costs $\Phi$ from (A.58).

We also need to compute the steady states of our auxiliary variables in the model. In steady state, the wage markup between marginal rate of substitution is

$$
M R S=\frac{1-\eta}{\eta} \frac{C}{1-N}
$$

while the real wage is given by

$$
\Xi^{w}=\frac{\theta_{w}}{\theta_{w}-1} .
$$




\section{A.4 Smoothed Volatilities from the Particle Smoother}

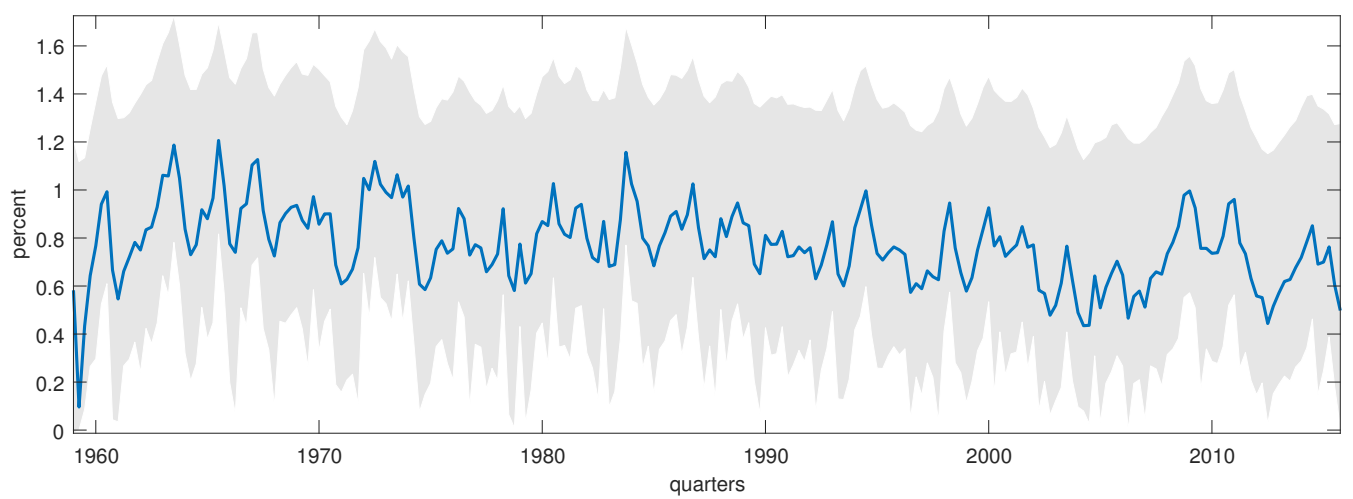

(a) Government Spending Volatility

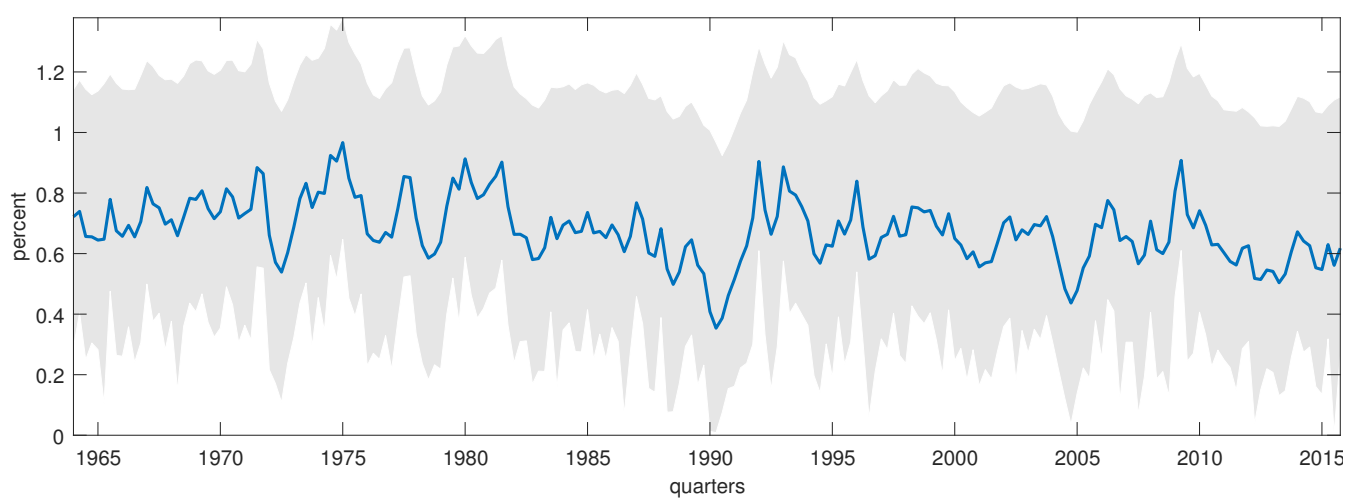

(b) TFP Volatility

Figure A.1: Median smoothed volatilities from the particle smoother, based on 20,000 particles for the forward pass and 20,000 particles for the backward smoothing routine. Shaded areas denote $90 \%$ highest posterior density intervals. 


\section{A.5 Additional Model IRFs}
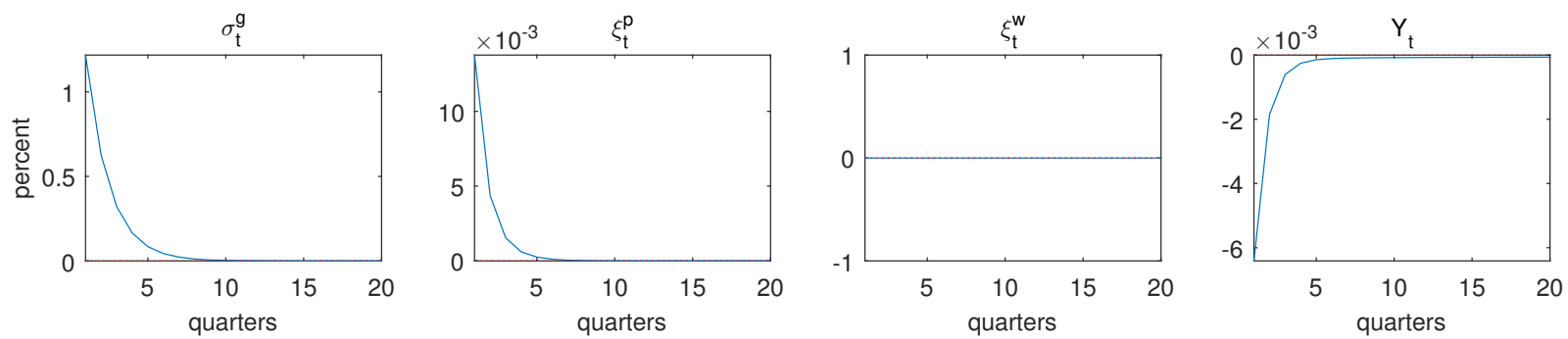

(a) Government Spending Volatility
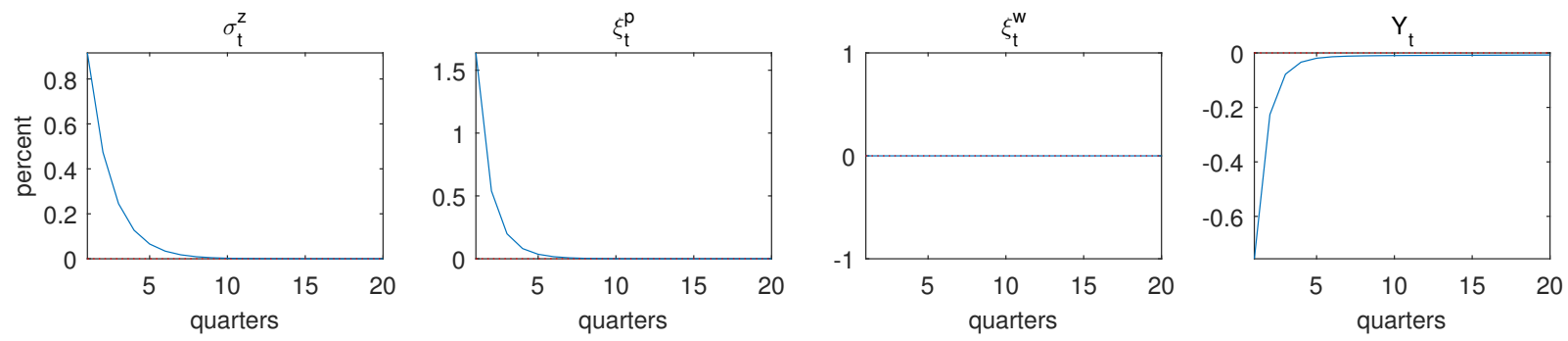

(b) Technology Volatility

Figure A.2: Model IRFs with sticky prices and flexible wages. Notes: Theoretical responses to a four-standard deviation shock measured in percentage deviations from the stochastic steady state.
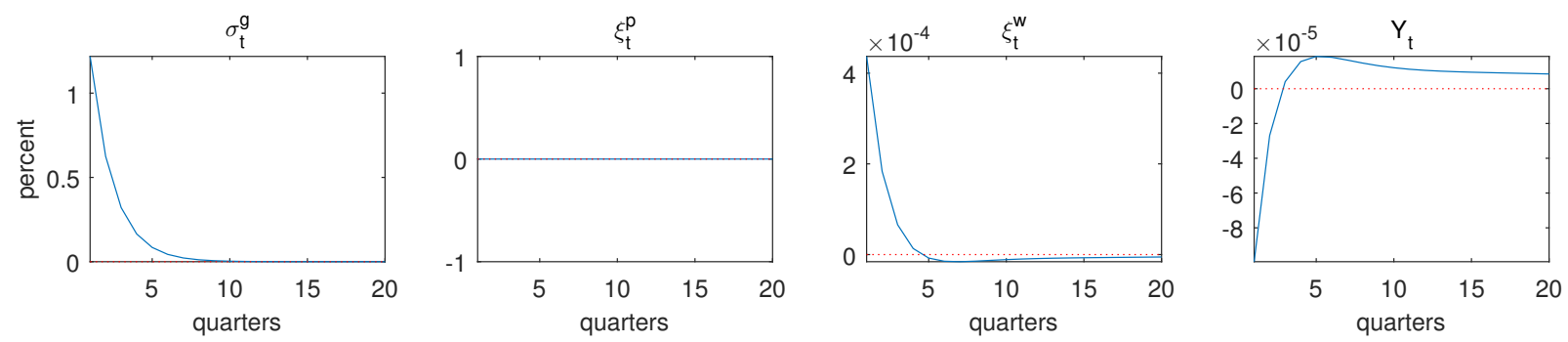

(a) Government Spending Volatility
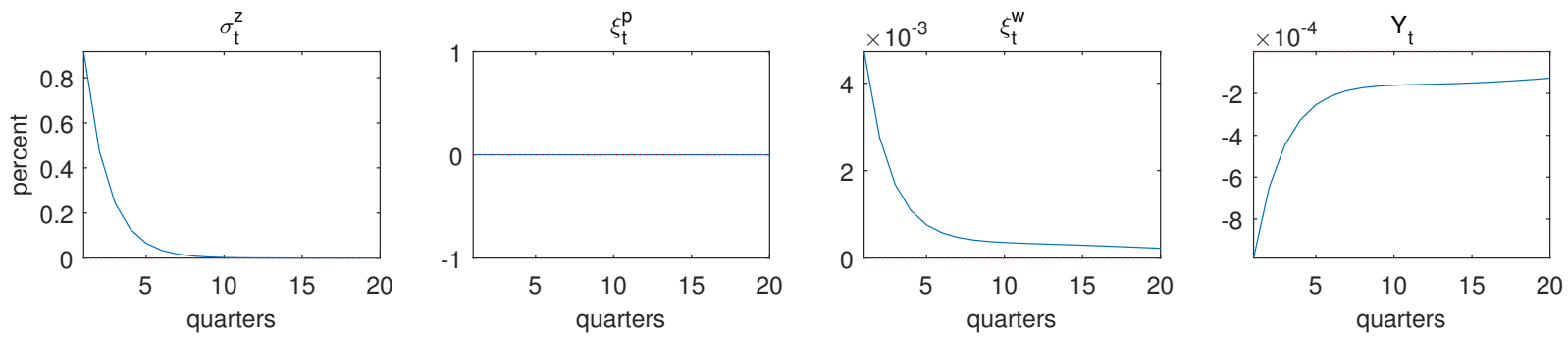

(b) Technology Volatility

Figure A.3: Model IRFs with sticky wages and flexible prices. Notes: Theoretical responses to a four-standard deviation shock measured in percentage deviations from the stochastic steady state. 

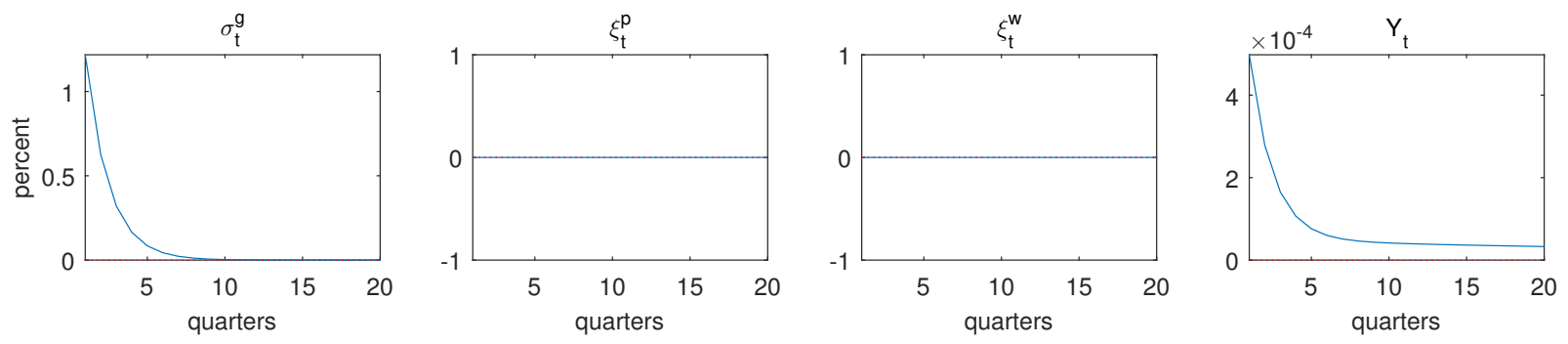

(a) Government Spending Volatility
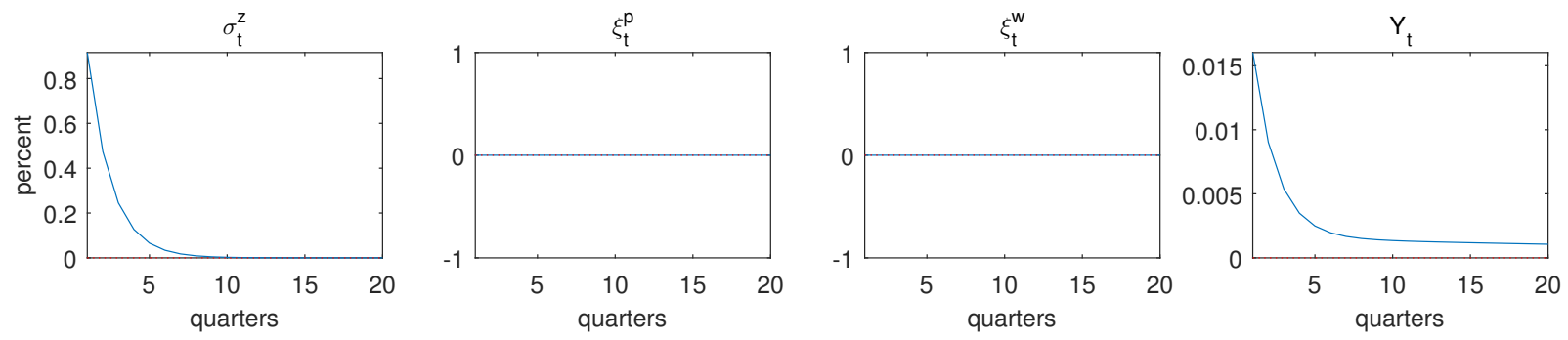

(b) Technology Volatility

Figure A.4: Model IRFs with flexible prices and wages. Notes: Theoretical responses to a four-standard deviation shock measured in percentage deviations from the stochastic steady state. 


\section{B Marginal Product of Labor for Markup Computa- tion}

Given our production function, the marginal product of labor is equal to

$M P L_{t}=Y^{\text {norm }}\left[\alpha K_{t}^{\frac{\psi-1}{\psi}}+(1-\alpha)\left(Z_{t}\left(N_{t}-N^{o}\right)\right)^{\frac{\psi-1}{\psi}}\right]^{\frac{\psi}{\psi-1}-1} \frac{(1-\alpha)\left(e^{Z_{t}}\left(N_{t}-N^{o}\right)\right)^{\frac{\psi-1}{\psi}}}{N_{t}-N^{o}}$.

This is equal to

$$
\begin{aligned}
M P L_{t}= & \left(Y^{n o r m}\left[\alpha K_{t}^{\frac{\psi-1}{\psi}}+(1-\alpha)\left(e^{Z_{t}}\left(N_{t}-N^{o}\right)\right)^{\frac{\psi-1}{\psi}}\right]^{\frac{\psi}{\psi-1}}\right)^{\frac{1}{\psi}} \\
& \times\left(Y^{n o r m}\right)^{\frac{\psi-1}{\psi}} \frac{(1-\alpha)\left(e^{Z_{t}}\left(N_{t}-N^{o}\right)\right)^{\frac{\psi-1}{\psi}}}{N_{t}-N^{o}}
\end{aligned}
$$

Using (A.1), we have that

$$
Y_{t}+\Phi=Y^{n o r m}\left[\alpha K_{t}^{\frac{\psi-1}{\psi}}+(1-\alpha)\left(e^{Z_{t}}\left(N_{t}-N^{o}\right)\right)^{\frac{\psi-1}{\psi}}\right]^{\frac{\psi}{\psi-1}}
$$

so that

$$
M P L_{t}=(1-\alpha)\left(Y^{n o r m}\right)^{\frac{\psi-1}{\psi}}\left(e^{Z_{t}}\right)^{\frac{\psi-1}{\psi}}\left(\frac{Y_{t}+\Phi}{N_{t}-N^{o}}\right)^{\frac{1}{\psi}} .
$$

In case of no fixed costs and no overhead labor, this reduces to the familiar

$$
M P L_{t}=(1-\alpha)\left(Y^{n o r m}\right)^{\frac{\psi-1}{\psi}}\left(e^{Z_{t}}\right)^{\frac{\psi-1}{\psi}}\left(\frac{Y_{t}}{N_{t}}\right)^{\frac{1}{\psi}}
$$

In logs, we have from (B.4)

$$
\log \left(M P L_{t}\right)=\log \left((1-\alpha)\left(Y^{n o r m}\right)^{\frac{\psi-1}{\psi}}\right)+\frac{\psi-1}{\psi} \log \left(e^{Z_{t}}\right)+\frac{1}{\psi} \log \left(\frac{Y_{t}+\Phi}{N_{t}-N^{o}}\right),
$$

where the first term is a constant that depends on the units of measurement. For the second term, we need a measure of labor-augmenting technology $Z_{t}$. Thus, the price markup can be computed as

$$
\xi_{t}^{p}=\log \left((1-\alpha)\left(Y^{n o r m}\right)^{\frac{\psi-1}{\psi}}\right)+\frac{\psi-1}{\psi} Z_{t}+\frac{1}{\psi} \log \left(\frac{Y_{t}+\Phi}{N_{t}-N^{o}}\right)-\log \left(\frac{W_{t}}{P_{t}}\right) .
$$

Technology movements are approximated using the Fernald (2012) utilization-adjusted TFP measure. This TFP measure, based on growth accounting, originally assumes a unit elasticity of output with respect to technology, which would correspond to Hicks-neutral 
technology growth. Starting from a general production function

$$
Y=Y(K, L, T F P)
$$

the contribution of TFP to output growth is effectively computed via the total differential as the part of output growth not accounted for by utilization adjusted factor growth:

$$
\frac{d T F P_{t}}{T F P_{t}}=\frac{d Y_{t}}{Y_{t}}-\varepsilon_{K, t} \frac{d K_{t}}{K_{t}}-\varepsilon_{N, t} \frac{d N_{t}}{N_{t}}
$$

where $\varepsilon$ denotes the respective output elasticities and where by construction $\varepsilon_{T F P, t}=1$. Thus, we need to transform this TFP measure to correspond to our measure of laboraugmenting (Kaldor-neutral) technology $A_{t}=e^{Z_{t}}$ as

$$
\frac{d T F P_{t}}{T F P_{t}}=\varepsilon_{A, t} \frac{d A_{t}}{A_{t}} \Rightarrow \log A_{t}=\frac{1}{\varepsilon_{A, t}} \log T F P_{t}
$$

where the integration constant has been set to 0. Thus, when knowing the elasticity of TFP with respect to labor-augmenting technology, $\varepsilon_{A, t}$, the Fernald (2012) measure can be transformed into our required technology measure. ${ }^{38}$ As $\varepsilon_{A, t}$ is invariant to multiplicative transformations of output, we first normalize output by steady state/balanced growth path output $\mathrm{Y}$ to get gross deviations from steady state: ${ }^{39}$

$$
\hat{Y} \equiv \frac{Y_{t}}{Y}=\frac{\left[\alpha K_{t}^{\frac{\psi-1}{\psi}}+(1-\alpha)\left(A e^{\hat{Z}_{t}}\left(N_{t}-N^{o}\right)\right)^{\frac{\psi-1}{\psi}}\right]^{\frac{\psi}{\psi-1}}-\Phi}{\left[\alpha K^{\frac{\psi-1}{\psi}}+(1-\alpha)\left(A\left(N-N^{o}\right)\right)^{\frac{\psi-1}{\psi}}\right]^{\frac{\psi}{\psi-1}}-\Phi},
$$

where $A$ is a constant capturing the unknown level of labor-augmenting technology and all other normalizations, e.g. the one introduced by using an index for output.

Noting that in steady state

$$
\begin{aligned}
& Y=\frac{1}{\left(1+\phi_{\text {fix }}\right)}\left[\alpha K^{\frac{\psi-1}{\psi}}+(1-\alpha)\left(A\left(N-N^{o}\right)\right)^{\frac{\psi-1}{\psi}}\right]^{\frac{\psi}{\psi-1}} \\
& \Phi=\frac{\phi_{\text {fix }}}{\left(1+\phi_{\text {fix }}\right)}\left[\alpha K^{\frac{\psi-1}{\psi}}+(1-\alpha)\left(A\left(N-N^{o}\right)\right)^{\frac{\psi-1}{\psi}}\right]^{\frac{\psi}{\psi-1}}
\end{aligned}
$$

equation (B.10) can be rewritten as

$$
\hat{Y}=\frac{\left(1+\phi_{f i x}\right)\left[\alpha K_{t}^{\frac{\psi-1}{\psi}}+(1-\alpha)\left(A e^{\hat{Z}_{t}}\left(N_{t}-N^{o}\right)\right)^{\frac{\psi-1}{\psi}}\right]^{\frac{1}{\psi}}}{\left[\alpha K^{\frac{\psi-1}{\psi}}+(1-\alpha)\left(A\left(N-N^{o}\right)\right)^{\frac{\psi-1}{\psi}}\right]^{\frac{\psi}{\psi-1}}}-\phi_{f i x} .
$$

\footnotetext{
${ }^{38}$ In the Cobb-Douglas case, we have $Y_{t}=K_{t}^{\alpha}\left(A_{t} L_{t}\right)^{1-\alpha}=A_{t}^{1-\alpha} K_{t}^{\alpha} L_{t}^{1-\alpha}$ so that a one percent change in labor-augmenting technology $A_{t}$ moves measured TFP by $\varepsilon_{A, t}=1-\alpha$ percent (up to first order).

${ }^{39}$ We suppress the assumed deterministic loglinear trend in A for notational convenience.
} 
Using the corresponding firm first-order conditions

$$
\frac{W_{t}}{P_{t}}=\Xi\left[\frac{(1-\alpha)\left(A e^{\hat{Z}_{t}}\left(N_{t}-N^{o}\right)\right)^{\frac{\psi-1}{\psi}}}{\alpha K_{t}^{\frac{\psi-1}{\psi}}+(1-\alpha)\left(A e^{\hat{Z}_{t}}\left(N_{t}-N^{o}\right)\right)^{\frac{\psi-1}{\psi}}}\right] \frac{Y_{t}+\Phi}{N_{t}-N^{o}}
$$

and

$$
R_{t}^{K}=\Xi\left[\frac{\alpha K_{t}^{\frac{\psi-1}{\psi}}}{\alpha K_{t}^{\frac{\psi-1}{\psi}}+(1-\alpha)\left(A e^{\hat{Z}_{t}}\left(N_{t}-N^{o}\right)\right)^{\frac{\psi-1}{\psi}}}\right] \frac{Y_{t}+\Phi}{K_{t}}
$$

equation (B.13) becomes

$$
\begin{aligned}
\hat{Y} & =\left(1+\phi_{f i x}\right)\left[\frac{\alpha K_{t}^{\frac{\psi-1}{\psi}}}{\alpha K^{\frac{\psi-1}{\psi}}+(1-\alpha)\left(A\left(N-N^{o}\right)\right)^{\frac{\psi-1}{\psi}}}+\frac{(1-\alpha)\left(A e^{\hat{Z}_{t}}\left(N_{t}-N^{o}\right)\right)^{\frac{\psi-1}{\psi}}}{\alpha K^{\frac{\psi-1}{\psi}}+(1-\alpha)\left(A\left(N-N^{o}\right)\right)^{\frac{\psi-1}{\psi}}}\right]^{\frac{\psi}{\psi-1}}-\phi_{f i x} \\
& =\left(1+\phi_{f i x}\right)\left[\frac{1}{\Xi} \frac{R^{K} K}{(Y+\Phi)}\left(\frac{K_{t}}{K}\right)^{\frac{\psi-1}{\psi}}+\frac{1}{\Xi} \frac{W}{P} \frac{\left(N-N^{o}\right)}{(Y+\Phi)}\left(\frac{A e^{\hat{Z}_{t}}\left(N_{t}-N^{o}\right)}{A\left(N-N^{o}\right)}\right)^{\frac{\psi-1}{\psi}}\right]^{\frac{\psi}{\psi-1}}-\phi_{f i x} .
\end{aligned}
$$

Defining the share of non-overhead labor compensation in output as

$$
\aleph^{o} \equiv \frac{\frac{W}{P}\left(N-N^{o}\right)}{Y}=\frac{\frac{W}{P} N}{Y} \frac{N-N^{o}}{N}=\aleph\left(1-\phi^{o}\right)
$$

and noting that the prefactors in front of capital and labor sum up to 1, equation (B.13) can be rewritten as

$$
\hat{Y}_{t}=\left(1+\phi_{f i x}\right)\left[\left(1-\frac{\aleph^{o}}{\Xi\left(1+\phi_{f i x}\right)}\right) \hat{K}_{t}^{\frac{\psi-1}{\psi}}+\frac{\aleph^{o}}{\Xi\left(1+\phi_{f i x}\right)}\left(e^{\hat{Z}_{t}} \hat{N}_{t}\right)^{\frac{\psi-1}{\psi}}\right]^{\frac{\psi}{\psi-1}}-\phi_{f i x}
$$

The elasticity of output with respect to technology $A_{t}$ can then be computed by differentiating net output deviations from steady state with respect to $\hat{Z}_{t}$,

$$
\begin{aligned}
& \varepsilon_{A, t}= \frac{\partial\left(\hat{Y}_{t}-1\right)}{\partial \hat{Z}_{t}} \\
&=\left(1+\phi_{f i x}\right)\left[\left(1-\frac{\aleph^{o}}{\Xi\left(1+\phi_{f i x}\right)}\right) \hat{K}_{t}^{\frac{\psi-1}{\psi}}+\frac{\aleph^{o}}{\Xi\left(1+\phi_{f i x}\right)}\left(e^{\hat{Z}_{t}} \hat{N}_{t}\right)^{\frac{\psi-1}{\psi}}\right]^{\frac{\psi}{\psi-1}-1} \\
& \times \frac{1}{\Xi\left(1+\phi_{f i x}\right)} \aleph^{o}\left(e^{\hat{Z}_{t}} \hat{N}_{t}\right)^{\frac{\psi-1}{\psi}} \\
& \stackrel{(\text { B.18) }}{=}\left[\frac{\hat{Y}_{t}+\phi_{\text {fix }}}{1+\phi_{\text {fix }}}\right]^{\frac{1}{\psi}} \frac{1}{\Xi} \aleph^{o}\left(e^{\hat{Z}_{t}} \hat{N}_{t}\right)^{\frac{\psi-1}{\psi}}
\end{aligned}
$$


In the Cobb-Douglas case in steady state, this simplifies to the well-known

$$
\varepsilon_{A, t}=\frac{1}{\Xi} \aleph
$$

To operationalize the aforementioned, we first need to detrend output with the rate of labor-augmenting technology growth.

\section{Data}

\section{C.1 Macro Data}

The data for the VARs is taken from FRED-MD (McCracken and Ng 2015), except for i) our constructed markup measure, ii) the respective uncertainty measure, iii) the shadow federal funds rate, which is taken from Wu and Xia (2016), and iv) real new orders, which are taken from Conference Board as the sum of "Orders: consumer goods" (A1M008) and "Orders: capital goods" (A1M027) and are deflated using the "PCE Implicit Price Deflator" (PCEPI) from FRED-MD.

For the particle filtering, we use Government Consumption Expenditures and Gross Investment (FRED: GCE) as our measure of government spending and Real Gross Domestic Product (FRED: GDPC1) as our output measure. Both are transformed to per capita values via division by Civilian non-institutional population (FRED: CNP16OV), smoothed with an HP-filter with $\lambda=10,000$ to solve the best levels problem (Edge et al. 2013). The resulting per capita series are then logged and detrended using a one-sided HP-filter.

For TFP, we cumulate the utilization adjusted TFP growth rates of Fernald (2012) (dtfp_util, transformed from annualized to quarterly growth rates), and detrend using a one-sided HP-filter.

\section{C.2 Uncertainty measures}

- The Jurado et al. (2015) macro uncertainty measure and the Ludvigson et al. (2015) financial uncertainty measure are available at Sidney Ludvigson's homepage at https://www.sydneyludvigson.com/data-and-appendixes/. We use the $h=1$ measures.

- The Baker et al. (2016) economic policy uncertainty measure is taken from FRED (USEPUINDXM)

- The VIX index is taken from FRED (VIXCLS) and averaged across months. Before the VIX becomes available in 1990, we use the realized stock return volatility. For that purpose, we compute the monthly standard deviation of the daily S\&P 500 stock price index returns. The stock price index values are taken from Datastream 
$(\mathrm{S} \& \mathrm{PCOMP}(\mathrm{PI}))$. The resulting index of realized volatilities is normalized to have the same mean and variance as the VIX index when they overlap from 1990 onwards. The correlation between the two during that period is 0.8776 .

\section{C.3 Wage Markup}

For the wage markup, i.e. the wedge between the marginal rate of substitution and the real wage, we focus on an encompassing measure of hours. Recall the equation for computing the wage markup

$$
\xi_{t}^{w}=\log \left(\frac{1-\tau_{t}^{n}}{1+\tau_{t}^{c}}\right)+\log \left(\frac{W_{t} N_{t}}{P_{t} Y_{t}}\right)+\log \left(\frac{Y_{t}}{C_{t}}\right)-\log \left(\frac{1-\eta}{\eta}\right)+\log \left(\frac{1-N_{t}}{N_{t}}\right) .
$$

Demeaning yields:

$$
\begin{aligned}
\xi_{t}^{w}-\xi^{w}= & {\left[\log \left(\frac{W_{t} N_{t}}{P_{t} Y_{t}}\right)-\log \left(\frac{W N}{P Y}\right)\right]+\left[\log \left(\frac{Y_{t}}{C_{t}}\right)-\log \left(\frac{Y}{C}\right)\right] } \\
& +\left[\log \left(\frac{1-N_{t}}{N_{t}}\right)-\log \left(\frac{1-N}{N}\right)\right] \\
& +\left[\log \left(\frac{1-\tau_{t}^{n}}{1+\tau_{t}^{c}}\right)-\log \left(\frac{1-\tau^{n}}{1+\tau^{c}}\right)\right],
\end{aligned}
$$

where the first term on the right hand side is the labor share. Expanding the fractions to get the wedge in terms of the labor share and the consumption to output ratio has the advantage of avoiding problems with different trends that may be contained in different data sources. ${ }^{40}$ In the isoelastic case with felicity function

$$
U\left(C_{t}, N_{t}\right)=\log \left(C_{t}\right)-\psi \frac{N_{t}^{1+\frac{1}{\varepsilon_{l}}}}{1+\frac{1}{\varepsilon_{l}}}
$$

where $\varepsilon_{l}$ is the Frisch elasticity and $\psi$ the weight of labor in the utility function, we get

$$
\xi_{t}^{w}=\log \left(\frac{1-\tau_{t}^{n}}{1+\tau_{t}^{c}}\right)+\log \left(\frac{W_{t} N_{t}}{P_{t} Y_{t}}\right)+\log \left(\frac{Y_{t}}{C_{t}}\right)+\log (\psi)+\left(1+\frac{1}{\varepsilon_{l}}\right) \log \left(N_{t}\right)
$$

In order to compute the wage markup, the right-hand-side variables are mapped to the data in the following way:

- $\frac{W_{t} N_{t}}{P_{t} Y_{t}}$ : to compute the labor share, we take the share of employees' compensation Compensation of Employees, Paid (FRED: COE) in net national income (NNI), where net national income is compute as National Income (FRED: NICUR) minus net indirect taxes, computed as the difference between taxes on production and

\footnotetext{
${ }^{40}$ For example, the trend in NIPA GDP and Average hourly earnings of production and nonsupervisory workers in the private sector differs, although theory says they should be the same.
} 
imports (FRED: GDITAXES) and subsidies (FRED: GDISUBS). To this we add part of the ambiguous proprietor's income (FRED: PROPINC). The share of proprietor's income assigned to labor is computed as the share of unambiguous labor income in total unambiguous income resulting in

$$
\frac{W N}{P Y}=\frac{C O E}{N N I-P R O P I N C}
$$

- $P_{t}$ : Gross Domestic Product: Implicit Price Deflator (FRED: GDPDEF).

- $Y_{t}$ : Gross Domestic Product (FRED: GDP), deflated by the GDP deflator and divided by population $\operatorname{Pop}_{t}$ (defined below).

- $C_{t}$ : real private consumption is computed as the sum of Personal Consumption Expenditures: Nondurable Goods (FRED: PCND) and Personal Consumption Expenditures: Services (FRED: PCESV), each deflated by the GDP deflator and divided by population Popt $_{t}{ }^{41}$

- $N_{t}$ : We use a quarterly total hours measure following Cociuba et al. (2012), divided by population $P o p_{t}$. For this purpose, we extend their measure to include more recent periods.

1. Compute the civilian non-institutional population between 16 and 65 years by subtracting the (Unadj) Population Level - 65 yrs. \& over (BLS: LNU00000097) from Civilian Noninstitutional Population (BLS: LNU00000000), both averaged over the respective quarter.

2. To compute the number of military personell, we first download the most recent vintage from Simona Cociuba's website at https://sites.google.com/site/ simonacociuba/research and then update Military Personnel- Total Worldwide using data from https://www.dmdc.osd.mil/appj/dwp/dwp_reports. jsp: Military Personnel -> Active Duty Military Personnel by Service by Rank/Grade (Updated Monthly); for the current year, we use the monthly PDFs. There, we use GRAND TOTAL- Total services. Again we average monthly values to get a quarterly series.

3. Civilian employment and weekly hours worked before 1976, which are based on Census and BLS data in printed books, are taken from the most recent vintage from Simona Cociuba's website.

4. Civilian employment after 1976 is taken from Number Employed, At Work (BLS: LNU02005053), while their weekly hours worked are from Average Hours, Total At Work, All Industries (BLS: LNU02005054).

\footnotetext{
${ }^{41}$ Due to chain-weighting, this separate deflating is required to preserve additivity.
} 
The series in 2 to 4 are first averaged over the quarter. When doing so for the civilian series in 3 and 4, we follow Cociuba et al. (2012) and check for outliers on the low side, i.e. we check whether $d_{t} \equiv \operatorname{mean}\left(m_{i}\right) / \min \left(m_{i}\right)<0.95$, where $m_{i}$ denotes the months belonging to a quarter. If $d_{t}<0.95$, we use $\left(3 \times \operatorname{mean}\left(m_{i}\right)-\min \left(m_{i}\right)\right) / 2$ and mean $\left(m_{i}\right)$ otherwise. The civilian quarterly series are then seasonally adjusted using the X13 routine of Eviews 8. Total quarterly hours are computed as the sum of civilian and military hours, both computed as the product of employment times weekly hours worked in the respective category. For military weekly hours, we assume a workweek of 40 hours. To get from weekly to quarterly hours, we assume 4 quarters with 13 weeks.

- $P o p_{t}$ : we use the sum of civilian non-institutional population between 16 and 65 and military personell, based on our update of Cociuba et al. (2012).

- Leisure $1-N_{t}$ : Following Karabarbounis (2014), who in turn is motivated by Aguiar et al. (2013), we normalize the discretionary time endowment available to 92 hours per week per person and compute leisure as the difference between this endowment and $N_{t}$. Again, the measure is transformed to per capita values by dividing by $P o p_{t}$.

- Labor tax rate $\tau_{t}^{n}$ : The average labor income tax rate is computed as the sum of taxes on labor income, $\tau^{L I}$, plus the "tax rate" on social insurance contributions, $\tau^{S I}$

$$
\tau^{n}=\tau^{L I}+\tau^{S I}
$$

We closely follow Mendoza et al. (1994), Jones (2002), and Leeper et al. (2010) and compute the tax rate from the national accounts by dividing the tax revenue by the respective tax base. For labor income tax rates, we need to compute the portion of personal income tax revenue that can be assigned to labor income. We first compute the average personal income tax rate

$$
\tau^{p}=\frac{I T}{W+P R I / 2+C I},
$$

where IT is personal current tax revenues computed as the sum of Federal government current tax receipts: Personal current taxes and State and local government current tax receipts: Personal current taxes (Table 3.1 line 3, FRED: A074RC1Q027SBEA + W071RC1Q027SBEA), $W$ is Compensation of Employees: Wages and Salary Accruals (Table 1.12 line 3, FRED: WASCUR), PRI is Proprietors' Income with Inventory Valuation Adjustment(IVA) and Capital Consumption Adjustment (CCAdj) (Table 1.12 line 9, FRED: PROPINC), and $C I$ is capital income. It is computed as

$$
C I \equiv P R I / 2+R I+C P+N I
$$


where RI is Rental Income of Persons with Capital Consumption Adjustment (CCAdj) (Table 1.12 line 12, FRED: RENTIN), CP is Corporate Profits with Inventory Valuation Adjustment (IVA) and Capital Consumption Adjustment (CCAdj) (Table 1.12 line 13, FRED: CPROFIT), and NI denotes Net interest and miscellaneous payments on assets (Table 1.12 line 18, FRED: W255RC1Q027SBEA). In doing so, the ambiguous proprietor's income is assigned in equal parts to capital and labor income. The labor income tax can then be computed as

$$
\tau^{L I}=\frac{\tau^{p}(W+P R I / 2)}{E C+P R I / 2},
$$

where EC is National Income: Compensation of Employees, Paid (Table 1.12 line 2, FRED: COE), which, in addition to wages, includes contributions to social insurance and untaxed benefits. The social insurance "tax rate" is given by

$$
\tau^{S I}=\frac{C S I}{E C+P R I / 2}
$$

where CSI denotes Government current receipts: Contributions for government social insurance (Table 3.1 line 7, FRED: W782RC1Q027SBEA).

- Consumption tax rate $\tau_{t}^{c}$ : The tax revenue from consumption taxes, $C T$, requires apportioning the indirect tax revenue to investment and consumption. ${ }^{42}$ We do this as:

$$
C T=\frac{P C}{P C+I} I N D T,
$$

where $P C$ is Personal Consumption Expenditures (FRED: PCE), I is Gross Private Domestic Investment (FRED: GPDI), and INDT is net indirect taxes, computed as the difference between Gross Domestic Income: Taxes on Production and Imports (FRED: GDITAXES) and Gross Domestic Income: Subsidies (FRED: GDISUBS). ${ }^{43}$ The consumption tax rate is then computed as

$$
\tau^{c}=\frac{C T}{P C-C T}
$$

\section{C.4 Price Markup}

For the price markup, i.e. the wedge between the real wage and the marginal product of labor, we focus on the private business sector. Recall the equation for computing the

\footnotetext{
${ }^{42}$ We opt to not attribute sales tax revenues to government purchases due to the different tax-exemption status of local, state, and federal purchases in different states. For example, government entities are sales tax-exempt in New York, but are tax-liable in California.

${ }^{43}$ The use of net indirect taxes follows Karabarbounis (2014) and differs from e.g. Mendoza et al. (1994) who use gross indirect taxes.
} 
price markup:

$$
\xi_{t}^{p}=\log \left((1-\alpha)\left(Y^{n o r m}\right)^{\frac{\psi-1}{\psi}}\right)+\frac{\psi-1}{\psi} Z_{t}+\frac{1}{\psi} \log \left(\frac{Y_{t}+\Phi}{N_{t}-N^{o}}\right)-\log \left(\frac{W_{t}}{P_{t}}\right) .
$$

Demeaning this expression yields:

$$
\begin{aligned}
\xi_{t}^{p}-\xi^{p}= & \frac{\psi-1}{\psi} \log \left(e^{Z_{t}}\right)+\frac{1}{\psi}\left[\log \left(\frac{Y_{t}+\Phi}{N_{t}-N^{o}}\right)-\log \left(\frac{Y+\Phi}{N-N^{o}}\right)\right] \\
& -\left[\log \left(\frac{W_{t}}{P_{t}}\right)-\log \left(\frac{W}{P}\right)\right]
\end{aligned}
$$

where

$$
\begin{aligned}
e^{Z_{t}} & =\frac{1}{\varepsilon_{A, t}} \log \operatorname{TFP}_{t} \\
\varepsilon_{A, t} & =\left[\frac{\hat{Y}_{t}+\phi_{\text {fix }}}{1+\phi_{\text {fix }}}\right]^{\frac{1}{\psi}} \frac{1}{\Xi} \aleph^{o}\left(e^{\hat{Z}_{t}} \hat{N}_{t}\right)^{\frac{\psi-1}{\psi}}
\end{aligned}
$$

We can then compute the price markup by using the following sources:

- $W_{t}$ : following the approach in Nekarda and Ramey (2013), we use the Average hourly earnings of production and nonsupervisory workers in the private sector (BLS: CES0500000008). ${ }^{44}$

- $P_{t}$ : Gross Domestic Product: Implicit Price Deflator (FRED: GDPDEF).

- $N_{t}-N^{o}$ : Average weekly hours of production and nonsupervisory employees, private business (BLS: CES0500000006) multiplied by Production and nonsupervisory employees, private business (CES: CES0500000006), divided by Civilian noninstitutional population.

- $Y_{t}$ : Current dollar output, private business (BLS: PRS84006053), deflated using the GDP deflator and divided by Civilian non-institutional population, detrended by an exponential trend.

- $\Phi$ : Consistent with our model, we assume additional fixed costs of $2.96 \%$ of steadystate output per capita, which we approximate using the average detrended log output per capita.

- Population: Civilian non-institutional population (FRED: CNP16OV), smoothed with an HP-filter with $\lambda=10,000$ to solve the best levels problem (Edge et al. 2013).

- $T F P_{t}$ : cumulated sum of the utilization adjusted or non-utilization adjusted TFP growth rates of Fernald (2012) (dtfp_util or dtfp, starting value initialized to 1,

\footnotetext{
${ }^{44}$ This implicitly assumes that all nonproduction and supervisory workers are overhead labor, which probably is an upper bound (see Ramey 1991).
} 
transformed from annualized to quarterly growth rates), detrended by an exponential trend.

- $\aleph^{\circ}$ : The labor share not accounting for overhead labor, $\aleph$ is computed as 1 minus Capital's share of income from Fernald (2012), ${ }^{45}$ which is "[B]ased primarily on NIPA data for the corporate sector". To derive the share of non-overhead labor $\aleph^{\circ}$, we use equation

$$
\aleph^{o} \equiv \frac{\frac{W}{P}\left(N-N^{o}\right)}{Y}=\frac{\frac{W}{P} N}{Y} \frac{N-N^{o}}{N}=\aleph\left(1-\phi^{o}\right)
$$

with $\phi^{o}=0.11$ as discussed in the calibration section.

In the Cobb-Douglas case, the price markup simplifies to

$$
\xi_{t}^{p}=\log \left(\frac{Y_{t}+\Phi}{N_{t}-N^{o}}\right)-\log \left(\frac{W_{t}}{P_{t}}\right),
$$

which, in the absence of fixed costs, reduces to the inverse labor share. In the robustness checks, we use three different measures:

- The labor share based on total compensation in the nonfinancial business sector is computed as Net value added of nonfinancial corporate business: Compensation of employees (FRED: A460RC1Q027SBEA), divided by Gross value added of nonfnancial corporate business (FRED: A455RC1Q027SBEA) minus Net value added of nonfinancial corporate business: Taxes on production and imports less subsidies (FRED: W325RC1Q027SBEA).

- The labor share in the private business sector is based on Business Sector: Labor Share (FRED: PRS84006173).

- The labor share based on total compensation in the private business sector is computed as the product of Production and Nonsupervisory Employees: Total Private (FRED: CES0500000006), Average Weekly Hours of Production and Nonsupervisory Employees: Total private (FRED: AWHNONAG) and Average Hourly Earnings of Production and Nonsupervisory Employees: Total Private (FRED: AHETPI) divided by Business Sector: Current Dollar Output (FRED: PRS84006053).

\section{C.5 Industry-level markups}

The majority of our data needed to construct industry-level price markups comes from the NBER-CES manufacturing industry database, which covers the SIC2 industries 20 to 39 at a four-digit granularity for the years 1958-2011.

\footnotetext{
${ }^{45}$ This series substitutes for Business Sector: Labor Share (FRED: PRS84006173), which is unfortunately only available in index form.
} 
We compute industry-level price markups using equations B.19, C.4, and C.5. As we have no information on fixed costs, we assume the absence of fixed costs such that

$$
\xi_{i, t}^{p}=\frac{\psi-1}{\psi} \log \left(e^{Z_{i, t}}\right)+\frac{1}{\psi} \log \left(\frac{Y_{t}}{N_{i, t}-N_{i}^{o}}\right)-\log \left(\frac{W_{i, t}}{P_{i, t}}\right),
$$

where

$$
e^{Z_{i, t}}=\frac{1}{\varepsilon_{A, i}} \log T F P_{i, t}
$$

Here, we use the steady-state elasticity $\varepsilon_{A, i}$ given by

$$
\varepsilon_{A, i}=\frac{1}{\Xi_{i}} \aleph_{i}^{o}
$$

where $\aleph_{i}^{o}$ is the labor share and $\Xi_{i}^{-1}$ is the gross markup.

The NBER-CES database only contains information on wages paid. But what matters for the labor margin is the total compensation of employees. For that reason we follow the approach of Chang and Hong (2006) and Nekarda and Ramey (2011) and multiply the wage bill in the CES database by the ratio of the total compensation (NIPA Table 6.2, Compensation of Employees by Industry) to wages (NIPA Table 6.3 Wages and Salaries by Industry) at the two-digit industry level. The respective mapping is displayed in Tables C.1 and C.2. When the SIC classifications in the NIPA tables change, we splice the respective adjustment factor series by giving precedence to the 1987 SIC series (NIPA Table B) when there is overlap and multiplying the earlier/later series by the ratio of the two series in the first/last period of overlap to ensure smooth pasting. Similarly, the database only contains hours of production workers (NBER-CES code: prodh). To compute total hours (toth), we compute the number of production workers as the difference between total employment (emp) and production workers (prode). We then assume that non-production workers are salaried and work 1960 hours per year as in Nekarda and Ramey (2011):

$$
\text { toth }=\text { prodh }+(e m p-\text { prode }) \times 1960 .
$$

The database contains information about real shipments which is not equal to output due to inventories. To compute real output accounting for inventories we follow Nekarda and Ramey (2011). A problem is that only the total value of inventories $I_{i, t}^{\text {nom }}$ (invent) is reported, which also includes inventories of materials that need to be subtracted. The first step is to compute the change in nominal finished-goods and work-in-process inventories $\Delta I_{i, t}^{f, n o m}$, which is equal to nominal value added $V_{i, t}^{\text {nom }}(v a d d)$ minus the value of shipments $S_{i, t}^{n o m}$ (vship) plus nominal material costs $M_{i, t}^{\text {nom }}$ (matcost):

$$
\Delta I_{i, t}^{f, n o m}=V_{i, t}^{n o m}-S_{i, t}^{n o m}+M_{i, t}^{n o m} .
$$


The change in materials inventories $\Delta I_{i, t}^{m, n o m}$ can then be computed as the difference between total inventory changes and changes in nominal finished-goods and work-in-process inventories:

$$
\Delta I_{i, t}^{m, n o m}=\Delta I_{i, t}^{n o m}-\Delta I_{i, t}^{f, n o m} .
$$

Real output $Y_{i, t}$ can then be computed $\operatorname{as}^{46}$

$$
Y_{i, t} \approx \frac{S_{i, t}^{n o m}}{P_{i, t}}+\left[\frac{I_{i, t}^{\text {nom }}}{P_{i, t}}-\frac{I_{i, t-1}^{\text {nom }}}{P_{i, t-1}}\right]-\frac{\Delta I_{i, t}^{m, n o m}}{P_{i, t}} .
$$

To implement the above formulas, we need a sectoral TFP estimate and the elasticity of labor productivity with respect to labor-augmenting technology $\varepsilon_{A, i}$.

\section{Elasticity of labor productivity with respect to labor-augmenting technology}

To compute the elasticity, we need to know both the average markup and the labor share. In the absence of fixed costs, the average markup can be directly computed from the average profit share, as one minus the profit share is then equal to the inverse steady-state gross industry markup.

The profit share in industry $i, \Pi_{i, t}^{p s}$ is computed as

$$
\Pi_{i, t}^{p s}=\left(Y_{i, t}^{n o m}-W_{i, t}^{\text {comp }, \text { nom }}-(0.05+\bar{\delta}) K_{i, t} P_{i, t}^{i n v}-M_{i, t}^{n o m}\right) / Y_{i, t}^{\text {nom }}
$$

where $Y_{i, t}^{\text {nom }}$ is nominal output defined as real output $Y_{i, t}$ times the shipment deflator ('pship'), $W_{i, t}^{\text {comp,nom }}$ it total compensation of employees, $M_{i, t}^{\text {nom }}$ is nominal materials costs (matcost), and $(0.05+\bar{\delta}) K_{i, t} P_{i, t}^{i n v}$ is the imputed nominal cost of capital, where we assume an interest rate of $5 \%$ per year.

We compute the average depreciation rate from

$$
\delta_{i, t}=1-\left(K_{i, t}-I_{i, t}\right) / K_{i, t-1}
$$

where real investment is obtained by dividing nominal investment ('invest') by the investment deflator $P_{i, t}^{i n v}$ ('piinv') and $K_{i, t}$ is the real capital stock ('cap'). When computing the average depreciation rate $\bar{\delta}$ over the sample, we discard observations that show negative depreciation rates and depreciation rates larger than $50 \%$.

The elasticity of labor productivity with respect to labor-augmenting technology is then given by the mean labor share, $1 / T \sum_{t=1}^{T} W_{i, t}^{\text {comp }, \text { nom }} / Y_{i, t}^{\text {nom }}$, times the inverse markup. ${ }^{47}$

\footnotetext{
${ }^{46}$ See the Technical Appendix (A.5) of Nekarda and Ramey (2011) and their discussion of the approximation error involved.

${ }^{47}$ The labor share is computed by dividing an appropriate measure of worker compensation by a output measure. Depending on the concept used, the worker compensation is either the one for production or production and supervisory workers. As the output measure we use either total value added or total value added minus material costs. The latter provides a labor share after abstracting from materials.
} 


\section{Industry-level TFP}

To get a measure of productivity, we follow Nekarda and Ramey (2013) and run a Galí (1999)-type VAR with labor productivity and hours in first differences. We compute labor productivity by dividing real output $Y_{i, t}$ by either total hours (toth) or hours of production workers (prodh).

Technology shocks are identified as the only shocks that moves productivity in the longrun. An estimated TFP series is then computed by cumulating the productivity growth rates resulting from simulating the long-run VAR with only the identified technology innovations. ${ }^{48}$

\footnotetext{
${ }^{48}$ Note that this approach assumes the equality between labor productivity movements caused by technology shocks and TFP.
} 
Table C.1: Mapping between SIC two digit codes and NIPA Table 6 lines: Total Compensation

\begin{tabular}{|c|c|c|c|c|c|c|c|c|c|}
\hline SIC code & line & 60200B Ann & Code & line & 60200C Ann & Code & line & 60200D Ann & Code \\
\hline 24 & 15 & Lumber and wood products & $\mathrm{J} 4115 \mathrm{C} 0$ & 15 & Lumber and wood products & $\mathrm{B} 4115 \mathrm{C} 0$ & 15 & Wood products & $\mathrm{N} 4115 \mathrm{C} 0$ \\
\hline 25 & 16 & Furniture and fixtures & J4116C0 & 16 & Furniture and fixtures & $\mathrm{B} 4116 \mathrm{C} 0$ & 24 & Furniture and related products & $\mathrm{N} 4124 \mathrm{C} 0$ \\
\hline 32 & 17 & Stone, clay, and glass products & $\mathrm{J} 4117 \mathrm{C} 0$ & 17 & Stone, clay, and glass products & $\mathrm{B} 4117 \mathrm{C} 0$ & 16 & Nonmetallic mineral products & $\mathrm{N} 4116 \mathrm{C} 0$ \\
\hline 33 & 18 & Primary metal industries & $\mathrm{J} 4118 \mathrm{C} 0$ & 18 & Primary metal industries & B4118C0 & 17 & Primary metals & $\mathrm{N} 4117 \mathrm{C} 0$ \\
\hline 34 & 19 & Fabricated metal products & $\mathrm{J} 4119 \mathrm{C} 0$ & 19 & Fabricated metal products & B4119C0 & 18 & Fabricated metal products & $\mathrm{N} 4118 \mathrm{C} 0$ \\
\hline 35 & 20 & Machinery, except electrical & $\mathrm{J} 4120 \mathrm{C} 0$ & 20 & Industrial machinery and equipment & $\mathrm{B} 4120 \mathrm{C} 0$ & 19 & Machinery & N4119C0 \\
\hline 36 & 21 & Electric and electronic equipment & $\mathrm{J} 4121 \mathrm{C} 0$ & 21 & Electronic and other electric equipment & $\mathrm{B} 4121 \mathrm{C} 0$ & 21 & Electrical equipment, appliances, and components & $\mathrm{N} 4121 \mathrm{C} 0$ \\
\hline 371 & 22 & Motor vehicles and equipment & $\mathrm{J} 4122 \mathrm{C} 0$ & 22 & Motor vehicles and equipment & B4122C0 & 22 & Motor vehicles, bodies and trailers, and parts & $\mathrm{N} 4122 \mathrm{C} 0$ \\
\hline 37 & 23 & Other transportation equipment & $\mathrm{J} 4123 \mathrm{C} 0$ & 23 & Other transportation equipment & $\mathrm{B} 4123 \mathrm{C} 0$ & 23 & Other transportation equipment & $\mathrm{N} 4123 \mathrm{C} 0$ \\
\hline 38 & 24 & Instruments and related products & $\mathrm{J} 4124 \mathrm{C} 0$ & 24 & Instruments and related products & $\mathrm{B} 4124 \mathrm{C} 0$ & 19 & Machinery & $\mathrm{N} 4119 \mathrm{C} 0$ \\
\hline 39 & 25 & Miscellaneous manufacturing industries & $\mathrm{J} 4125 \mathrm{C} 0$ & 25 & Miscellaneous manufacturing industries & $\mathrm{B} 4125 \mathrm{C} 0$ & 25 & Miscellaneous manufacturing & $\mathrm{N} 4125 \mathrm{C} 0$ \\
\hline 20 & 27 & Food and kindred products & $\mathrm{J} 4127 \mathrm{C} 0$ & 27 & Food and kindred products & $\mathrm{B} 4127 \mathrm{C} 0$ & 27 & Food and beverage and tobacco products & $\mathrm{N} 4127 \mathrm{C} 0$ \\
\hline 21 & 28 & Tobacco manufactures & $\mathrm{Q} 4128 \mathrm{BC} 0$ & 28 & Tobacco products & Q4128C0 & 27 & Food and beverage and tobacco products & $\mathrm{N} 4127 \mathrm{C} 0$ \\
\hline 22 & 29 & Textile mill products & J4129C0 & 29 & Textile mill products & B4129C0 & 28 & Textile mills and textile product mills & N4129C0 \\
\hline 23 & 30 & Apparel and other textile products & $\mathrm{J} 4130 \mathrm{C} 0$ & 30 & Apparel and other textile products & B4130C0 & 29 & Apparel and leather and allied products & $\mathrm{N} 4130 \mathrm{C} 0$ \\
\hline 26 & 31 & Paper and allied products & $\mathrm{J} 4131 \mathrm{C} 0$ & 31 & Paper and allied products & Q4131C0 & 30 & Paper products & $\mathrm{N} 4132 \mathrm{C} 0$ \\
\hline 27 & 32 & Printing and publishing & $\mathrm{Q} 4132 \mathrm{BC} 0$ & 32 & Printing and publishing & $\mathrm{Q} 4132 \mathrm{C} 0$ & 31 & Printing and related support activities & $\mathrm{N} 4133 \mathrm{C} 0$ \\
\hline 28 & 33 & Chemicals and allied products & $\mathrm{J} 4133 \mathrm{C} 0$ & 33 & Chemicals and allied products & $\mathrm{B} 4133 \mathrm{C} 0$ & 33 & Chemical products & $\mathrm{N} 4135 \mathrm{C} 0$ \\
\hline 29 & 34 & Petroleum and coal products & $\mathrm{J} 4134 \mathrm{C} 0$ & 34 & Petroleum and coal products & $\mathrm{B} 4134 \mathrm{C} 0$ & 32 & Petroleum and coal products & $\mathrm{N} 4134 \mathrm{C} 0$ \\
\hline 30 & 35 & Rubber and miscellaneous plastics products & $\mathrm{J} 4135 \mathrm{C} 0$ & 35 & Rubber and miscellaneous plastics products & $\mathrm{B} 4135 \mathrm{C} 0$ & 34 & Plastics and rubber products & $\mathrm{N} 4136 \mathrm{C} 0$ \\
\hline 31 & 36 & Leather and leather products & $\mathrm{J} 4136 \mathrm{C} 0$ & 36 & Leather and leather products & $\mathrm{B} 4136 \mathrm{C} 0$ & 29 & Apparel and leather and allied products & N4130C0 \\
\hline
\end{tabular}

Notes: In Table "60200D Ann." we do not assign NIPA line 20 "Computer and electronic products" (N4020C0) to any two-digit industry, because in SIC 1987 it was part "Industrial machinery and equipment" and later became a separate category, introducing a structural break. 
Table C.2: Mapping between SIC two digit codes and NIPA Table 6 lines: Wages

\begin{tabular}{|c|c|c|c|c|c|c|c|c|c|}
\hline SIC code & line & 60300B Ann & Code & line & 60300C Ann & Code & line & 60300D Ann & Code \\
\hline 24 & 15 & Lumber and wood products & $\mathrm{J} 4115 \mathrm{C} 0$ & 15 & Lumber and wood products & $\mathrm{B} 4115 \mathrm{C} 0$ & 15 & Wood products & $\mathrm{N} 4115 \mathrm{C} 0$ \\
\hline 25 & 16 & Furniture and fixtures & $\mathrm{J} 4116 \mathrm{C} 0$ & 16 & Furniture and fixtures & B4116C0 & 24 & Furniture and related products & $\mathrm{N} 4124 \mathrm{C} 0$ \\
\hline 32 & 17 & Stone, clay, and glass products & $\mathrm{J} 4117 \mathrm{C} 0$ & 17 & Stone, clay, and glass products & $\mathrm{B} 4117 \mathrm{C} 0$ & 16 & Nonmetallic mineral products & N4116C0 \\
\hline 33 & 18 & Primary metal industries & $\mathrm{J} 4118 \mathrm{C} 0$ & 18 & Primary metal industries & B4118C0 & 17 & Primary metals & N4117C0 \\
\hline 34 & 19 & Fabricated metal products & $\mathrm{J} 4119 \mathrm{C} 0$ & 19 & Fabricated metal products & B4119C0 & 18 & Fabricated metal products & $\mathrm{N} 4118 \mathrm{C} 0$ \\
\hline 35 & 20 & Machinery, except electrical & $\mathrm{J} 4120 \mathrm{C} 0$ & 20 & Industrial machinery and equipment & B4120C0 & 19 & Machinery & N4119C0 \\
\hline 36 & 21 & Electric and electronic equipment & $\mathrm{J} 4121 \mathrm{C} 0$ & 21 & Electronic and other electric equipment & B4121C0 & 21 & Electrical equipment, appliances, and components & N4121C0 \\
\hline 371 & 22 & Motor vehicles and equipment & $\mathrm{J} 4122 \mathrm{C} 0$ & 22 & Motor vehicles and equipment & $\mathrm{B} 4122 \mathrm{C} 0$ & 22 & Motor vehicles, bodies and trailers, and parts & $\mathrm{N} 4122 \mathrm{C} 0$ \\
\hline 37 & 23 & Other transportation equipment & $\mathrm{J} 4123 \mathrm{C} 0$ & 23 & Other transportation equipment & $\mathrm{B} 4123 \mathrm{C} 0$ & 23 & Other transportation equipment & $\mathrm{N} 4123 \mathrm{C} 0$ \\
\hline 38 & 24 & Instruments and related products & $\mathrm{J} 4124 \mathrm{C} 0$ & 24 & Instruments and related products & B4124C0 & 19 & Machinery & N4119C0 \\
\hline 39 & 25 & Miscellaneous manufacturing industries & $\mathrm{J} 4125 \mathrm{C} 0$ & 25 & Miscellaneous manufacturing industries & $\mathrm{B} 4125 \mathrm{C} 0$ & 25 & Miscellaneous manufacturing & $\mathrm{N} 4125 \mathrm{C} 0$ \\
\hline 20 & 27 & Food and kindred products & $\mathrm{J} 4127 \mathrm{C} 0$ & 27 & Food and kindred products & B4127C0 & 27 & Food and beverage and tobacco products & $\mathrm{N} 4127 \mathrm{C} 0$ \\
\hline 21 & 28 & Tobacco manufactures & $\mathrm{Q} 4128 \mathrm{BC} 0$ & 28 & Tobacco products & $\mathrm{Q} 4128 \mathrm{C} 0$ & 27 & Food and beverage and tobacco products & $\mathrm{N} 4127 \mathrm{C} 0$ \\
\hline 22 & 29 & Textile mill products & J4129C0 & 29 & Textile mill products & B4129C0 & 28 & Textile mills and textile product mills & $\mathrm{N} 4129 \mathrm{C} 0$ \\
\hline 23 & 30 & Apparel and other textile products & $\mathrm{J} 4130 \mathrm{C} 0$ & 30 & Apparel and other textile products & $\mathrm{B} 4130 \mathrm{C} 0$ & 29 & Apparel and leather and allied products & N4130C0 \\
\hline 26 & 31 & Paper and allied products & $\mathrm{J} 4131 \mathrm{C} 0$ & 31 & Paper and allied products & Q4131C0 & 30 & Paper products & $\mathrm{N} 4132 \mathrm{C} 0$ \\
\hline 27 & 32 & Printing and publishing & $\mathrm{Q} 4132 \mathrm{BC} 0$ & 32 & Printing and publishing & $\mathrm{Q} 4132 \mathrm{C} 0$ & 31 & Printing and related support activities & $\mathrm{N} 4133 \mathrm{C} 0$ \\
\hline 28 & 33 & Chemicals and allied products & J4133C0 & 33 & Chemicals and allied products & B4133C0 & 33 & Chemical products & $\mathrm{N} 4135 \mathrm{C} 0$ \\
\hline 29 & 34 & Petroleum and coal products & $\mathrm{J} 4134 \mathrm{C} 0$ & 34 & Petroleum and coal products & B4134C0 & 32 & Petroleum and coal products & N4134C0 \\
\hline 30 & 35 & Rubber and miscellaneous plastics products & $\mathrm{J} 4135 \mathrm{C} 0$ & 35 & Rubber and miscellaneous plastics products & $\mathrm{B} 4135 \mathrm{C} 0$ & 34 & Plastics and rubber products & $\mathrm{N} 4136 \mathrm{C} 0$ \\
\hline 31 & 36 & Leather and leather products & $\mathrm{J} 4136 \mathrm{C} 0$ & 36 & Leather and leather products & B4136C0 & 29 & Apparel and leather and allied products & N4130C0 \\
\hline
\end{tabular}

Notes: In Table "60300D Ann." we do not assign NIPA line 20 "Computer and electronic products" (N4020C0) to any two-digit industry, because in SIC 1987 it

was part "Industrial machinery and equipment" and later became a separate category, introducing a structural break. 


\section{Mixed-Frequency VARs}

\section{D.1 Priors}

We use a shrinking prior of the Independent Normal-Wishart type (Kadiyala and Karlsson 1997), where the mean and precision are derived from from a Minnesota-type prior (Doan et al. 1984; Litterman 1986). Denote the vector of stacked coefficients with $\beta=\operatorname{vec}\left(\left[\mu \alpha A_{1}, \ldots, A_{p}\right]^{\prime}\right)$. It is assumed to follow a normal prior

$$
\beta \sim N(\underline{\beta}, \underline{V})
$$

For the prior mean $\underline{\beta}$, we assume the variables to follow a univariate $\mathrm{AR}(1)$-model with mean of 0.9 for levels and mean 0 for growth rates, while all other coefficients are 0 . The prior precision $\underline{V}$ is assumed to be a diagonal matrix with the highest precision for the first lag and exponential decay for the other lags. The weighting of cross-terms is conducted according to the relative size of the error terms in the respective equations, while a rather diffuse prior is used for deterministic terms. The diagonal element corresponding to the $j$ th variable in equation $i, \underline{V}_{i, j j}$ is:

$$
\underline{V}_{i, j j}= \begin{cases}\frac{\underline{a}_{1}}{r^{2}}, & \text { for coefficients on own lag } r \in\{1, \ldots, p\} \\ \frac{a_{2} s_{i}^{2}}{r^{2} s_{j}^{2}}, & \text { for coefficients on lag } r \in\{1, \ldots, p\} \text { of variable } j \neq i \\ \underline{a}_{3} s_{i}^{2}, & \text { for coefficients on exogenous variables }\end{cases}
$$

where $s_{i}^{2}$ is the OLS estimate of the error variance of an $A R(p)$ model with constant and trend estimated for the $i$ th variable (see Litterman 1986). ${ }^{49}$ We follow Koop and Korobilis (2010) and set $\underline{a}_{1}=0.2, \underline{a}_{2}=0.5$ and $\underline{a}_{3}=10^{4}$. The prior error covariance is assumed to follow

$$
\underline{\Sigma} \sim I W(\underline{S}, \underline{\nu})
$$

with $\underline{\nu}=60$ "pseudo-observations", corresponding to $\approx 10 \%$ of the observations, and $\underline{S}$ being the OLS covariance matrix.

As a practical matter, we use z-scored the data (including the trend) to avoid numerical problems arising from under-/overflow during the posterior computations that involve sum of squares. We also impose a stability condition on our VAR by drawing from the conditional distribution for $\beta$ until all eigenvalues of the companion form matrix are smaller than 1.

\footnotetext{
${ }^{49}$ In case of the quarterly variable, we estimate the $A R(p)$ model on linearly interpolated data.
} 


\section{D.2 11+1 Variable VAR}

The Jurado et al. (2015) 11+1-variable VAR is given by (FRED-MD Acronyms in brackets, see Appendix $\mathrm{C}$ for details on other variables)

$\left[\begin{array}{c}\log (\text { real IP }(\text { INDPRO })) \\ \log (\text { employment (PAYEMS })) \\ \log (\text { real consumption (DPCERA3M086SBEA })) \\ \log (\text { PCE Deflator }(\text { PCEPI })) \\ \log (\text { real new orders }) \\ \log (\text { real wage }(\text { CES3000000008 })) \\ \text { hours (AWHMAN }) \\ \text { shadow federal funds rate } \\ \log (\text { S\&P } 500 \text { Index (S\&P 500) }) \\ \text { growth rate of M2 (M2SL) } \\ \text { uncertainty proxy } \\ \log (\text { markup })\end{array}\right]$



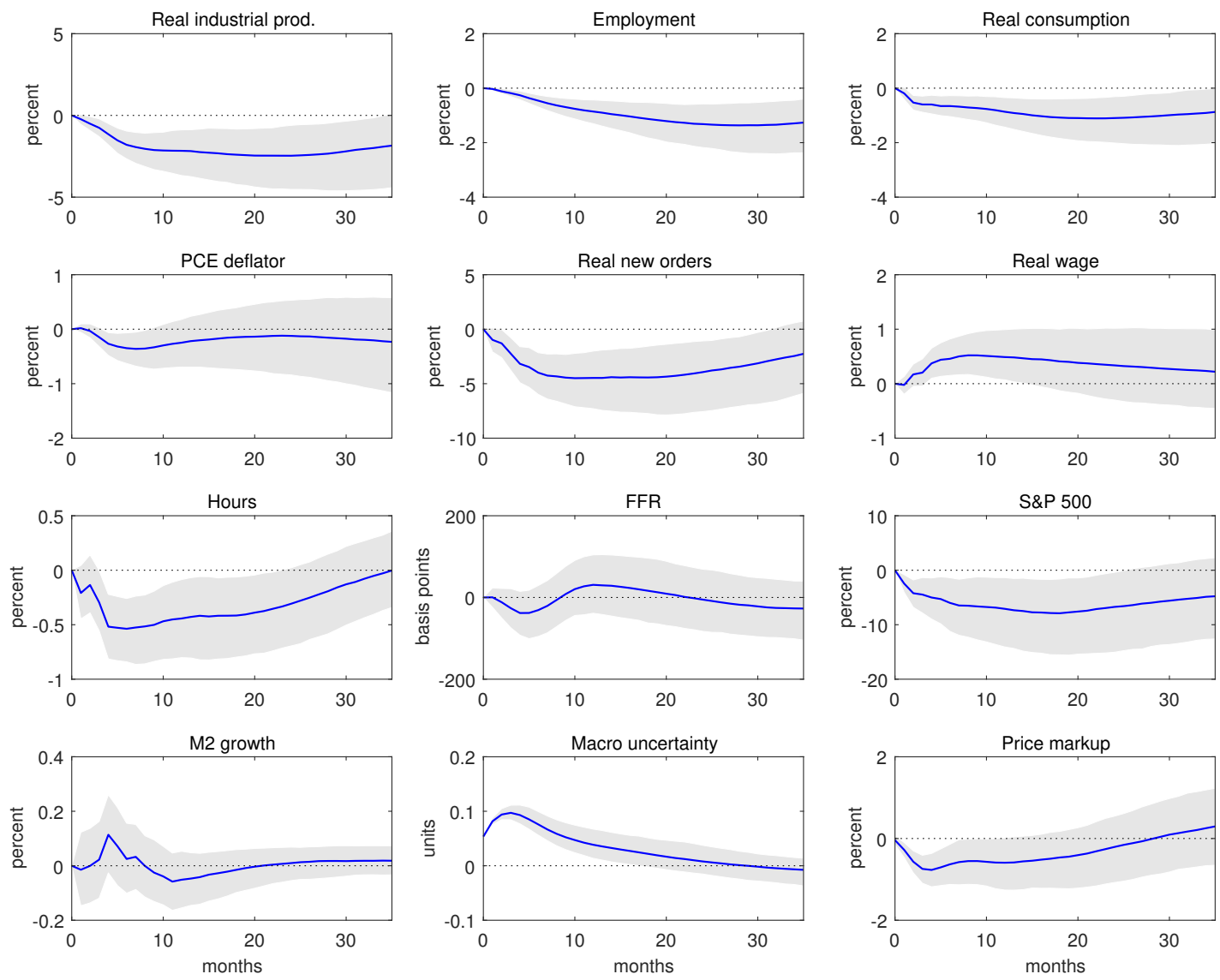

(a) Price Markup
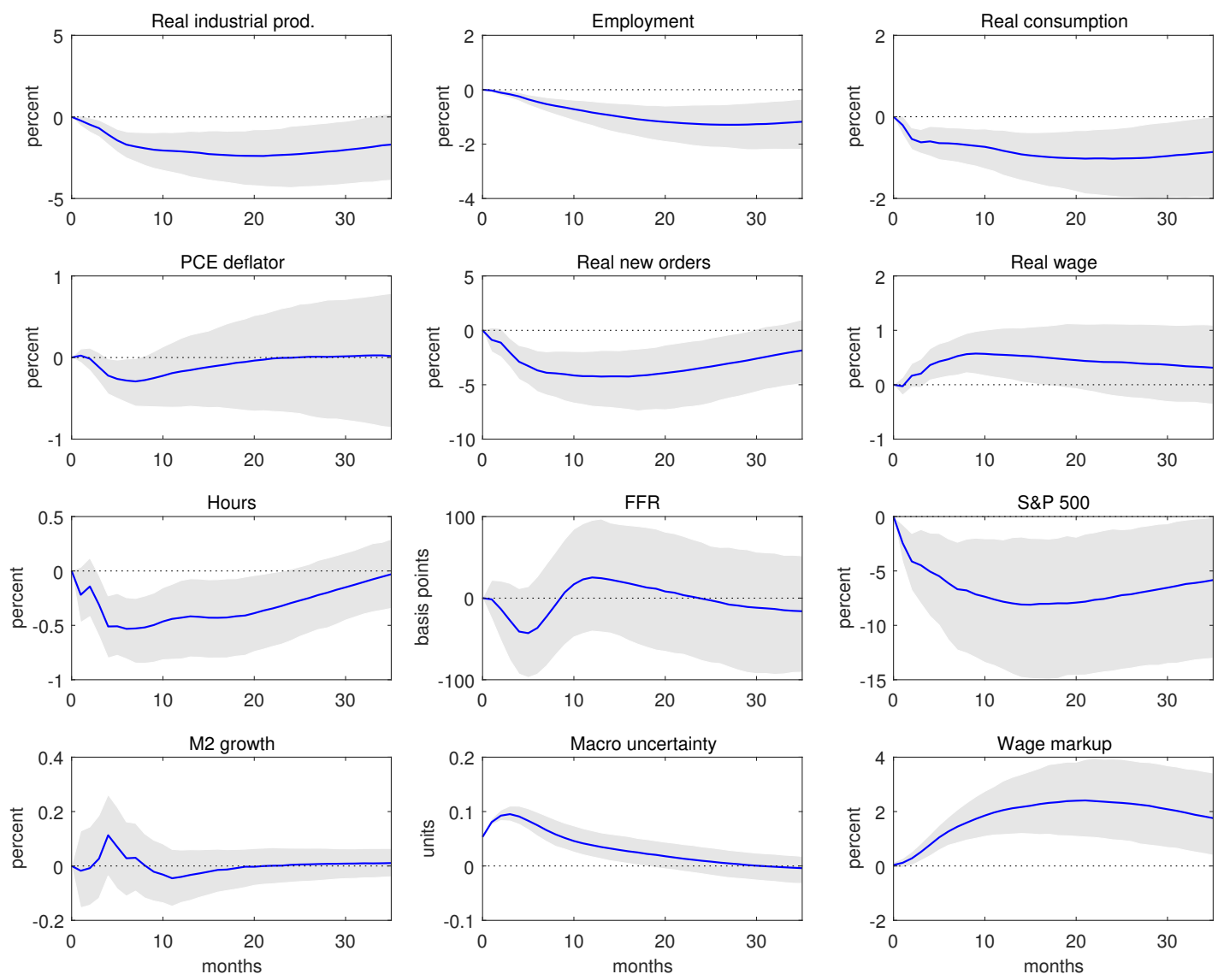

(b) Wage Markup

Figure D.5: IRFs to JLN-based uncertainty shock in the $11+1$ variable mixed-frequency VAR. Notes: Bands are pointwise 90\% HPbis. 
Table D.3: Unconditional forecast error variance explained by uncertainty shock

\begin{tabular}{|c|c|c|c|c|c|c|c|c|c|c|c|}
\hline$Y$ & Emp. & $C$ & $P$ & Orders & $W / P$ & $N$ & $R$ & $S \& P$ & $\Delta M 2$ & Uncert. & Markup \\
\hline \multicolumn{12}{|c|}{ Price Markup VAR } \\
\hline 12.45 & 12.54 & 11.31 & 6.70 & 14.33 & $\begin{array}{c}7.59 \\
\text { Wage M }\end{array}$ & $\begin{array}{l}10.76 \\
\text { arkup }\end{array}$ & $\begin{array}{l}6.95 \\
\text { VAR }\end{array}$ & 9.85 & 4.92 & 22.78 & 7.52 \\
\hline \multicolumn{12}{|c|}{ Total Markup VAR } \\
\hline 12.56 & 11.99 & 11.37 & 5.95 & 13.49 & 7.84 & 11.42 & 6.68 & 11.26 & 4.90 & 23.14 & 11.10 \\
\hline
\end{tabular}

Notes: Mean posterior forecast error variance share explained by the uncertainty shock in the $11+1$ variable mixed-frequency VAR with the Jurado et al. (2015) uncertainty measure ordered second-to-last. Based on 1000 posterior draws. First row: VAR with price markup measure; Second row: VAR with wage markup measure.

\section{D.3 $8+1$ Variable VAR}

The Bloom (2009) 8+1 variable VAR is given by

$\left[\begin{array}{c}\log (\text { S\&P } 500 \text { Index (S\&P 500)) } \\ \text { uncertainty proxy } \\ \text { shadow federal funds rate } \\ \log (\text { real wage (CES3000000008) }) \\ \log (\text { CPI (CPIAUCSL })) \\ \text { hours (AWHMAN) } \\ \log (\text { manufacturing employment (MANEMP })) \\ \log (\text { real manufacturing production (IPMANSICS })) \\ \log (\text { markup) }\end{array}\right]$



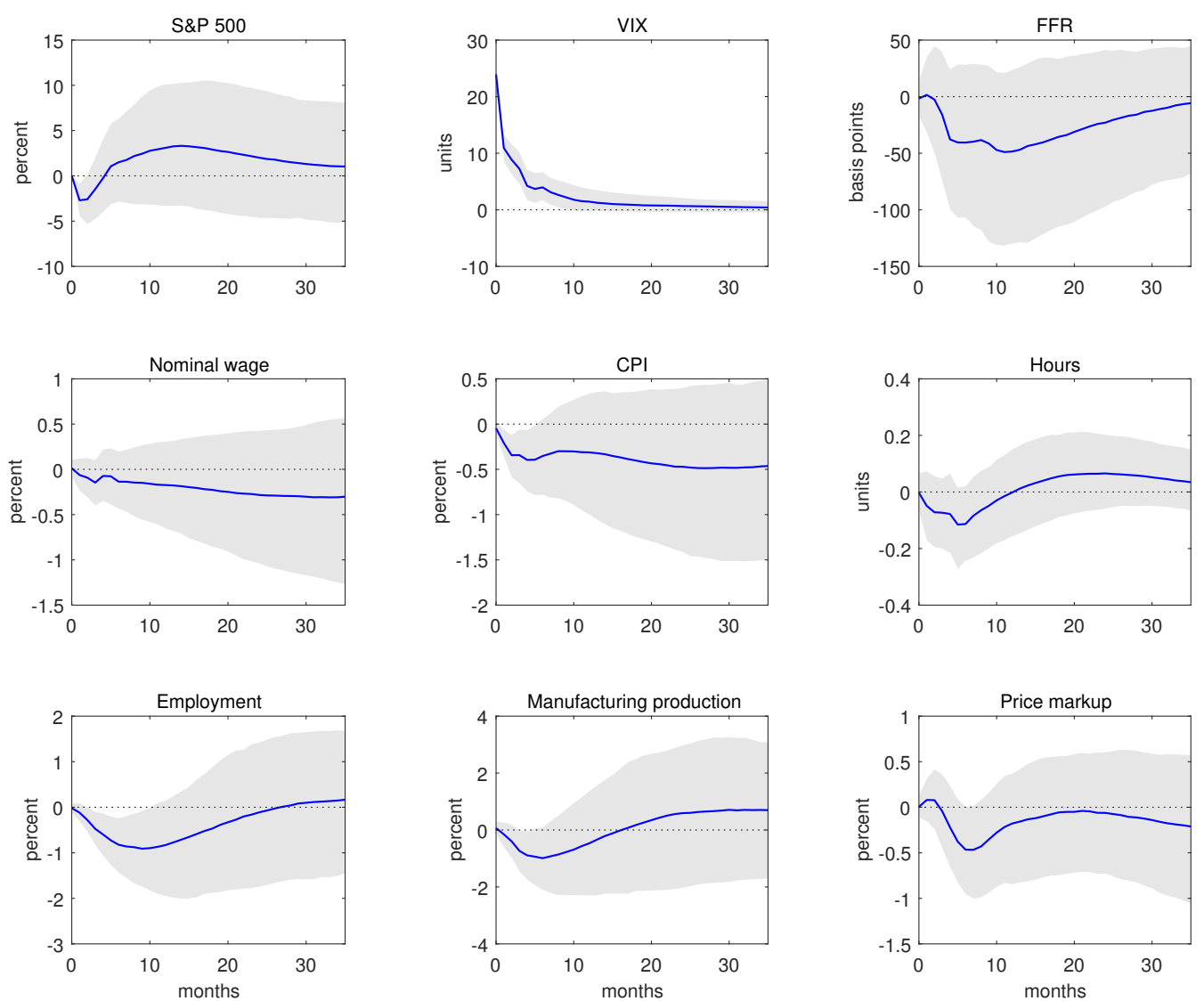

(a) Price Markup
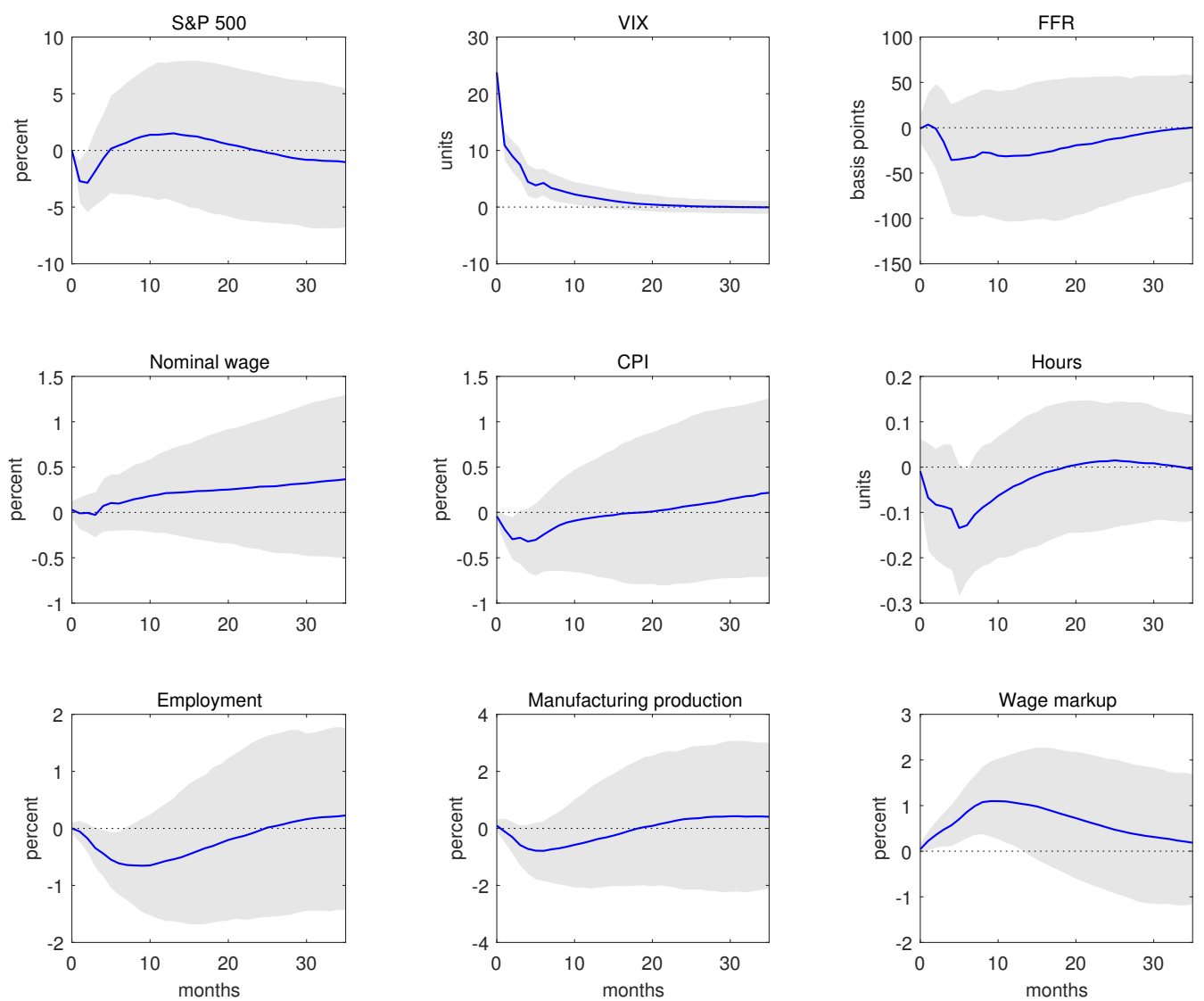

(b) Wage Markup

Figure D.6: IRFs to VIX-based uncertainty shock in the $8+1$ variable mixed-frequency VAR. Notes: Bands are pointwise $90 \%$ HPDIs. 


\section{D.4 Additional MF-VAR Figures}
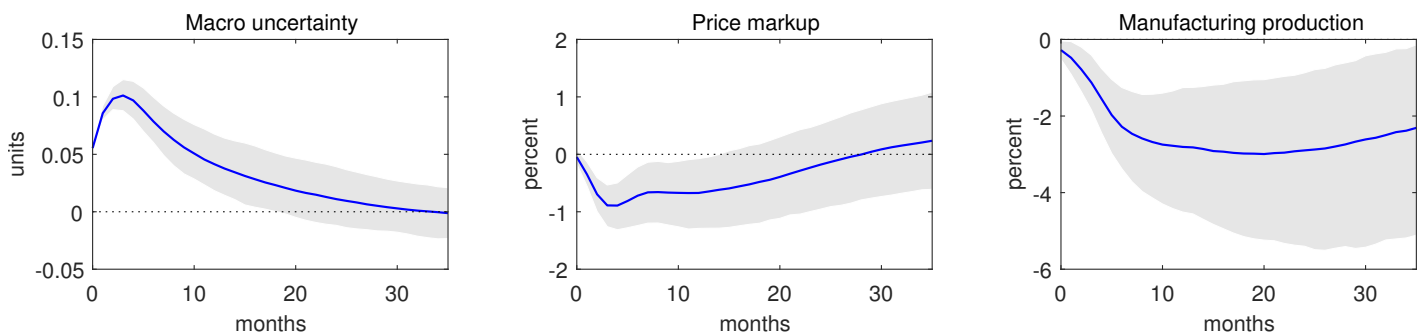

(a) Price Markup
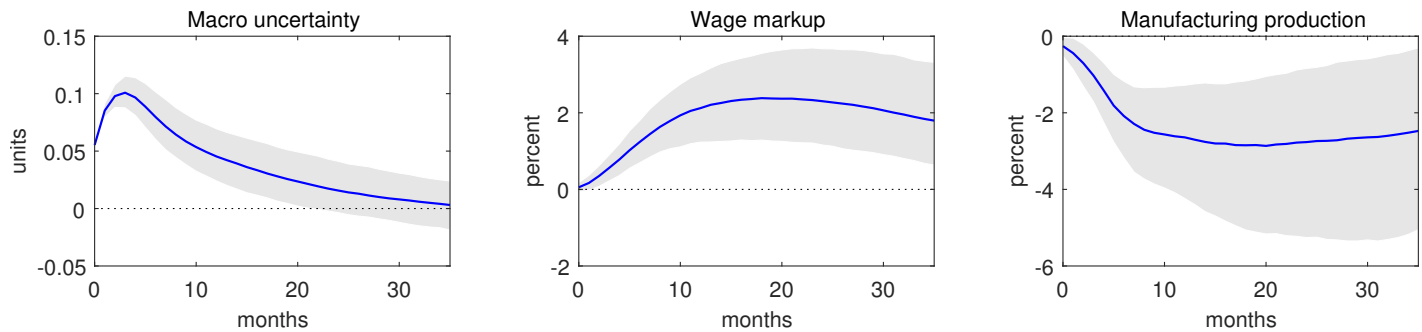

(b) Wage Markup

Figure D.7: IRFs to JNL-based uncertainty shock in the $8+1$ variable mixed-frequency VAR. Notes: Bands are pointwise 90\% HPDIs.
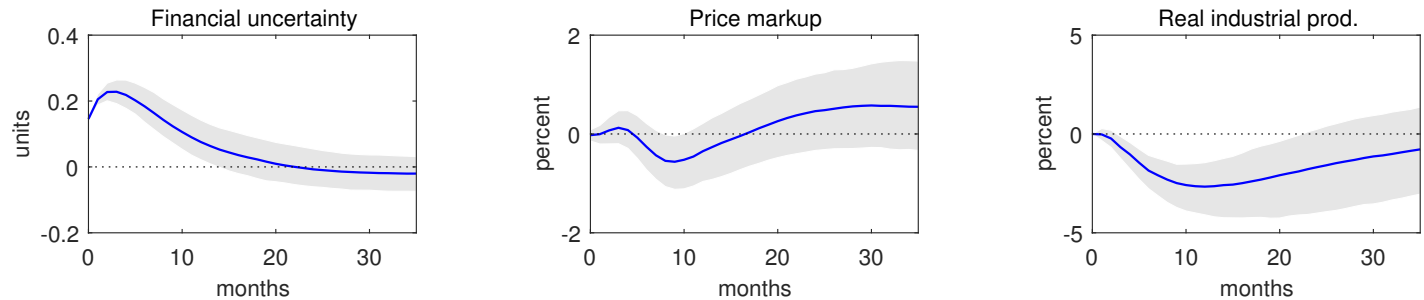

(a) Price Markup
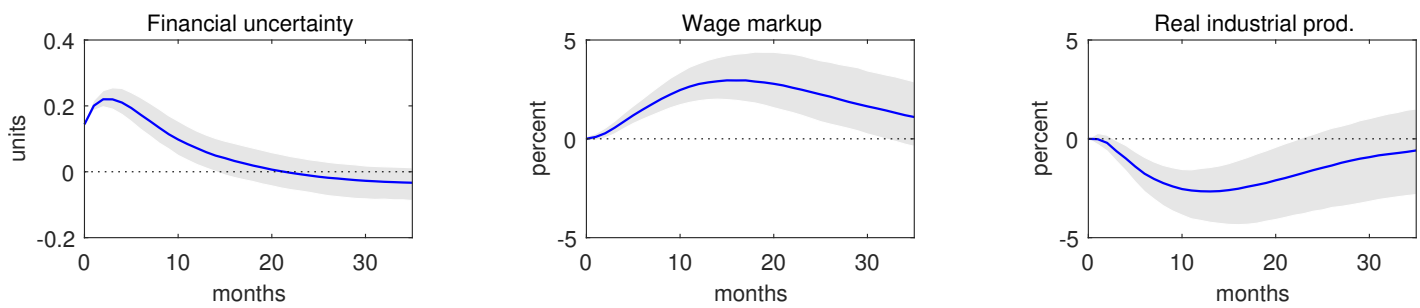

(b) Wage Markup

Figure D.8: IRFs to financial uncertainty shock in the $11+1$ variable mixed-frequency VAR. Notes: Bands are pointwise 90\% HPDIs. 

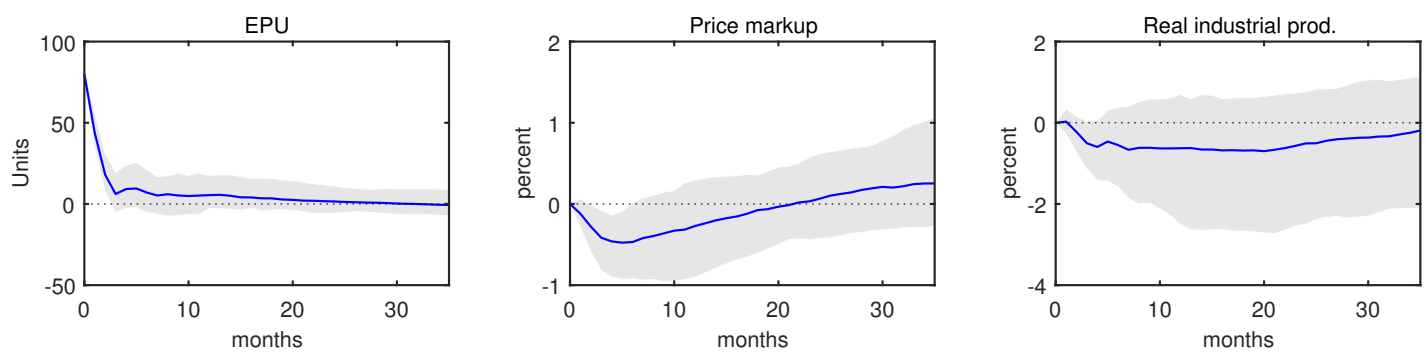

(a) Price Markup
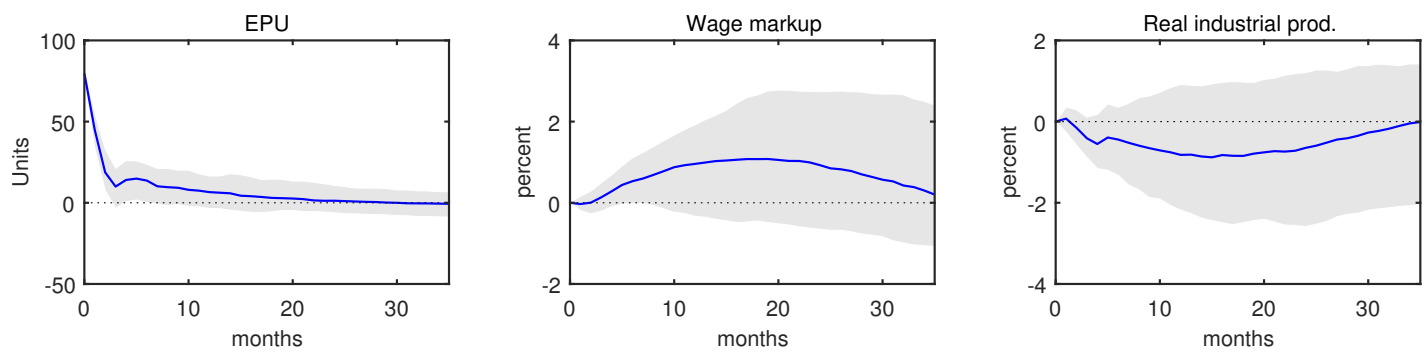

(b) Wage Markup

Figure D.9: IRFs to EPU-based uncertainty shock in the $11+1$ variable mixed-frequency VAR. Notes: Bands are pointwise $90 \%$ HPDIs. 